\title{
Field Evaluation of Highly Insulating Windows in the Lab Homes: Winter Experiment
}

FINAL REPORT

GB Parker

NN Bauman

SH Widder

June 2012

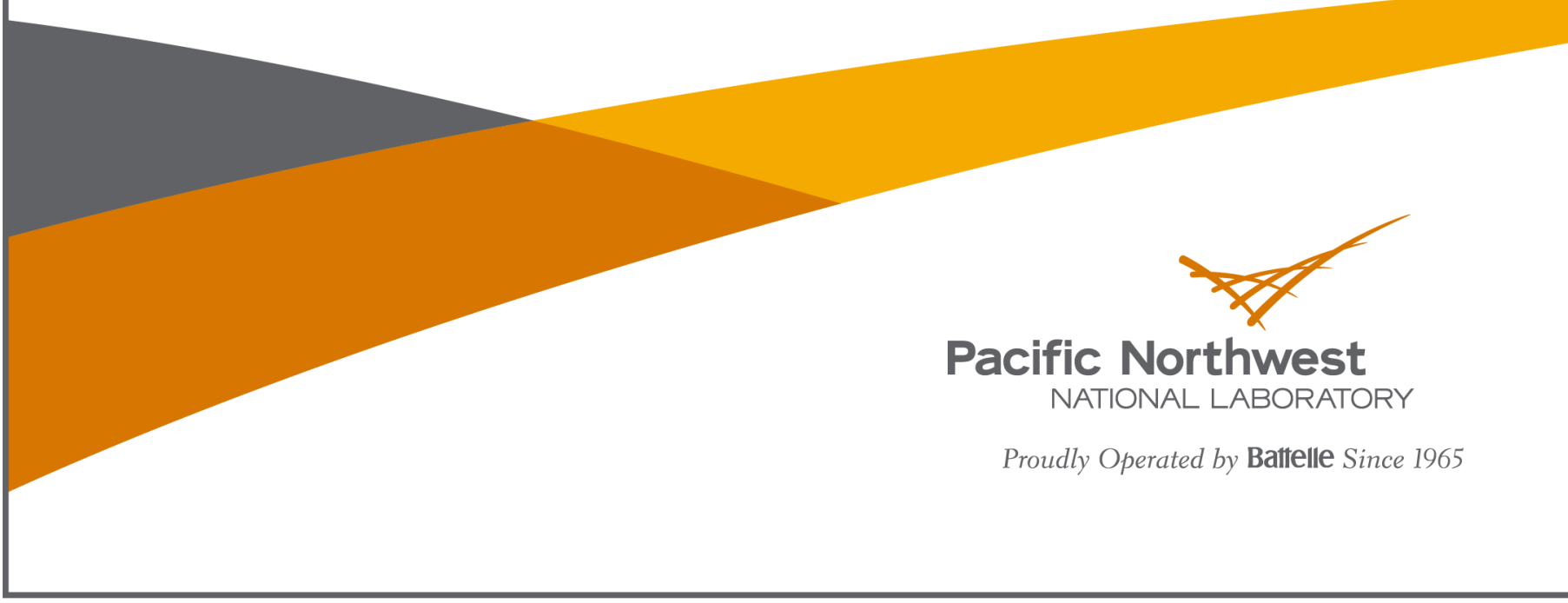




\title{
DISCLAIMER
}

This report was prepared as an account of work sponsored by an agency of the United States Government. Neither the United States Government nor any agency thereof, nor Battelle Memorial Institute, nor any of their employees, makes any warranty, express or implied, or assumes any legal liability or responsibility for the accuracy, completeness, or usefulness of any information, apparatus, product, or process disclosed, or represents that its use would not infringe privately owned rights. Reference herein to any specific commercial product, process, or service by trade name, trademark, manufacturer, or otherwise does not necessarily constitute or imply its endorsement, recommendation, or favoring by the United States Government or any agency thereof, or Battelle Memorial Institute. The views and opinions of authors expressed herein do not necessarily state or reflect those of the United States Government or any agency thereof.

\author{
PACIFIC NORTHWEST NATIONAL LABORATORY \\ operated by \\ BATTELLE \\ for the \\ UNITED STATES DEPARTMENT OF ENERGY \\ under Contract DE-AC05-76RL01830
}

Printed in the United States of America
Available to DOE and DOE contractors from the Office of Scientific and Technical Information,
P.O. Box 62, Oak Ridge, TN 37831-0062;
ph: (865) 576-8401
fax: $(865)$ 576-5728
email: reports@adonis.osti.gov
Available to the public from the National Technical Information Service
5301 Shawnee Rd., Alexandria, VA 22312 ph: (800) 553-NTIS (6847)
email: orders@ntis.gov $<$ http://www.ntis.gov/about/form.aspx $>$
Online ordering: http://www.ntis.gov

This document was printed on recycled paper. 


\section{Field Evaluation of Highly Insulating Windows in the Lab Homes: Winter Experiment}

GB Parker

NN Bauman

SH Widder

June 2012

Prepared for

the U.S. Department of Energy

under Contract DE-AC05-76RL01830

Pacific Northwest National Laboratory

Richland, Washington 99352 



\section{Executive Summary}

This field evaluation of highly insulating windows was undertaken in a matched pair of "Lab Homes" located on the Pacific Northwest National Laboratory (PNNL) campus during the 2012 winter heating season. Improving the insulation and solar heat gain characteristics of a home's windows has the potential to significantly improve the home's building envelope and overall thermal performance by reducing heat loss (in the winter), and cooling loss and solar heat gain (in the summer) through the windows. A high-quality installation and/or window retrofit will also minimize or reduce air leakage through the window cavity and thus also contribute to reduced heat loss in the winter and cooling loss in the summer. These improvements all contribute to decreasing overall annual home energy use. Occupant comfort (non-quantifiable) can also be increased by minimizing or eliminating the cold 'draft' (temperature) many residents experience at or near window surfaces that are at a noticeably lower temperature than the room air temperature. Lastly, although not measured in this experiment, highly insulating windows (triple-pane in this experiment) also have the potential to significantly reduce the noise transmittance through windows compared to standard double-pane windows.

The metered data taken in the Lab Homes and data analysis presented here represents 70 days of data taken during the 2012 heating season. As such, the savings from highly insulating windows in the experimental home (Lab Home B) compared to the standard double-pane clear glass windows in the baseline home (Lab Home A) are only a portion of the energy savings expected from a year-long experiment that would include a cooling season. The cooling season experiment will take place in the homes in the summer of 2012, and results of that experiment will be reported in a subsequent report available to all stakeholders.

\section{Homes Description}

The Lab Homes are factory-built, ${ }^{1}$ all-electric, and nearly 1,500 square feet with 3 bedrooms/ 2 bathrooms and have approximately 196 square feet of window area. One of the homes (Lab Home Athe baseline home) was retrofit with "standard" double-pane clear aluminum-frame slider windows and patio doors typically found in many existing homes built in the decades of the 60s through 80s throughout the Pacific Northwest (PNW) region and across the country. ${ }^{2}$ The other home (Lab Home B-the experimental home) was retrofit with Jeld-Wen ${ }^{\circledR}$ triple-pane vinyl-frame slider windows and patio doors. The retrofit windows' characteristics are given in Table S.1.

The homes were fully instrumented to collect energy end-use and environmental data. Data were collected from February 3, 2012 through April 13, 2012. The homes are identical in every way except for the windows. Occupancy in the homes was identically simulated during the time period of data collection.

\footnotetext{
${ }^{1}$ The homes were built at the Marlette Industries factory in Hermiston, Oregon.

${ }^{2}$ These double-pane clear windows are typical of many windows installed in homes across the country in the late 60s through the late 90s. They were also the 2006-2012 Federal Housing and Urban Development (HUD)-mandated nationwide minimum code for manufactured housing (see http://www.gpo.gov/fdsys/pkg/CFR-2003-title24voll/content-detail.html).
} 
Table S.1. Window Performance Characteristics of the Windows in Lab Home A (Standard Retrofit Windows and Patio Doors), and Lab Home B (Highly Insulating Windows and Patio Doors) Retrofit in the Lab Homes.

\begin{tabular}{lcccc}
\hline & \multicolumn{2}{c}{ Lab Home A } & \multicolumn{2}{c}{ Lab Home B } \\
& \multicolumn{2}{c}{ Standard Retrofit Windows } & Highly Insulating Retrofit Windows \\
\cline { 2 - 5 } Value & Windows & Patio Doors & Windows & Patio Doors \\
\hline U-factor & 0.68 & 0.66 & 0.20 & 0.20 \\
SHGC $^{(a)}$ & 0.7 & 0.66 & 0.19 & 0.19 \\
VT $^{(b)}$ & 0.73 & 0.71 & 0.36 & 0.37 \\
\hline (a) solar heat gain coefficient & & & \\
(b) visible transmittance & & & \\
\hline
\end{tabular}

\section{Building Shell Air Leakage}

To assess the performance of the retrofit highly insulating windows as compared to the retrofit baseline windows, the building shell air leakage, energy use and interior temperatures of the homes were compared.

Building shell air leakage was measured prior to the windows retrofit and after the windows retrofit to determine whether there was any difference in the windows or installation techniques. Prior to the windows retrofit and after the metering equipment and sensors were installed in the homes, the blower door results show the air leakage of the two homes statistically the same, with $95 \%$ confidence. The homes are both fairly tight, which is typical of the manufactured housing industry in the Pacific Northwest. Lab Home A has leakage of $657.6 \pm 27.8$ cubic feet/minute (CFM) at 50 Pascals depressurization (CFM50) and Lab Home B has an air leakage of 701.4 \pm 26.7 CFM50. These values correspond to $0.15 \pm 0.01$ natural air changes per hour $\left(\mathrm{ACH}_{\mathrm{n}}\right)$ in $\mathrm{Lab}$ Home $\mathrm{A}$ and $0.16 \pm 0.01 \mathrm{ACH}_{\mathrm{n}}$ in Lab Home B.

The windows in Lab Home B were retrofitted by the general contractor (GC) with technical assistance and materials (foam sealant and window drain mat material) provided by Jeld-Wen and according to the documented recommendations by Jeld-Wen for their windows. The windows in Lab Home A were retrofitted by the same GC staff using standard caulking technique and no special flashing nor added air barrier. ${ }^{1}$

In Lab Home B, air leakage, as characterized by the CFM50 depressurization with respect to the outside, decreased $46.4 \pm 34.9$ CFM50 or $6.9 \%$. Conversely, air leakage in Lab Home A increased $50.3 \pm 34.1$ CFM50. While the error is large in comparison to the magnitude of the change, the overall impact of these changes was statistically significant. This decrease in air leakage in Lab Home B is attributed primarily to the quality of the retrofit given that the air leakage (AL) rating of the highly insulating windows and patio doors $\left(\mathrm{AL}=0.3 \mathrm{cfm} / \mathrm{ft}^{2}\right)$ is greater than the factory-supplied windows and patio doors $\left(\mathrm{AL}=0.1 \mathrm{cfm} / \mathrm{ft}^{2}\right){ }^{2}$ This is therefore compelling evidence of the positive impact of the installation of the retrofit windows on home air leakage.

\footnotetext{
${ }^{1}$ The Lab Homes were constructed without an air barrier as an air barrier was not a requirement in the specifications nor required to meet the HUD code thermal performance.

${ }^{2}$ The AL rating of the retrofit windows in Lab Home A is unknown as this attribute was not included in the windows certification data provided to PNNL by the manufacturer.
} 


\section{Whole-House Energy Savings and Solar Insolation Impacts}

The measured energy savings in Lab Home B averaged 5,821 watt-hours per day (Wh/day) or 279.5 kilowatt hours $(\mathrm{kWh})$ over the 70 days of the experiment. The overall whole-house energy savings of Lab Home B compared to Lab Home A are $11.6 \% \pm 1.53 \%$ over the 70 day period.

Given that the Lab Home B windows have low-e coatings ${ }^{1}$ that results in a very low SHGC compared to Lab Home A, and that neither home had window coverings, the relationship between whole-house energy use and solar insolation measured at the west-facing window in each home was examined. An analysis of the whole-house energy use in watt-hours (Wh) versus solar insolation in watts per square meter $\left(\mathrm{W} / \mathrm{m}^{2}\right)$ for Lab Home A and Lab Home B was undertaken. In both homes, increased solar insolation decreased whole-house energy use. However, the difference in solar heat gain between the homes can clearly be seen in that the measured solar insolation through the window is $83.2 \% \pm 1.2 \%$ lower through the window in Lab Home B compared to the window in Lab Home A over the study period. As such, the solar heat gain impacts the whole-house energy savings. Data analysis of wholehouse energy savings on overcast days showed energy savings for Lab Home B compared to Lab Home A of $14.6 \% \pm 1.86 \%$, while the energy savings on clear days are $8.9 \% \pm 1.42 \%$.

Average indoor temperature in the kitchen of each home was examined on a sunny day in February. Both homes' thermostat setpoint was $75^{\circ} \mathrm{F}$. The average outside temperature on this day was $39^{\circ} \mathrm{F}$. The data showed Lab Home B maintaining a much more consistent indoor temperature throughout the daytime, peaking at nearly $78^{\circ} \mathrm{F}$. The interior temperature in Lab Home A rose to nearly $84^{\circ} \mathrm{F}$. This could cause a comfort problem for any occupants at home during this time, even in these cold winter months.

Given the observed winter data, additional whole-house energy savings are anticipated during the summer/cooling season and these will be determined in a follow-on experiment in the Lab Homes in the summer of 2012 being conducted for the U.S. Department of Energy/Building America Program.

\section{Thermal Comfort}

The window surface temperatures impact comfort in the home felt by occupants. A window with a colder surface temperature is noticeable to an occupant (near the window area) even through the room dry bulb temperature is at a comfortable level. This effect is partially illustrated by the dramatically cooler window surface temperatures observed in Lab Home A (baseline home) of as low as $50^{\circ} \mathrm{F}$ recorded on the west-facing living room window. Lab Home B (experimental home) highly insulating window's surface temperature never dropped below $60^{\circ} \mathrm{F}$, the lowest temperature measured on the same window. When considering the average interior glass surface temperature measurement of all the windows over this period, a difference of $7^{\circ} \mathrm{F}$ is observed, with an average interior glass surface temperature of $68.7 \pm 0.05^{\circ} \mathrm{F}$ in the baseline home compared to $75.7 \pm 0.04^{\circ} \mathrm{F}$ in the experimental home.

\footnotetext{
${ }^{1}$ Low-emittance (low-e) coatings are microscopically thin, virtually invisible, metal or metallic oxide layers deposited on a window surface primarily to reduce the heat loss through the glass by suppressing radiative heat flow. The principal mechanism of heat transfer in multilayer glazing is thermal radiation from a warm pane of glass to a cooler pane. Coating a glass surface with a low-e material and facing that coating into the gap between the glass layers of multi-pane windows blocks a significant amount of this radiant heat transfer, thus lowering the total heat flow through the window.
} 
Mean radiant temperature (MRT) is a measured proxy for thermal comfort/discomfort resulting from the radiant heat exchange between an occupant (a body) and surrounding surface temperatures such as the surface temperature of a window or a wall. Each Lab Home has two MRT sensors: one located in the master bedroom and one in the northwest corner of the living area. The average indoor MRT in Lab Home A and Lab Home B was determined after the windows retrofit over a one-week time period when the outside temperature averaged $49^{\circ} \mathrm{F}$.

The average MRT in Lab Home A during the nighttime period during the week when radiant heat loss was most extreme was $79.0 \pm 0.02^{\circ} \mathrm{F}$ in both the master bedroom and the living room compared to an average room temperature of $80.2 \pm 0.11^{\circ} \mathrm{F}$. The average MRT of both the living area and master bedroom was $1.63 \pm 0.01^{\circ} \mathrm{F}$ lower than the average interior room temperature in Lab Home A. The maximum MRT recorded in Lab Home A was $86.3^{\circ} \mathrm{F}$ and the minimum MRT was $77.0^{\circ} \mathrm{F}$.

In contrast, in Lab Home B, the average MRT in the living area and master bedroom was $1.64 \pm 0.01^{\circ} \mathrm{F}$ lower than the average room temperature of $80.4 \pm 0.01^{\circ} \mathrm{F}$ in the living area and master bedroom. The maximum MRT recorded in Lab Home B was $81.7^{\circ} \mathrm{F}$ and the minimum MRT was $77.7^{\circ} \mathrm{F}$. Overall, the average nighttime MRT in Lab Home B was $0.345 \pm 0.004^{\circ} \mathrm{F}$ warmer than the average MRT in Lab Home A during the nighttime periods when radiant heat loss is most extreme. The very small temperature differences between the room temperature and MRT in Lab Home B compared to the larger difference in Lab Home A, as well as the higher average MRT in Lab Home B, suggest the highly insulating windows can provide a noticeably greater comfort level for occupants. Also, the MRT in Lab Home B was much more consistent, varying only $4.9^{\circ} \mathrm{F}$, while Lab Home A varied $9.2^{\circ} \mathrm{F}$.

\section{Condensation/Moisture on Windows}

Condensation on windows is of concern to homeowners and can be a health issue since moisture can lead to mold growth. A direct measurement was not made of condensation or moisture on windows in either Lab Home A or Lab Home B. ${ }^{1}$ However, using windows' inside surface temperature measurements allowed a calculation of the potential for condensation to form on the windows. An interior window temperature as low as $50^{\circ} \mathrm{F}$ was recorded in Lab Home A, while the lowest interior window temperature was $60^{\circ} \mathrm{F}$ in Lab Home B. With these temperatures and an average interior room temperature of $75^{\circ} \mathrm{F}$, the relative humidity of the air in Lab Home B would have to exceed $70 \%$ to cause condensation on the highly insulating windows, while a $40 \%$ relative humidity would cause condensation on the double-pane windows in Lab Home B. For reference, during the study period, the average relative humidity in Lab Home A was $20.7 \%$, with a maximum of $31.7 \%$, and the average relative humidity in Lab Home B was $21.7 \%$, with a maximum of $28.1 \%$.

\section{Windows Cost}

A delivered (to the PNW) cost range for highly insulating windows and sliding glass doors in small quantities for retrofit were obtained from the U.S. Department of Energy (DOE) windows volume purchase program. ${ }^{2}$ These costs ranged from $\$ 21 /$ square foot to $\$ 40 /$ square foot for windows and

\footnotetext{
${ }^{1}$ Humidity to represent occupants and occupant activity was not generated in the Lab Homes for this experiment.

${ }^{2}$ The window vendors selected for estimating costs from the qualified vendors in the DOE High Performance Windows Volume Purchase Program were vendors who offered both sliders and patio doors and who sold products in the PNW. An average cost/square foot across the multiple sizes of highly insulating windows for Lab Home B was determined from these windows suppliers.
} 
$\$ 23 /$ square foot to $\$ 36 /$ square foot for sliding glass doors. Installation and material costs were estimated at $\$ 3 /$ square foot based on observed retrofit of the windows at the Lab Homes. Therefore total installed cost for the retrofit of the highly insulating windows and sliding glass doors in Lab Home B is estimated to be $\$ 4,300$ to $\$ 7,600$.

If the highly insulating windows were installed on the factory floor, the incremental cost of the windows is estimated to be $\$ 4.00 /$ square foot with no additional labor cost for installation, and a $\$ 0.25 /$ square foot additional cost for materials (sill plate and foam). ${ }^{1}$ Therefore, total incremental factoryinstalled cost for highly insulating windows is estimated to be $\$ 4.25 /$ square foot. For a home with the same window area as the Lab Homes $\left(195.7 \mathrm{ft}^{2}\right)$, this incremental cost would be $\$ 832$.

The return on investment for retrofitting highly insulating windows versus installing highly insulating windows on the factory floor will be dependent upon the heating plus cooling energy savings. These savings will be determined and reported after the summer experiment is carried out.

\section{Peak Load Reduction}

Another impact of reduced energy use that is important to mention from a utility and resource planning perspective is the ability to reduce peak load. The peak load impacts due to the highly insulating windows in Lab Home B were determined during a one-week period of the experiment. The data are shown in Figure S.1. The peak power consumed over this period in Lab Home B was $33.9 \pm 0.6 \%$ less than the peak power consumed in Lab Home A. The peak load in both homes occurred during the evening hours after sunset. Although there is no direct financial benefit to most residential customers of a utility for peak reduction (customers with time-of-use rates notwithstanding), this significant reduction in peak power can be of benefit to the utility depending upon the time of the utility or system peak.

\footnotetext{
${ }^{1}$ Note that less interior trim materials will be needed for a highly insulating window and sliding glass door due to the additional thickness of the window. The cost reduction for less trim material is considered small and not accounted for in the installed cost.
} 


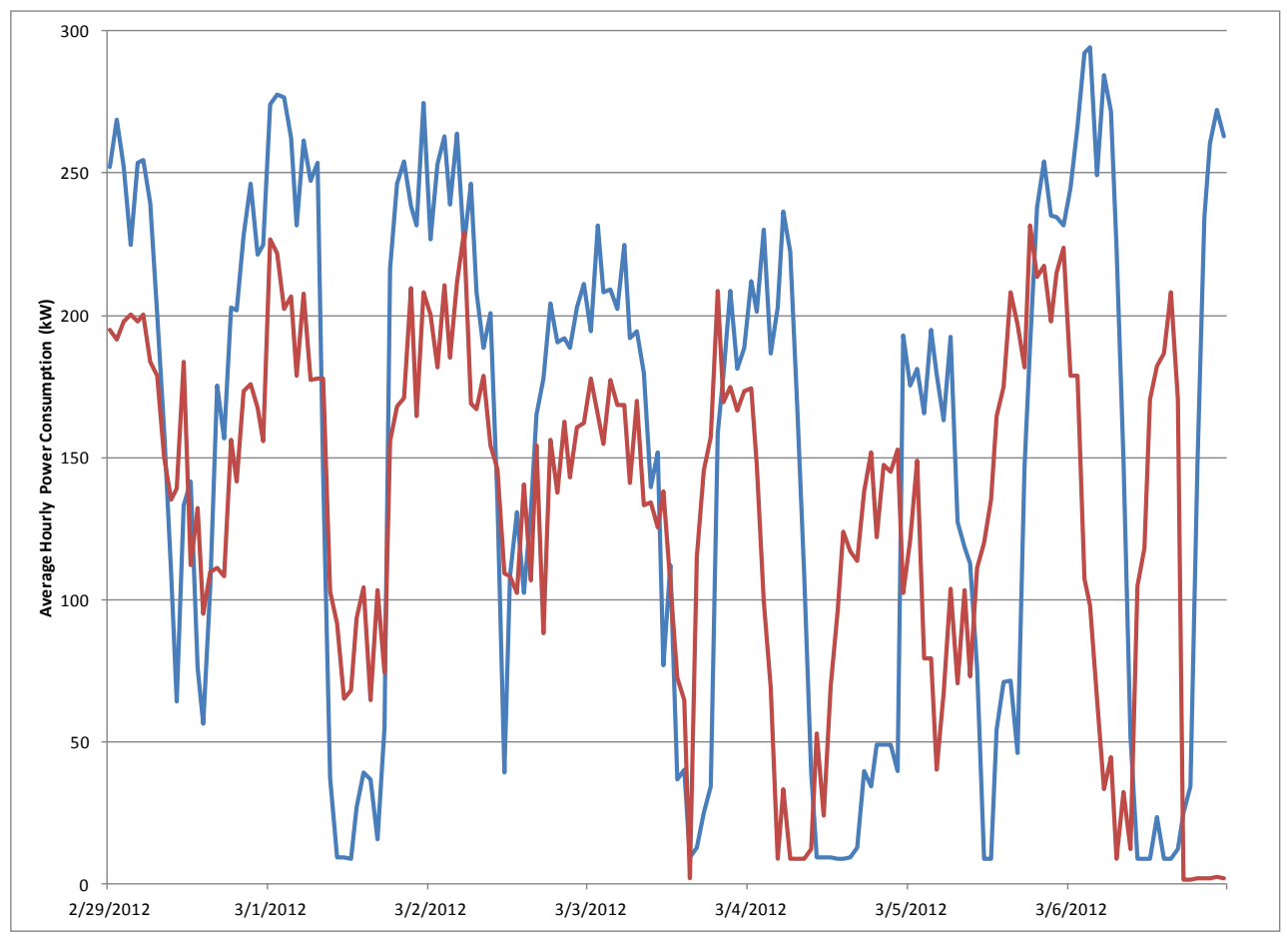

Figure S.1. Average Hourly Power Use for Lab Home A (blue) and Lab Home B (red) During a One-Week Period from 2/29/2012 to 3/6/2012

\section{Energy Modeling}

An EnergyPlus model was created for the Lab Homes to compare modeled savings from the highly insulating windows to measured results. The EnergyPlus analysis run with weather data obtained from the nearby Pasco, Washington, airport station shows average whole-building energy savings in Lab Home B from the highly insulating windows to be $9.7 \%$ during the simulation period (February 2012 to April 2012). The general trends in energy use and savings are also comparable to, but slightly lower than, the measured data, which observed savings of $11.6 \pm 1.53 \%$ in Lab Home B compared to Lab Home A. The modeled results generated using EnergyPlus compare to the measured energy use and savings fairly well. The model will be calibrated with the summer windows experiment data and with actual (site) weather data, and will be re-run at the end of that experiment. 


\section{Acknowledgments}

This project was funded by the U.S. Department of Energy, Energy Efficiency and Renewable Energy (Marc LaFrance, Program Manager/David Lee, Program Manager); the Bonneville Power Administration (Kacie Bedney, Project Manager); and the U.S. Department of Energy, Office of Electricity Delivery and Energy Reliability (Dan Ton, Program Manager). Additional support was provided by Battelle Memorial Institute; Northwest Energy Works (Tom Hews/Brady Peeks); Washington State University Extension Energy Program (Ken Eklund/Emily Salzberg); GE Appliances (Dave Najewicz); Tri Cities Research District (Diahann Howard); the City of Richland, Washington (Bob Hammond) and JELD-WEN®, inc. (Ray Garris/Mike Westfall).

Other stakeholders in this project include the U.S. Department of Energy Pacific Northwest Site Office, Northwest Energy Efficiency Alliance, the Energy Trust of Oregon, and Marlette Industries.

PNNL staff significantly contributing to this project include facilities, operations, contracting and financial staff: Raul Carreno, Garret Hyatt, Sheena Kanyid, David Koontz, Bob Turner, Ray Sadesky, T.R. Hensyel, Jim Bixler, Vicki Stephens, Sam Martinez and Jamie Spangle; media relations staff: Annie Haas, Dawn Zimmerman, Megan Neer, Tim Ledbetter, and Kevin Kautzky; editor: Maura Zimmerschied; management staff: Evan Jones, Sean McDonald, Mark Morgan, Todd Samuel, Sriram Somasundaram, Terry Brog, Rob Pratt and Gary Spanner; and technical staff: Vrushali Mendon, Susan Sande, Jeremy Blanchard, Eric Richman, Susan Loper, Michael Kintner-Meyer, and Michael Baechler.

The authors also acknowledge the technical support provided by Greg Sullivan, Principal, Efficiency Solutions, LLC, Richland, Washington, for specification development, occupancy simulation development, metering and data collection. 



\section{Acronyms and Abbreviations}

$\mathrm{ACH} 50$

$\mathrm{ACHn}$

AL

ARRA

ASTM

BPA

BTP

Btu

$\mathrm{CFM} / \mathrm{cfm}$

CFM25

CFM50

CT

DNP3

DOE

DOE/OE

ELA

EMC

ER

FTP

GC

$\mathrm{h}$

HP

HSPF

HUD

HVAC

IEC

IR

$\mathrm{kW}$

MRT

$\mathrm{NE}$

NEC

NEW

NFRC

NREL

PE

PEX air changes per hour at 50 Pascals depressurization

natural air changes per hour

air leakage

American Recovery and Reinvestment Act of 2009

ASTM International, formerly the American Society for Testing and Materials

Bonneville Power Administration

Buildings Technology Program

British thermal unit(s)

cubic feet per minute

cubic feet per minute at 25 Pascals depressurization

cubic feet per minute at 50 Pascals depressurization

current transformers

Distributed Network Protocol 3

U.S. Department of Energy

DOE Office of Electricity Delivery \& Energy Reliability

effective leakage area

electromagnetic compatibility

electric resistance

file transfer protocol

general contractor

hour(s)

heat pump

heating seasonal performance factor

U.S. Department of Housing and Urban Development

heating, ventilating and air conditioning

International Electrical Code

infrared

kilowatt(s)

mean radiant temperature

northeast

National Electric Code

Northwest Energy Works

National Fenestration Rating Council

National Renewable Energy Laboratory

polyethylene

cross-linked polyethylene 


$\begin{array}{ll}\text { PNNL } & \text { Pacific Northwest National Laboratory } \\ \text { PNW } & \text { Pacific Northwest } \\ \text { R } & \text { thermal resistance }\left(\mathrm{ft}^{2} \cdot{ }^{\circ} \mathrm{F} \cdot \mathrm{h} / \mathrm{Btu}\right) \\ \text { R\&D } & \text { research and development } \\ \text { RH } & \text { relative humidity } \\ \text { SE } & \text { southeast } \\ \text { SEER } & \text { Seasonal Energy Efficiency Ratio } \\ \text { SHGC } & \text { solar heat gain coefficient } \\ \text { SMTP } & \text { Simple Mail Transfer Protocol } \\ \text { TCP/IP } & \text { Transmission Control Protocol/Internet Protocol } \\ \text { TI/C } & \text { Technology Innovation Council } \\ \text { TMY } & \text { typical meteorological year } \\ \text { U } & \text { overall heat transfer coefficient }\left(B t u /\left(h \cdot{ }^{\circ} \mathrm{F} \cdot \mathrm{ft}^{2}\right)\right) \\ \text { VT } & \text { visible transmittance } \\ \text { W } & \text { Watt }(\mathrm{s}) \\ \text { WSU } & \text { Washington State University }\end{array}$




\section{Contents}

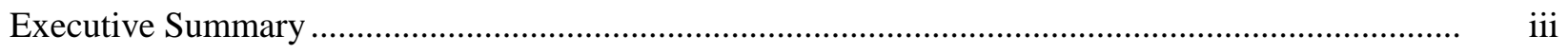

Acknowledgments................................................................................................................... ix

Acronyms and Abbreviations ............................................................................................ xi

1.0 Background and History of Building Research in Manufactured Housing ................................. 1.1

2.0 Development, Expansion and Relevance of this Field Evaluation Project................................... 2.1

3.0 Project Tasks and Schedule ............................................................................................ 3.1

4.0 Construction Features and Siting of the Lab Homes .................................................................. 4.1

5.0 Metering, Monitoring and Experimental Plan ............................................................................. 5.1

5.1 Metering and Monitoring Approach............................................................................ 5.1

5.2 Electrical Measurements ............................................................................................ 5.3

5.2.1 Temperature and Environmental Sensors............................................................... 5.3

5.3 Windows Experiment General Approach....................................................................... 5.3

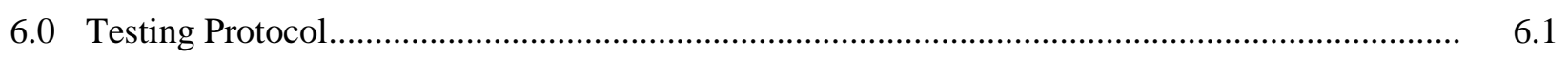

6.1 Post Siting Testing of the Homes .................................................................................. 6.2

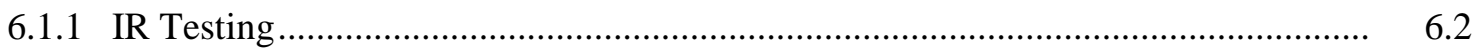

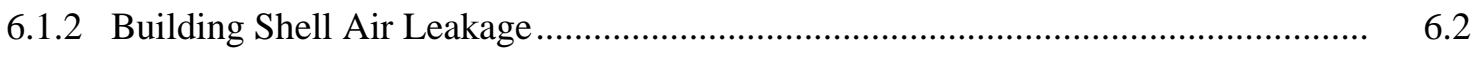

6.1.3 Duct Leakage and Pressure Mapping ……………….......................................... $\quad 6.2$

6.1.4 Ventilation Fan Flow Rate ……………………………………………….. 6.2

6.1.5 Heat Pump Performance..................................................................................... 6.2

6.2 Post Siting Instrumentation Installation and Data Collection Protocols ............................. 6.3

6.3 Float, HVAC and Full System Null Testing …………………………........................... 6.3

6.4 Windows Retrofit ........................................................................................... 6.3

6.5 Initiate Windows Field Evaluation................................................................................. $\quad 6.5$

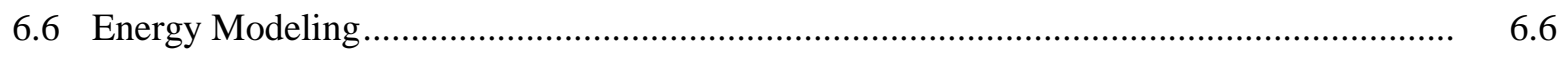

6.6.1 Energy Simulation Tool ............................................................................ 6.6

6.6.2 Building Energy Model.................................................................................. 6.6

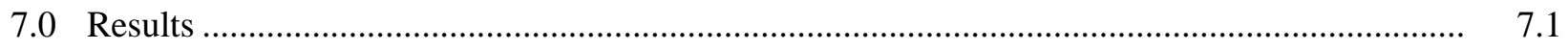

7.1 Highly Insulating Windows Retrofit Installed Costs ......................................................... 7.1

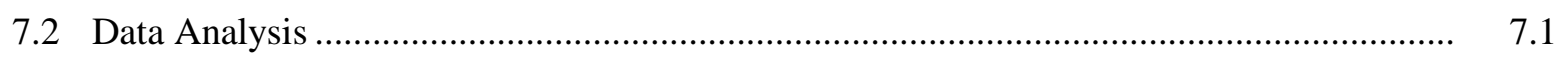

7.3 Lab Homes Thermal Performance ………………….............................................. 7.1

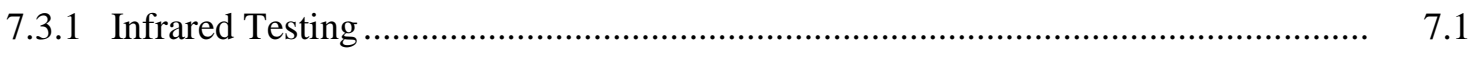

7.3.2 Pre-Windows-Retrofit Building Shell Air Leakage .................................................. 7.3

7.3.3 Duct Leakage and Pressure Mapping ……………….......................................... 7.4

7.3.4 Ventilation Fan Flow Rate ……………………........................................... 7.5

7.4 Heat Pump and Air Handler Performance........................................................................ $\quad 7.6$

7.5 Pre-Windows-Retrofit Null Testing ............................................................................... 7.6 
7.6 Post-Windows-Retrofit Building-Shell Air Leakage .................................................... 7.7

7.7 Post-Windows-Retrofit HVAC and Whole-House Thermal Performance ......................... 7.8

7.7.1 Thermal Comfort and Condensation .............................................................. 7.16

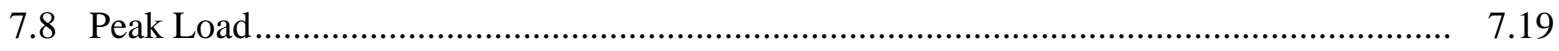

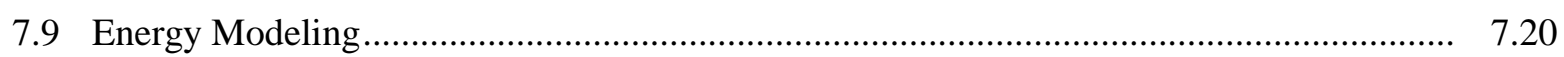

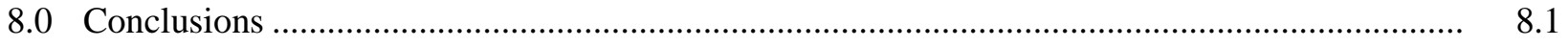

8.1 Lab Homes and Experimental Design................................................................ 8.1

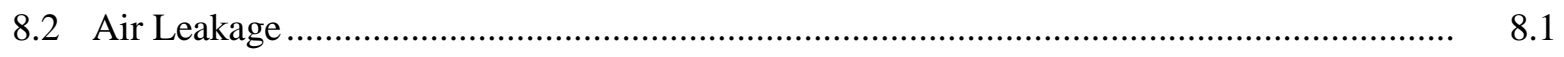

8.3 Pre-Windows Retrofit Performance During Null Testing ................................................ 8.1

8.4 Whole House Energy Performance …........................................................................ 8.2

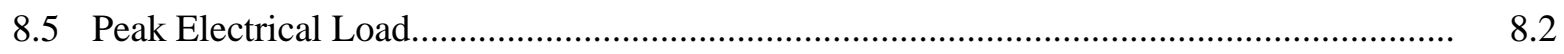

8.6 Solar Heat Gain Effects ............................................................................................ 8.2

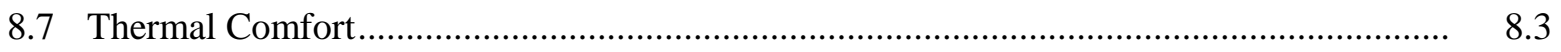

8.8 Condensation/Moisture on Windows …................................................................ 8.3

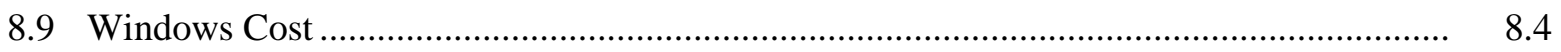

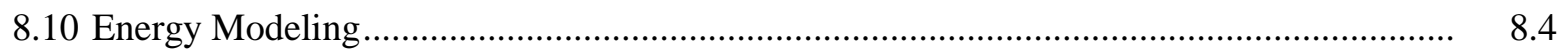

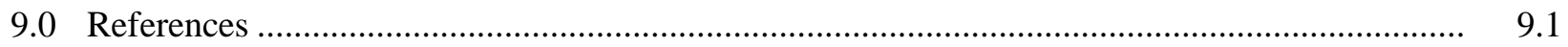

Appendix A - Lab Home A and B Construction Specifications and Alterations ............................. A.1

Appendix B - Photographs of the Exterior and Interior of the Lab Homes...................................... B. 1

Appendix C - Occupancy Simulation Schedule ….................................................................. C.1

Appendix D - Electrical Metering Equipment and Sensors …................................................... D. 1

Appendix E - Windows Retrofit Description and Photos ......................................................... D. 1

Appendix F - Interior Light Level Measurements................................................................ F. 1 


\section{Figures}

4.1 Floor Plan of the Lab Homes as Constructed....................................................................

4.2 Lab Home B and Lab Home A after Setup During Final Site Preparation.............................. 4.2

4.3 North Side and North and West Sides of Lab Home A......................................................... 4.3

4.4 West and South Sides of Lab Home B ...........................................................................

4.5 South Side of Lab Home B .........................................................................................

6.1 NFRC Certification Label for Jeld-Wen Highly Insulating Windows Installed in Lab

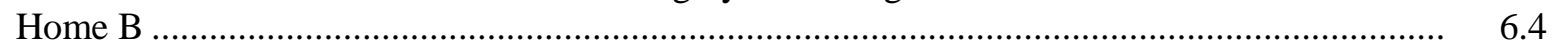

6.2 Building Geometry Exported from OpenStudio ........................................................ 6.7

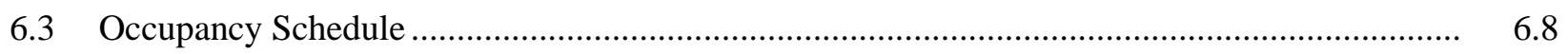

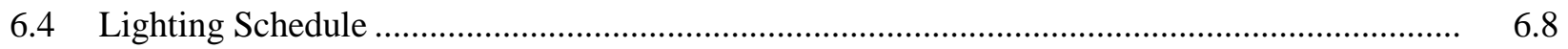

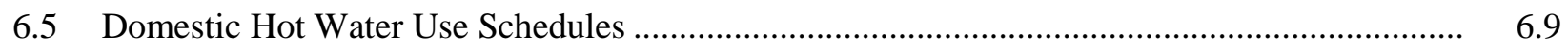

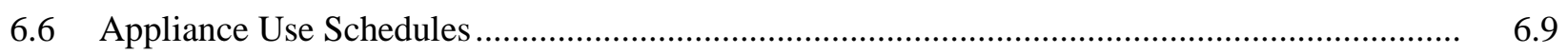

7.1 Baseline and Experimental Homes Exterior Side/Endwall Corner Thermal Images ................. $\quad 7.2$

7.2 Thermal Image of Experimental Home East End Wall from the Master Bedroom ................... 7.3

7.3 Comparison of Cumulative HVAC Energy Use of Lab Home A versus Lab Home B ............. 7.7

7.4 Whole-House Energy Use and Whole-House Energy Savings versus Outdoor Air Temperature

7.5 Daily Whole House Energy Savings Due to Highly Insulating Windows for Overcast, Clear, Partly Cloudy, and Dusty Conditions ..................................................................... 7.11

7.6 Whole-House Energy Use and Indoor Temperature for the Experimental Home and the Baseline Home on a Sunny Day...................................................................................... 7.12

7.7 Interior Temperature Distribution for Lab Home A and Lab Home B on a Sunny Day............ 7.12

7.8 Cumulative Energy Use of Lab Home B versus Lab Home A on a Sunny Day ....................... 7.13

7.9 Whole-House Energy Use and Indoor Temperature for the Experimental Home and the Baseline Home on a Cloudy Day ...................................................................................... 7.14

7.10 Cumulative Energy Use of Lab Home B versus Lab Home A on a Cloudy Day ..................... 7.14

7.11 Whole-House Energy Use in Lab Home A versus Solar Insolation ......................................... 7.15

7.12 Whole House Energy Use in Lab Home B versus Solar Insolation ........................................ 7.16

7.13 Interior Window Temperatures and Dew Point Temperatures Based on a $75^{\circ} \mathrm{F}$ Interior Air Temperature in the Baseline Home from March 11, 2012, through March 17, 2012 ............... 7.17

7.14 Interior Window Temperatures and Dew Point Temperatures based on a $75^{\circ} \mathrm{F}$ Interior Air Temperature in the Experimental Home from March 11, 2012, through March 17, 2012 .........

7.15 Average Indoor Air Temperature and Mean Radiant Temperature in Lab Home A and Lab Home B

7.16 Average Hourly Power Use for Lab Home A and Lab Home B During a One-Week Period from February 29, 2012, to March 6, 2012

7.17 Modeled and Measured Whole House Energy Use for Lab Home A ...................................... 7.20

7.18 Modeled and Measured Whole House Energy Use for Lab Home B. ................................... 7.21

7.19 Modeled and Measured Energy Savings ........................................................................... 7.21 


\section{Tables}

3.1 Schedule for Tasks and Major Activities in the Lab Homes Windows Field Evaluation.......... 3.4

5.1 Electrical Points Monitored..................................................................................... 5.1

5.2 Temperature and Environmental Points Monitored .......................................................... 5.2

6.1 Window Performance Characteristics of the Factory-Installed, Baseline Retrofit, and Highly Insulating Retrofit Windows and Patio Doors Installed in the Lab Homes .................. 6.5

6.2 Envelope Insulation Levels ......................................................................................... 6.7

6.3 Peak Power Value for Each Internal Gains Component ....................................................... 6.10

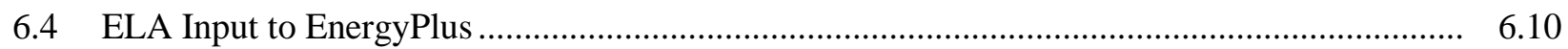

7.1 Building Envelope Air Leakage of Baseline and Experimental Home As-Received and

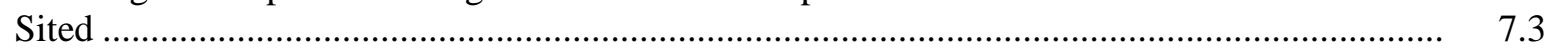

7.2 Building Envelope Leakage as Measured by Blower Door Tests in the Baseline and Experimental Home with Metering Equipment Installed................................................... $\quad 7.4$

7.3 Duct Leakage Measurements in Lab Home A and Lab Home B .......................................... 7.5

7.4 Duct Distribution System Performance, Static Pressure and Flows in Baseline Lab Home A

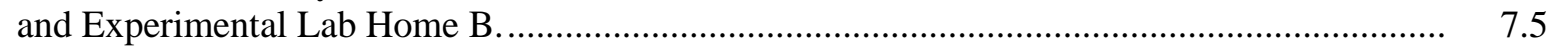

7.5 Flow Rate of Bath and Whole House Ventilation Exhaust Fans Measured in the Baseline and Experimental Homes ........................................................................................... 7.6

7.6 Heat Pump Temperature Differential Across Coil ................................................................ 7.6

7.7 Air Handler Flow and Static Operating Pressure ..............................................................

7.8 Building Shell Leakage in the Baseline and Experimental Homes after Window Retrofits ....... $\quad 7.8$

7.9 Average Energy Savings and 95\% Confidence Interval from Highly Insulating Windows in Different Operating Scenarios: With and without Occupancy Simulation and in HP versus ER Heating Modes. 


\subsection{Background and History of Building Research in Manufactured Housing}

In 2002, the Bonneville Power Administration demonstrated multiple technologies in a zero-energy manufactured home. This project involved the demonstration, promotion, and monitoring of two manufactured homes: a zero-energy manufactured home, and a base (Housing and Urban Development [HUD]-code) home. Bonneville partnered with the Nez Perce Tribe, the Washington State University (WSU) Extension Energy Program, and the U.S. Department of Energy (DOE) Building America Industrialized Housing Partnership as well as a number of industry partners.

The zero-energy manufactured home used innovative energy-saving technologies and building practices, such as ENERGY STAR lighting, appliances, and windows, a heat-recovery, whole-house ventilation system, Icynene ${ }^{\circledR}$ wall insulation, a solar water heating system, and a heat pump that extracts heat from the crawlspace. It also incorporated a renewable energy system- $4.2 \mathrm{~kW}$ of photovoltaic panels on the roof - that converts the sun's energy into electricity. The base home is a typical manufactured home built to Super Good Cents (SGC) and ENERGY STAR standards.

In addition, there is a nationwide ENERGY STAR qualified manufactured home program. ${ }^{1}$ To qualify as ENERGY STAR, a manufactured home is required to be substantially more energy efficient than a comparable HUD-code home. This includes not only the thermal envelope, but also the estimate of total energy use for space heating, space cooling, and water heating. ENERGY STAR has developed preapproved design packages of energy features that meet or exceed the ENERGY STAR requirements. For each climate region, pre-approved ENERGY STAR design packages are provided. The variety of packages gives the manufacturer fairly wide latitude in deciding how to design an ENERGY STAR qualified home. A package contains requirements for several features that must be used together to qualify as an ENERGY STAR qualified manufactured home. All the packages are roughly equivalent in energy terms. That is, applied to the same home, each package will result in approximately the same total energy use.

The federal government is currently undertaking rulemaking to improve the energy efficiency of current HUD-code manufactured homes. ${ }^{2}$ As part of that rulemaking, multiple scenarios are being evaluated for cost-effectively improving the building shell of the manufactured home. Among the measures being analyzed are highly insulating windows. These analyses are being done across multiple climate zones.

The DOE Buildings Technology Program is undertaking a number of research and development $(R \& D)$ and demonstration projects on envelopes and windows focused almost exclusively on site-built homes. ${ }^{3}$ The focal point for all subprogram elements is the goal of advancing technologies that contribute to net zero-energy buildings. Specifically, the Residential and Commercial Buildings Integration subprograms have identified the building shell and window needs for reducing home energy use by 30$50 \%$ (compared to the 2009 energy codes for new homes and pre-retrofit energy use for existing homes). Overall, highly insulating windows can become one of the key technologies in the building shell and

\footnotetext{
${ }^{1}$ See http://www.energystar.gov/index.cfm?c=bldrs_lenders_raters.pt_builder_manufactured

${ }^{2}$ See http://www.energycodes.gov/status/mfg housing.stm

${ }^{3}$ See http://www1.eere.energy.gov/buildings/building_america/index.html
} 
contribute to DOE's goals. In fact, studies suggest that advanced highly insulating windows have the technical potential to just about completely offset the current 4 quads net energy use attributed to windows. In any given building energy simulation, results show that improved windows and shell measures are key to achieving DOE's whole-building energy goals. 


\subsection{Development, Expansion and Relevance of this Field Evaluation Project}

Pacific Northwest National Laboratory (PNNL) proposed a joint-funded research project to the Bonneville Power Administration (BPA) Request for Offers 1515 in the Spring of 2010. In the PNNL proposal, joint funding was provided by the DOE Buildings Technology Program (BTP) Envelope and Windows R\&D. The $\$ 200 \mathrm{~K}$ initial proposal was a demonstration of the energy performance of highly insulating windows retrofitted in a matched pair of single-wide manufactured homes leased/rented for $\sim 1$ year. The homes would be baselined for a short time period before retrofitting one home with doublepane, clear, metal frame windows typical of existing homes and the other home with highly insulating (U-factor of 0.22 or lower equivalent to $\sim \mathrm{R}-5$ ) windows. The highly insulating windows were to be selected from a window manufacturer who is participating in the DOE volume purchase program for highly insulating windows. ${ }^{1}$

After the project was awarded, additional joint funding became available from DOE to expand the capabilities of undertaking residential retrofit research and smart grid enabled residential technologies beyond the highly insulating windows demonstration. The additional funding was provided through the American Recovery and Reinvestment Act (ARRA) funds allocated to DOE's Building America Program and from DOE's Office of Electricity Delivery and Energy Reliability (OE) smart grid appliances R\&D program. The scope of the ARRA project is to undertake field demonstrations of a portfolio new and emerging retrofit technologies in the residential building sector. ${ }^{2}$ The scope of the DOE/OE smart grid $\mathrm{R} \& \mathrm{D}$ program is to undertake a demonstration of smart grid enabled appliances and technologies.

With the additional joint funding and with the agreement of BPA and DOE/BTP, the windows demonstration experiment was re-scoped to take place in a matched pair of double-wide manufactured "Lab Homes" located side-by-side on the PNNL campus in Richland, Washington. ${ }^{3}$ As the expanded project was developed, it became a joint effort among many agencies and partners contributing over $\$ 1 \mathrm{M}$ to the establishment of the Lab Homes at PNNL. The partners include the following:

- U.S. Department of Energy/BTP (ARRA, Building America, Envelope and Windows R\&D)

- Bonneville Power Administration

- U.S. Department of Energy/OE

- PNNL Facilities

- Battelle Memorial Institute

- GE Appliances

- Tri Cities Research District

\footnotetext{
${ }_{1}^{1}$ www.windowsvolumepurchase.org

2 Additional retrofit technologies will be evaluated in the Lab Homes under a broad-based research and development demonstration program in these homes at the conclusion of the highly insulating windows demonstration project. Therefore, the pair of homes will remain at the PNNL campus for these experiments for an additional 5 to 7 years beyond the end of the highly insulating windows demonstration project.

${ }^{3}$ http://labhomes.pnnl.gov
} 
- City of Richland, Washington, Energy Services

- Northwest Energy Works (NEW)

- Washington State University Extension Energy Program

- Jeld-Wen®, Inc.

Improving the insulation and solar heat gain characteristics of a home's windows has the potential to significantly improve the home's building envelope and overall thermal performance by reducing heat loss (in the winter), and cooling loss and solar heat gain (in the summer) through the windows. A high-quality installation and/or window retrofit will also minimize or reduce air leakage through the window cavity and thus also contribute to reduced heat loss in the winter and cooling loss in the summer. These changes both decrease overall yearly home energy use and increase occupant comfort.

The outcome of this field evaluation has relevance to the recent activity by BPA to develop new specifications for High Performance Manufactured Homes (HPMH) that go beyond today's ENERGY STAR specifications. This activity is designed to obtain deep energy savings in the manufactured housing sector in the Pacific Northwest (PNW). The approach is designed to 1) develop a set of specifications for the construction of manufactured homes that address all aspects of home energy use; 2) to develop a new market for high-performance manufactured homes and 3) to provide large, cost-effective electric savings to the region. The draft specifications were presented to the Regional Technical Forum in April 2012. ${ }^{1}$ In these proposed specifications was a recommendation for $\mathrm{U}$-factor $=0.22$ windows, the same $\mathrm{U}$-factor as the windows being evaluated in this project, and a maximum air infiltration of 0.21 air changes/hour (natural). Therefore, the data from this field evaluation (and from the summer windows experiment) can be of value to the ongoing regional dialog and analysis required for the adoption of the HPMH specifications.

\footnotetext{
${ }^{1}$ See http://www.nwcouncil.org/energy/rtf/meetings/2012/04/
} 


\subsection{Project Tasks and Schedule}

The re-scoped project required additional time for site preparation, procurement of the homes, permitting and to deliver and set up the homes. As such, the windows demonstration Tasks and Stage Gates schedule was revised. The tasks are designed to meet the project research objectives. The stage gates are critical review points in the project to ascertain project progress (including schedule and spending), and review any preliminary results. At each stage gate, PNNL and BPA consulted on project status and outcomes and made decisions on whether to proceed into the next phase (tasks) of the project or to make modifications to the downstream tasks to meet project objectives.

The revised tasks and stage gates for the projects are as follows:

Task 1: Project Design and Management Plan. In this task, PNNL developed and documented the design of the windows demonstration project in a Project Design and Management Plan (Plan). The Plan included 1) the research questions to be answered, including the data to be collected and the duration of data collection; 2) the project team and their roles; 3) the project plan; 4) the draft construction specifications for the purchase of the matched pair of manufactured homes; and 5) how the highly insulating windows could be included in future specifications for highly insulating manufactured homes in the PNW Region and future codes for manufactured housing.

Stage Gate 1: At this stage gate, PNNL presented the Plan to the BPA Technology Innovation Council (TI/C). The role of the TI/C is to determine whether the project as designed and documented in the Plan answers the research questions agreed upon and if so, whether the funding and time available are adequate to do so. Based on the presentation to the TI/C, the re-scoped project was determined sufficient to accomplish the research objectives, and had adequate funding and therefore could move to Tasks 2 and 3 and Stage Gate 2. PNNL provided the TI/C approved Plan to DOE.

- Task 1 Completion: December 15, 2010

- Deliverable: Project Design and Management Plan

- Presentation to the TI/C: February 4, 2011

Task 2: Prepare Solicitation for the Procurement of the Matched Pair of Manufactured Homes. Specifications were developed for the homes with input from the project stakeholders, and an initial solicitation was developed for a manufacturer to build, transport and set up two modified manufactured homes at a site on the PNNL campus to be prepared by a separate subcontractor selected by PNNL Facilities. This solicitation was issued on January 24, 2011 with a closing date of February 25, 2011. No bids from the manufactured housing industry in the Pacific Northwest were received at the closing date. The deadline was extended to March 25, 2011, and one bid was received but was higher than the budgeted amount for the two homes. In consultation with BPA and with input from the project team/PNNL Facilities, the specifications were modified and solicitation was "bundled" and reissued on May 16, 2011 for a General Contractor (GC) to 1) procure a matched pair of standard HUD-code doublewide manufactured homes; 2) prepare the site on the PNNL campus for the homes; and 3) perform alterations in each home (designated Lab Home A [Baseline Home] and Lab Home B [Experimental Home]) according to the specifications once the homes are set up on the PNNL campus. The procurement of the homes included the transport and setup of the homes. The schedule for construction, setup and alterations of the homes was included in the solicitation. The final specifications to which the two homes were constructed and altered by the GC are given in Appendix A. 
- Task 2 Completion: May 16, 2011 (Final Solicitation)

- Deliverable: PNNL-issued solicitation for a GC: Request for Proposal for Purchase and Alterations of Two Manufactured Homes.

Task 3: Prepare Solicitation for Purchase of Windows. T As a part of the GC solicitation in Task 2, PNNL specified the procurement of highly insulating ( $\mathrm{U}$-factor $=0.20-0.22)^{1}$ windows and sliding glass doors for retrofit in Lab Home B, and the standard windows and sliding glass doors for retrofit in Lab Home A. ${ }^{2}$ The highly insulating windows were specified from Jeld-Wen ${ }^{\circledR}$, a window manufacturer who is a participant in the DOE volume purchase program for high-performance windows. The standard windows (double-pane clear with aluminum frame) were specified to represent windows commonly found in existing homes. The labor and materials requirements for the installation of the highly insulating and the standard windows were monitored and documented (see Appendix B).

Stage Gate 2: At this juncture of the project, PNNL consulted with the BPA Project Manager on the final specifications for the low-performance and highly insulating windows for retrofits. BPA agreed with the specifications and the project moved forward to Task 4.

- Completion date: June 9, 2011.

- Deliverable: PNNL-issued solicitation for a GC (with windows procurement included): Request for Proposal for Purchase and Alterations of Two Manufactured Homes.

Task 4: Develop Metering/Monitoring Plan. An electrical end-use and environmental metering/monitoring plan was developed that included whole-house energy use, end-use metering of nearly every individual home circuit (42 breakers), indoor temperatures, windows' interior and exterior surface temperatures, mean radiant temperature (2 locations), indoor humidity, outdoor temperature, wind speed, and solar insolation. Each home also was subject to blower door/duct leakage testing before and after the windows retrofit. The metering plan also incorporated strategies to simulate occupancy using heated 'black bodies' and by turning on and off programmable motorized circuits.

- Completion: February 15, 2011.

- Deliverable: Metering Plan.

Task 5: Make Award for Construction of Homes and Highly Insulating Windows. The final solicitation for a GC closed on July 5, 2011. PNNL made the award for the solicitation developed in Task 2.

- Completion: July 19, 2011

- Deliverable: Award made to a GC for the procurement, transport, siting, and alterations to the two manufactured homes. GC award also included site preparation.

\footnotetext{
${ }^{1}$ The rate of heat loss through a window assembly is indicated in terms of the U-factor. The lower the U-factor, the greater a window's resistance to heat flow and the better its insulating properties.

${ }^{2}$ Both Lab Homes were constructed with windows and sliding glass doors that met HUD performance codes per the specifications. These were double-pane, low-e vinyl frame with a U-factor of 0.29-0.31 and solar heat gain coefficient of $0.30-0.31$.
} 
Task 6: Transport, Set Up and Alter Homes, and Install Metering Equipment. The GC was responsible for transporting and setting up the homes as well as verifying that the homes complied with the set-up specifications prepared in Task 2. The GC altered the homes according the specifications (not including the windows retrofits at this time). PNNL completed the installation of the metering equipment, including a weather station, and commissioned the metering systems. The homes were then prepared for null testing (baselining) described in Task 7.

Stage Gate 3: At this point in the project, PNNL alerted BPA to the completion of Task 6. BPA was provided a description of the metering installation and protocols for baselining the homes. PNNL was prepared to make a presentation to BPA management and/or the TI/C to present project progress, future plans and schedule if requested by BPA. BPA determined that this was not necessary at this juncture and PNNL was directed to proceed to Task 7.

- Completion: October 14, 2011

- Deliverable: Homes delivered and set up at the PNNL site, homes altered by the GC and metering equipment installed and commissioned.

Task 7: Normalize/Baseline Meter Homes/Retrofit Windows. The pair of homes was given blower door tests and duct leakage tests to determine ventilation characteristics. Leaks in the envelope and ducts were sealed to bring the homes to nearly identical air leakage characteristics. Infrared (IR) images were also taken of both homes to show heat loss pathways. A null test with identical thermostat (heating) set points in each home was conducted over a period of $\sim 1$ week to ascertain their baseline performance profile. Normalization was undertaken in order to be assured that energy savings due to the highly insulating windows is the only variable between the homes. At the conclusion of normalization, the standard windows were retrofitted in Lab Home A and the highly insulating (R-5) windows were installed in Lab Home B. Blower door testing was once again conducted on each home after retrofit to measure the change in air leakage due to the windows retrofit. Summary results of these tests were provided to BPA and DOE and are described in more detail below.

- Completion of null testing before windows retrofit: November 18, 2011

- Completion of windows retrofit in Lab Home A and Lab Home B: January 26, 2012

- Deliverable: Blower-door (before and after windows retrofit) and null-testing summary results.

Task 8: Collect and Analyze Data. Both homes were set up to identically simulate occupancy per the Plan. The heating system was set to heat the home with the central heating, ventilating and air conditioning (HVAC) system at set points ranging from 70 to $80^{\circ} \mathrm{F}$. Data were collected according to the Plan and the experiment was terminated on April 13, 2012.

Stage Gate 4: PNNL provided preliminary data collected during January and February to BPA and DOE. The results were discussed with the BPA and DOE project managers and both agreed that the data collection and preliminary analysis are providing reasonable outcomes.

- Completion of data collection: April 13, 2012

- Deliverable: Interim data collection summary report: March 5, 2012. 
Task 9: Present Draft Data Analysis to BPA TI/C. PNNL presented the status of the project and data collected as of January 2012 in a summary analysis report to the TI/C at the Technology Innovation Summit in Portland, Oregon.

- Completion date: February 1, 2012

- Deliverable: PowerPoint presentation of the status and preliminary results of the highly insulating windows evaluation to the TI/C.

Task 10: Final Report. PNNL prepared this Final Report of the field evaluation of the highly insulating windows. In this report, PNNL provided recommendations for a path forward for integrating highly insulating windows into the manufactured homes industry, utilities and the retrofit industry for developing improved codes, market transformation programs and efficiency programs to help meet BPA’s 2010-2014 regional energy savings goals.

- Completion: June 30, 2012

- Deliverable: Final field evaluation project report.

A summary of the schedule for the tasks and activities in the Lab Homes windows field evaluation is shown in Table 3.1.

Table 3.1. Schedule for Tasks and Major Activities in the Lab Homes Windows Field Evaluation.

\begin{tabular}{lccc}
\hline \multicolumn{1}{c}{ Activity } & Start Date & End Date & Duration (days) \\
\hline Lab Homes Setup/Modifications by GC & $09 / 12 / 11$ & $11 / 17 / 11$ & 67 \\
Metering/Instrumentation & $12 / 01 / 11$ & $01 / 06 / 12$ & 37 \\
Pre-Retrofit Air Leakage Testing & $01 / 12 / 12$ & $01 / 13 / 12$ & 2 \\
Pre-Retrofit Null Testing & $01 / 16 / 12$ & $01 / 23 / 12$ & 8 \\
Windows Retrofit & $01 / 24 / 12$ & $01 / 25 / 12$ & 2 \\
Post-Retrofit Air Leakage Testing & $01 / 30 / 12$ & $01 / 31 / 12$ & 2 \\
Windows Experiment & $02 / 04 / 12$ & $04 / 13 / 12$ & 70 \\
\hline
\end{tabular}




\subsection{Construction Features and Siting of the Lab Homes}

The matched pair of Lab Homes were constructed at a Marlette ${ }^{\circledR}$ Homes manufacturing plant in Hermiston, Oregon, during the time period August 11 through August 23, 2011. The homes are both HUD-code Marlette Value Edition Model \#2856B with the options identified in the specifications given in Appendix A. The thermal calculations provided by the manufacturer show a heat transfer coefficient of 345.36 Btu/hr $\mathrm{ft}^{2}{ }^{\circ} \mathrm{F}$. The floor plan of the homes as constructed is shown in Figure 4.1.

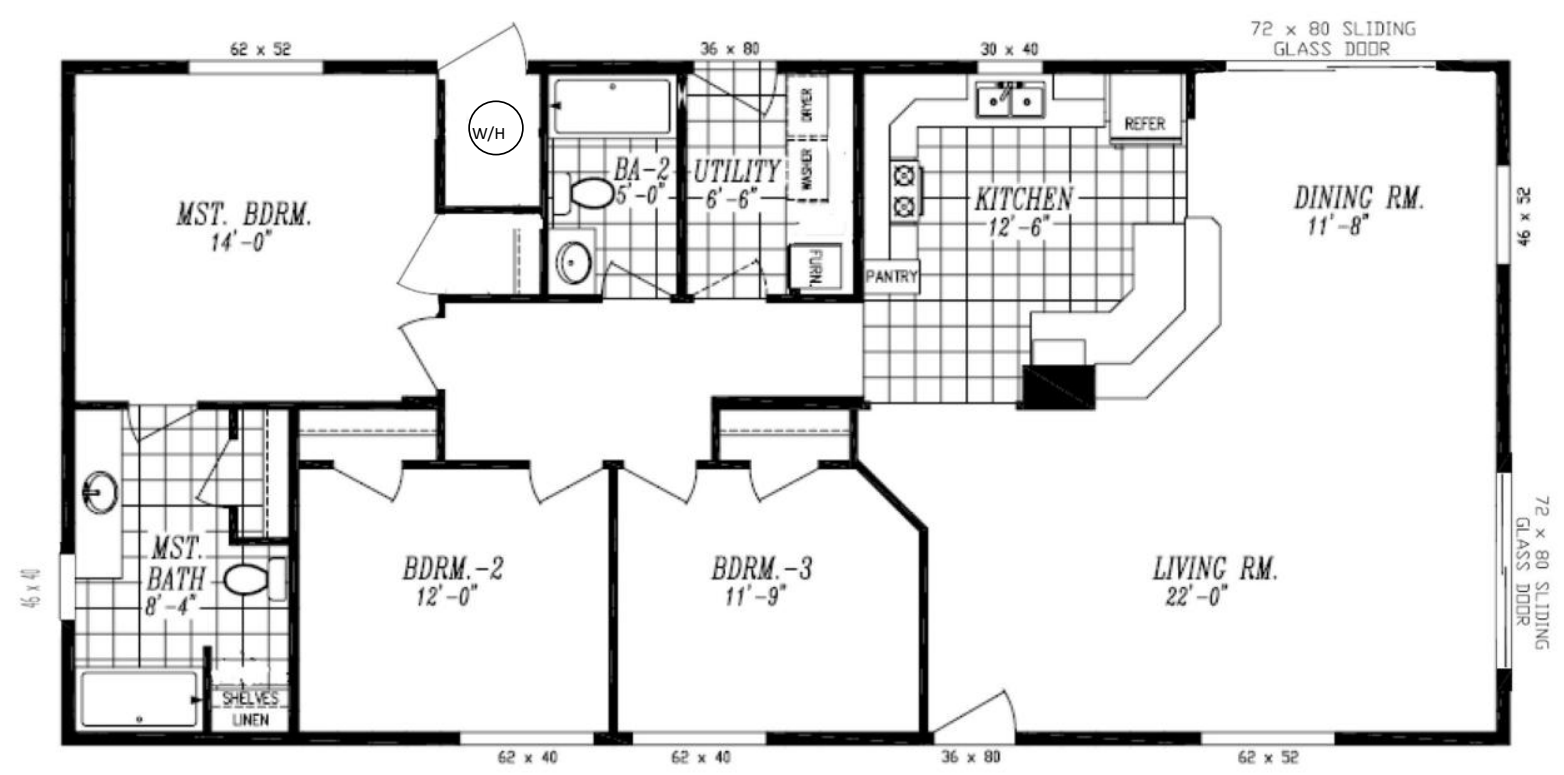

Figure 4.1. Floor Plan of the Lab Homes as Constructed

Features of the $1493 \mathrm{ft}^{2}$ double-wide 3 bedroom/2 bathroom homes that are relevant to the highly insulating windows evaluation include:

- all-electric

- window area: $195.7 \mathrm{ft}^{2}$ or $\sim 13 \%$ of the floor area

- frame: 2 in. $\times 6$ in. walls; 2 in. $\times 10$ in. floor and ceiling

- insulation: R-22 floors (with belly wrap), R-11 walls; R-22 vaulted ceiling, R-4.2 exterior ducts

- heating/cooling: non-set back central thermostat-controlled ducted 2.5 ton heat pump - 13 Seasonal Energy Efficiency Ratio (SEER)/7.7 Heating Seasonal Performance Factor (HSPF) with single speed air handler, plus alternative heating provided by Cadet Model \#RMC151W 120V fan wall heaters with individual thermostats ${ }^{1}$

- underfloor ducting

- lighting: $100 \%$ incandescent

- 6-inch (overhang) vented eaves all around

\footnotetext{
${ }^{1}$ Note that the locations of the Cadet wall heaters are not shown in Figure 1. These heaters were not used/not activated during any part of the highly insulating windows winter evaluation.
} 
- bath fans, kitchen range hood and whole-house exhaust fan

- $\operatorname{wood}\left(\text { SmartSide }{ }^{\circledR}\right)^{1}$ panel siding

- carpet + vinyl flooring

- vented crawlspace with Rapid Wall 2-inch thick expanded polystyrene foam-backed aluminum with R-9 insulation value with access panels

- exterior access foam-core door to water heater.

The homes were located 90 feet apart on the PNNL campus in a flat, open area with no buildings or trees near the homes that would create shade on the homes during any time of the year. The homes were oriented in an east/west direction with the main entry doors to the living room facing north. This orientation resulted in one patio door facing west and the other patio door facing south.

The homes are surrounded by irrigated grass with gravel driveways on the east end and a gravel walkway all around the homes. The homes are adjacent to an irrigated alfalfa field to the east. Figure 4.2, Figure 4.3, Figure 4.4 and Figure 4.5 show the homes as they are currently sited. Appendix B shows additional photos of the exterior and interior of the homes.

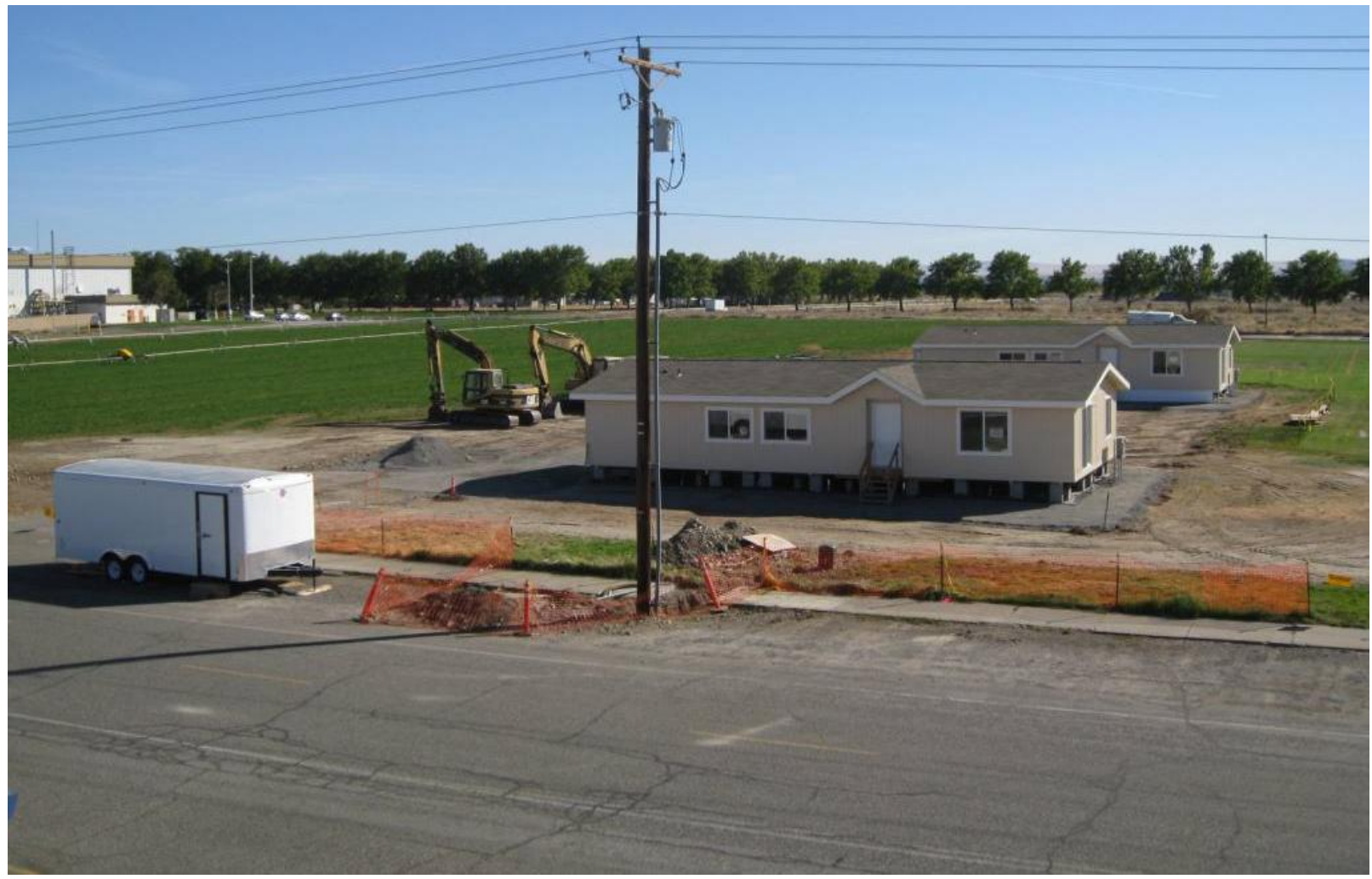

Figure 4.2. Lab Home B (foreground) and Lab Home A (background) after Setup During Final Site Preparation

\footnotetext{
${ }^{1}$ Registered trademark of Louisiana-Pacific Corporation
} 

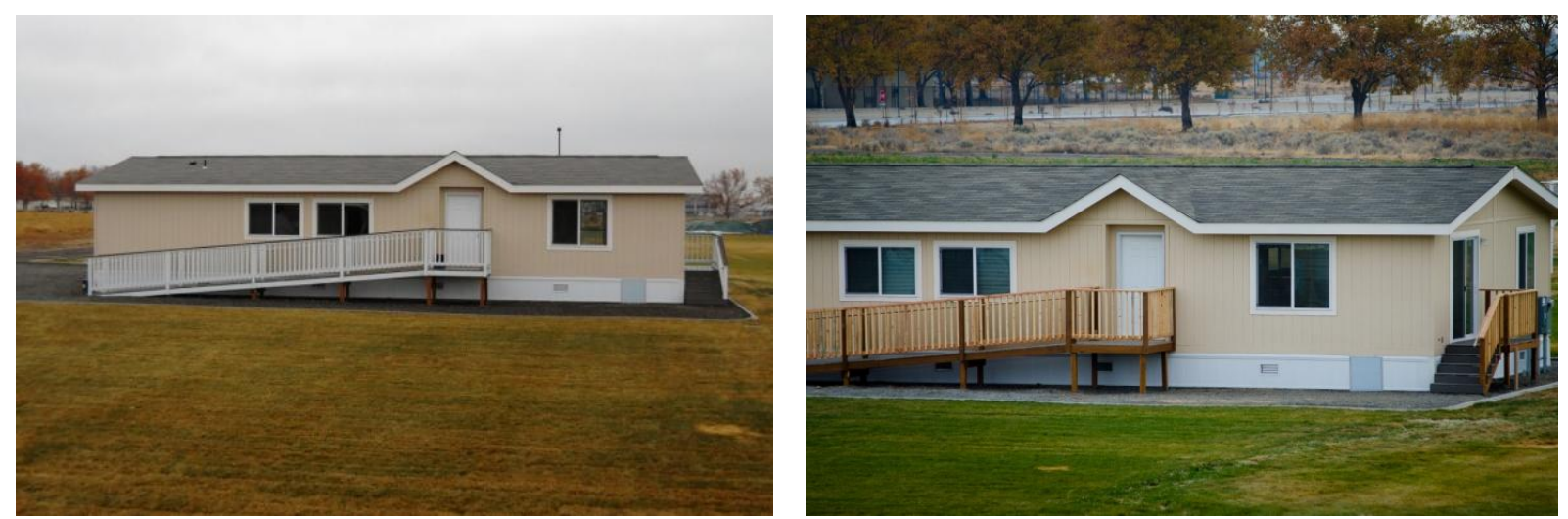

Figure 4.3. North Side and North and West Sides of Lab Home A (Baseline Home)

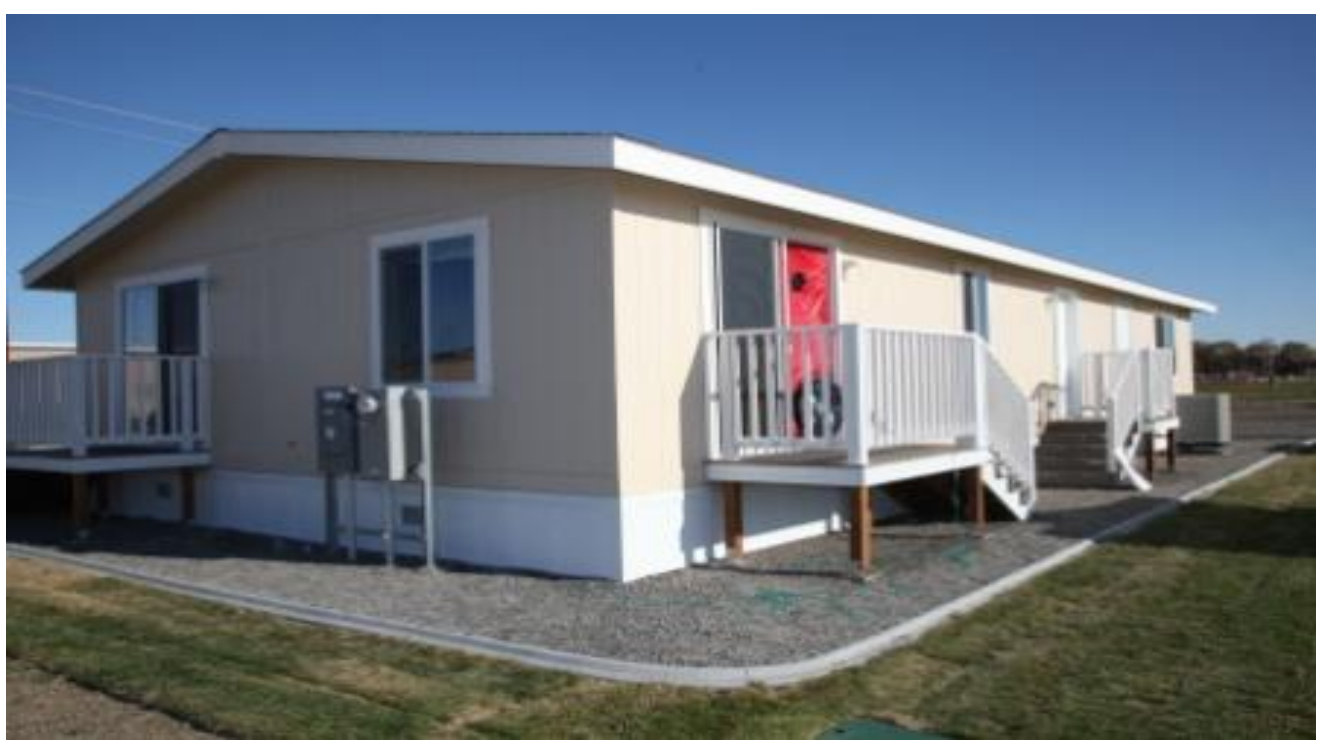

Figure 4.4. West and South Sides of Lab Home B (Experimental Home)

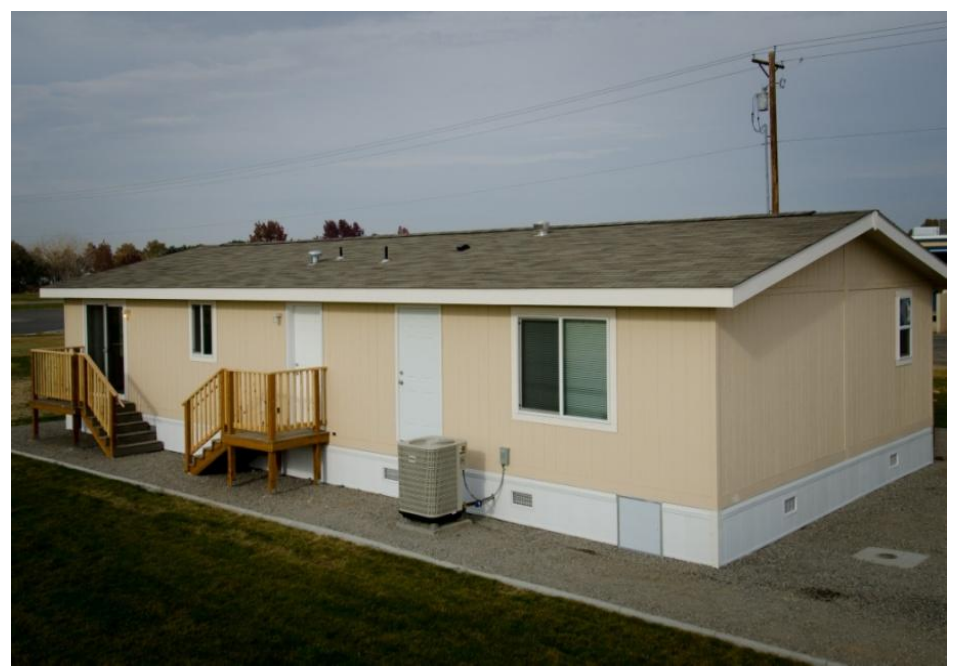

Figure 4.5. South Side of Lab Home B (Experimental Home) 



\subsection{Metering, Monitoring and Experimental Plan}

The windows performance evaluation relied on a tiered approach to performance and evaluation in the Lab Homes. The approach was designed to generate a multilevel performance evaluation whereby each level was used to aggregate to the next highest level (component, to building system, and then whole building) to arrive at the net impact. A major benefit to this approach is the ability to implement a "checksum" methodology to the evaluation, i.e., the sum of the end-use parts compared to the expected/metered whole with a capability to drill down to the individual component level.

\subsection{Metering and Monitoring Approach}

The approach to the metering included metering and system-control activities taking place at both the electrical panel and at the end-use or point of use. Monitoring was broken into electrical (Table 5.1) and temperature/other (Table 5.2). Each table highlights the performance metric (the equipment/system being monitored), the monitoring method and/or point, the monitored variables, and the data application.

Table 5.1. Electrical Points Monitored

\begin{tabular}{|c|c|c|c|}
\hline $\begin{array}{l}\text { Performance } \\
\text { Metric }\end{array}$ & $\begin{array}{c}\text { Monitoring } \\
\text { Method/Points }\end{array}$ & $\begin{array}{l}\text { Monitored } \\
\text { Variables }\end{array}$ & Data Application \\
\hline $\begin{array}{l}\text { Whole Building } \\
\text { Energy Use }\end{array}$ & $\begin{array}{l}\text { Electrical panel } \\
\text { mains }\end{array}$ & $\mathrm{kW}$, amps, volts & $\begin{array}{l}\text { Comparison and difference calculations between } \\
\text { homes of: } \\
\text { - power profiles } \\
\text { - time-series energy use } \\
\text { - differences and savings }\end{array}$ \\
\hline \multirow[t]{3}{*}{$\begin{array}{l}\text { HVAC Energy } \\
\text { Use (heat pump) }\end{array}$} & $\begin{array}{l}\text { Panel metering } \\
\text { compressor }\end{array}$ & $\mathrm{kW}$, amps, volts & \multirow{3}{*}{$\begin{array}{l}\text { Comparison and difference calculations between } \\
\text { systems of: } \\
\text { - power profiles } \\
\text { - time-series energy use } \\
\text { - differences and savings }\end{array}$} \\
\hline & $\begin{array}{l}\text { Panel metering air } \\
\text { handling unit }\end{array}$ & $\mathrm{kW}$, amps, volts & \\
\hline & $\begin{array}{l}\text { End-use metering } \\
\text { condensing unit (CU) } \\
\text { fan/controls }\end{array}$ & $\mathrm{kW}$, amps, volts & \\
\hline $\begin{array}{l}\text { HVAC Energy } \\
\text { Use (ventilation) }\end{array}$ & $\begin{array}{l}\text { Panel metering of } 3 \\
\text { ventilation breakers } \\
\text { ( } 2 \text { bathroom and } \\
\text { whole-house fans) }\end{array}$ & $\mathrm{kW}$, amps, volts & $\begin{array}{l}\text { Comparison and difference calculations between } \\
\text { systems of: } \\
\text { - power profiles } \\
\text { - time-series energy use } \\
\text { - differences and savings }\end{array}$ \\
\hline Water Heating & $\begin{array}{l}\text { Panel metering of } \\
\text { water heater breakers }\end{array}$ & $\mathrm{kW}$, amps, volts & $\begin{array}{l}\text { Comparison and difference calculations between } \\
\text { systems of: } \\
\text { - power profiles } \\
\text { - time-series energy use } \\
\text { - differences and savings }\end{array}$ \\
\hline $\begin{array}{l}\text { Appliances and } \\
\text { Lighting }\end{array}$ & $\begin{array}{l}\text { Panel metering of all } \\
\text { appliance and } \\
\text { lighting breakers }\end{array}$ & $\mathrm{kW}$, amps, volts & Comparison and difference calculations. \\
\hline
\end{tabular}


Table 5.2. Temperature and Environmental Points Monitored

\begin{tabular}{|c|c|c|c|}
\hline $\begin{array}{l}\text { Performance } \\
\text { Metric }\end{array}$ & Monitoring Method/Points & Monitored Variables & Data Application \\
\hline \multirow[t]{2}{*}{$\begin{array}{l}\text { Space } \\
\text { Temperatures }\end{array}$} & $\begin{array}{l}13 \text { Ceiling-hung } \\
\text { thermocouples/1-2 sensors } \\
\text { per room/area, and } 1 \text { HVAC } \\
\text { duct supply temperature per } \\
\text { home }\end{array}$ & Temp. ${ }^{\circ} \mathrm{F}$ & $\begin{array}{l}\text { Comparison and difference calculations } \\
\text { between homes of: } \\
\text { - temperature profiles } \\
\text { - time-series temperature changes }\end{array}$ \\
\hline & $\begin{array}{l}2 \text { mean radiant sensors per } \\
\text { home (main living area, } \\
\text { master bedroom) }\end{array}$ & Temp. ${ }^{\circ} \mathrm{F}$ & \\
\hline $\begin{array}{l}\text { Space Relative } \\
\text { Humidity }(\mathrm{RH})\end{array}$ & $\begin{array}{l}2 \text { percent-relative-humidity } \\
\text { sensors per home (main } \\
\text { living area, hall outside of } \\
\text { bathroom) }\end{array}$ & $\% \mathrm{RH}$ & $\begin{array}{l}\text { Comparison and difference calculations } \\
\text { between homes of: } \\
\text { - RH profiles } \\
\text { - time-series RH changes }\end{array}$ \\
\hline $\begin{array}{l}\text { Glass Surface } \\
\text { Temperatures }\end{array}$ & $\begin{array}{l}22 \text { thermocouples ( } 2 \text { sensors } \\
\text { per window interior/exterior } \\
\text { center of glass); west } \\
\text { window with } 6 \text { sensors }\end{array}$ & Temp. ${ }^{\circ} \mathrm{F}$ & $\begin{array}{l}\text { Comparison and difference calculations } \\
\text { between homes of: } \\
\text { - temperature profiles } \\
\text { - time-series temperature changes }\end{array}$ \\
\hline $\begin{array}{l}\text { Through-Glass } \\
\text { Solar } \\
\text { Radiation }\end{array}$ & $\begin{array}{l}1 \text { pyranometer sensor per } \\
\text { home trained on west-facing } \\
\text { window }\end{array}$ & Watts $/ \mathrm{m}^{2}$ & $\begin{array}{l}\text { Comparison and difference calculations } \\
\text { between homes of: } \\
\text { - profiles by window and location }\end{array}$ \\
\hline $\begin{array}{l}\text { Meteorological } \\
\text { Station }\end{array}$ & $\begin{array}{l}\text { Package station mounted on } \\
\text { Lab Home B }\end{array}$ & $\begin{array}{l}\text { Temp. }{ }^{\circ} \mathrm{F} \\
\text { Humidity } \% \\
\text { Wind speed } \mathrm{m} / \mathrm{s} \\
\text { Wind direction } \\
\text { Barometric pressure } \\
\text { mm } \\
\text { Rainfall, inches }\end{array}$ & $\begin{array}{l}\text { Analytical application to quantify setting } \\
\text { and develop routines for application to } \\
\text { other climate zones }\end{array}$ \\
\hline
\end{tabular}

All metering was done using Campbell Scientific data loggers and matching sensors. Two Campbell data loggers were installed in each home, one allocated to electrical measurements and one to temperature and other data collection. Data from all sensors were collected via cellular modems that were individually connected to each of the loggers. The polling computer located in the metering lab on the PNNL campus connected to each logger utilizing Campbell Scientific software.

Initially, data were collected at tight intervals (starting at 1 minute integration) to make sure all systems and equipment are operating as expected - both within each home and in comparison home-tohome. These 1 minute data have been supplemented with 15 minute and 1 hour data to afford different analysis activities.

In a parallel effort, occupancy in the homes was simulated via programmed access to a customdesigned breaker panel (one per home) employing motorized breakers. These breakers were programmed to activate connected loads on schedules to simulate human occupancy. The occupancy simulation schedule is included in Appendix C. Technical information on the controllable breaker panel, the Campbell data logger, and relevant sensors is included in Appendix D. 


\subsection{Electrical Measurements}

In each home, all 42 of the panel electrical breakers were monitored for amperage and voltage. The resulting data were used to calculate apparent and real power $(\mathrm{kVA} / \mathrm{kW})$. All data were captured at 1 minute intervals by the Campbell Scientific data logger.

\subsubsection{Temperature and Environmental Sensors}

Space Temperature. To provide for maximum flexibility for existing and future experiments, identical networks of temperature sensors were deployed in both homes. Each defined area of the home (individual rooms, hallway, and open living areas) had at least one thermocouple; a total of 13 space temperature thermocouples were installed per home. All temperature measurements were taken with type T thermocouples at 1 minute intervals by the Campbell data logger.

Glass Surface Temperature. All seven windows and two sliding glass doors in each home were instrumented with surface-mount type $\mathrm{T}$ thermocouples in a center-of-glass position on both the interior and exterior surfaces. The west-facing 46 in. $\times 52$ in. window in each home was instrumented with three thermocouples to capture variance in temperature from the center of glass to the window edge and frame. A total of 22 window/sliding glass door surface temperature thermocouples were installed per home.

Mean Radiant Temperature. To estimate thermal comfort, MRT sensors were installed in each home. One was located in the living room in the northwest corner (facing the west window and the north sliding glass door) and the other was located in the master bedroom facing the north window. These devices, also known as black-globe temperature sensors, use a thermistor inside a 6 in. hollow black copper sphere to measure incident radiant temperature. This measurement becomes a proxy for thermal comfort/discomfort resulting from the radiant heat exchange between an occupant and surrounding (e.g., window) surface temperatures.

Relative Humidity. Two humidity sensors were installed in each home, one in the living area and one in the hallway. These data were collected and compared to verify that comparable humidity profiles were present in each home.

Transmitted Solar Radiation. Through-glass transmission of solar radiation was measured with a thermopile pyranometer. Each home was instrumented with one solar pyranometer facing the west window. The pyranometers were installed identically (height and distance from the window) in each home to provide a measure of comparative transmitted solar radiation.

Light Level Measurements. Light level measurements were taken by PNNL staff in each home before and after the windows retrofit (See Appendix F). The instrument used was a Konica Minolta T-10 illuminance meter with detachable head, cable and connector.

\subsection{Windows Experiment General Approach}

The metering and data collection approach for the highly insulating windows demonstration were designed to make sure that the performance data collected in the windows experiment would reflect only the performance impact of the windows retrofitted in the two homes and that all other variables that would impact the performance would be identical in the two homes. The experimental approach followed Tasks 7 and 8 above. 



\subsection{Testing Protocol}

A summary of the experimental testing protocol is given below in chronological order of implementation. The details of the testing and the schedule and duration of each test follow.

1. Post-Siting Testing of the Homes. After the homes were sited and modified, but before the instrumentation was installed, PNNL, NEW and WSU-Extension Energy staff conducted blower door tests, duct testing and IR scans. These tests were conducted to determine qualitatively the comparative construction and setup of the two homes.

2. Post Instrumentation Installation Testing. After post-setup testing the Lab Homes, PNNL instrumented both manufactured homes with appropriate monitoring, sensors and data collection/archiving equipment used to determine comparative energy performance of the two homes. After equipment installation, the homes were blower door tested to determine building shell air leakage, and penetrations due to the instrumentation were sealed to bring the homes to a statistically identical level of air tightness. The HVAC (heat pump) operation and performance in each home was also ascertained.

3. Float Null Testing. Temperatures were monitored in both homes in a float null case (no heating, cooling, lighting, etc., loads enabled) to determine any differences in the homes as delivered and set up.

4. HVAC Null Testing. Temperatures, whole-house energy use and HVAC energy use were monitored in both homes in an HVAC system-enabled null case with identical thermostat set points in both homes to determine any differences in whole house or HVAC system performance.

5. Full-System Null Testing. Both homes were monitored in a full-system activation null case that included operating the HVAC systems (heat pumps) at identical thermostat set points and identical occupancy simulation in both homes to determine any differences in systems performance.

6. Windows Retrofit and Initiate Experiment. Once the homes were full-system null tested, the windows experiment was initiated. The original (factory-supplied) windows in Lab Home A were retrofitted with double-pane, clear, aluminum-frame windows and the windows in Lab Home B were retrofit with the Jeld-Wen triple-pane, argon gas-filled ${ }^{1}$, low-e coated windows. Windows performance testing included monitoring of:

- whole building energy use

- HVAC-specific energy use

- multiple interior zone/space temperature measurement

- interior relative humidity measurement (two locations)

- window surface temperatures - interior/exterior center-of-glass measurements

- window solar irradiation (solar radiation transmittance)

- $\quad$ MRT (black body) measurement (two locations).

\footnotetext{
${ }^{1}$ Window manufacturers fill the sealed gap in multi-pane windows with an inert gas such as argon to reduce the conduction of heat between panes and thus increase the overall U-factor of the window assembly.
} 
The testing undertaken, the retrofit windows specifications, and post-windows retrofit testing protocol for the Lab Homes described in detail below. The data from the testing are given in Section 7.

\subsection{Post-Siting Testing of the Homes}

After siting of lab homes, extensive baseline testing was conducted to verify similar construction, envelope leakage, duct leakage, ventilation fan flow rates, and heat pump (HP) operation. These physical parameters were evaluated by PNNL, with assistance from WSU-Extension Energy Program and NEW using industry standard methods and protocols. These were:

\subsubsection{IR Testing}

Similar construction and thermal performance was evaluated from the interior and exterior using a Fluke Ti32 IR camera. Scans were recorded in the Fluke proprietary is2 file format with descriptive vocal annotations to locate the image in the proper home and location within the home.

\subsubsection{Building Shell Air Leakage}

Air leakage through the building shell was quantified in both homes using a Minneapolis Blower Door Model 3 and DG-700 digital pressure gauge in accordance ASTM E779, Standard Test Method for Determining Air Leakage Rate by Fan Pressurization (ASTM 2010) and manufacturer recommendations. The accuracy of the blower door is $3 \%$ of the reading, as stated in manufacturer's literature (The Energy Conservatory 2012).

\subsubsection{Duct Leakage and Pressure Mapping}

Duct leakage was measured using a Minneapolis Duct Blaster Series B fan and DG-700 digital pressure gauge supplied by The Energy Conservatory. The test was conducted according the protocol defined the duct blaster operating manual (The Energy Conservatory 2011). The accuracy of the duct blaster fan is 3\% of the measurement, as stated in the manufacturer's literature (The Energy Conservatory 2011). Distribution of the duct system was also characterized in each home by measuring the flow through each supply register using an Exhaust Fan Flow Meter from The Energy Conservatory (The Energy Conservatory 2010).

\subsubsection{Ventilation Fan Flow Rate}

Flow rates of the whole-house ventilation fan and two bathroom exhaust fans were measured using an Exhaust Fan Flow Meter and DG-700 digital pressure gauge from The Energy Conservatory. The stated accuracy of the Exhaust Fan Flow Meter is $\pm 10 \%$ of the reading (The Energy Conservatory 2010).

\subsubsection{Heat Pump Performance}

The performance of both homes' heat pumps was verified by measuring the temperature differential across the coil in both homes when heating was called for. This was done using a small digital readout thermometer. Temperature sensor accuracy was not verified and measurement error is not known for this 
device. The heat pump was allowed to run for at least 20 minutes prior to taking readings and the supply air temperature was taken immediately downstream from the indoor coil.

Flow through the air handler was also measured using an Energy Conservatory TrueFlow air handler flow meter and DG-700 digital pressure gauge. The accuracy of the combined system is $\pm 7 \%$ of the reading, as stated in manufacturer literature (The Energy Conservatory 2006). For this measurement, the duct system pressure tap was placed in the duct at the north entryway register to obtain system operating pressure readings and Plate 20 was used in the air handler. The automated procedure in the DG-700 gauge was used to obtain corrected airflow readings directly.

\subsection{Post-Siting Instrumentation Installation and Data Collection Protocols}

All metering equipment, data loggers and indoor and outdoor sensors were installed and commissioned prior to initiating null testing. Data from all sensors were collected via four data acquisition systems, one for environmental sensors and one for energy sensors in each home. Data were downloaded using Internet Protocol (IP) cellular modems. A polling computer, located in the metering lab on the PNNL campus, was connected to each logger using Campbell Scientific software. Data were recorded on one-minute, 15 minute, and hourly intervals. One-minute data was used for all analysis to capture any short-duration changes in energy use within the home-for example from a heating element cycling on - and to limit error introduced from averaging over longer time periods. Data were averaged over 15 minute intervals.

The metering equipment is described in Section 5 with equipment specifications given in Appendix D.

\subsection{Float, HVAC and Full-System Null Testing}

Baseline null testing was performed prior to any retrofits occurring in either of the homes by comparing the whole-house energy use given identical operating conditions. Null testing was performed for eight days over the period of January 16, 2012 through January 23, 2012, with the thermostat set point increased by $5^{\circ} \mathrm{F}$ increments in each home (identically) from $60^{\circ} \mathrm{F}$ on the first day to $85^{\circ} \mathrm{F}$ on the last day of testing. This was done to verify identical performance of the homes over a range of interior temperatures and indoor/outdoor temperature differentials. During the null tests the homes were operated identically in heat pump and electric resistance modes.

\subsection{Windows Retrofit}

The windows that came with the homes from the factory were Kinro Series 1500 and the two sliding glass doors (patio doors) were Kinro Series 1600. The windows were horizontal sliders with double glaze, argon-filled low-e 036 coating with vinyl frames. ${ }^{1}$ The patio doors were also vinyl-framed, double glazed, argon-filled with low-e 036 coating. The factory windows provided were selected to meet the HUD

\footnotetext{
${ }^{1}$ The window in the master bathroom was retrofit with a single hung window because that was the window type supplied by the factory. The Jeld-Wen retrofit window, however, was not frosted as is the case for the retrofit window in Lab Home A (see footnote on next page).
} 
overall building shell thermal performance criteria for manufactured homes in the climate zone of Richland, Washington. ${ }^{1}$

In Lab Home B, the factory-supplied slider windows and two patio doors were replaced by JeldWen ${ }^{\circ}$ Premium Energy Saver-MAX-K slider vinyl windows and patio doors. ${ }^{2}$ These vinyl-frame windows are triple-pane, argon/krypton-filled with low-e coatings on both inside glass surfaces.

Additionally, these windows use Jeld-Wen's Low-E3-366 coating, which employs three layers of silver particles instead of two for increased insulation performance and decreased solar heat gain. A photo of the National Fenestration Rating Council (NFRC) label from one of the windows installed in the experimental home is included as Figure 6.1.

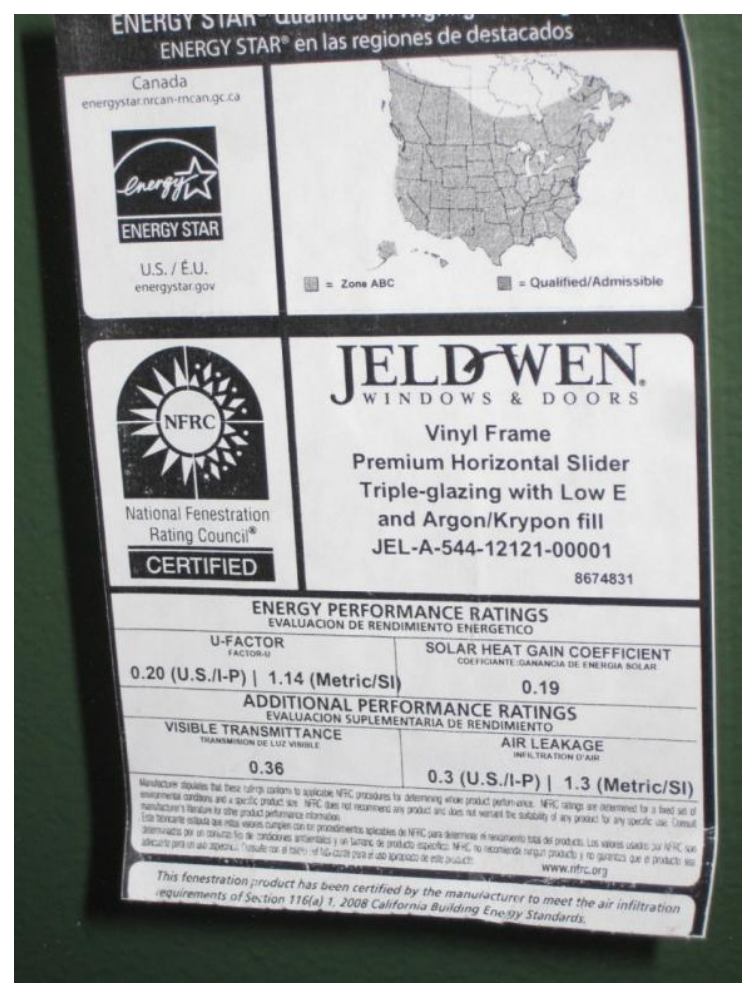

Figure 6.1. NFRC Certification Label for Jeld-Wen Highly Insulating Windows Installed in Lab Home B

The Jeld-Wen highly insulating windows were installed by the GC with guidance provided on site by Jeld-Wen-trained installers and according to the documented instructions provided by Jeld-Wen on each window for retrofitting their windows. Installation included removal of the existing window, installation of a drain mat with self-sticking foam moisture barrier on the sill plate, installation of the new highly insulating windows squarely in the opening, and sealing around the window with preformed rolled foam and caulk. See Appendix E for more details and photos of the Lab Home B windows retrofit.

In Lab Home A, windows representative of a large percentage of existing home construction in the PNW Region and across much of the country were installed. These windows are double pane, clear glass

\footnotetext{
${ }^{1}$ See http://www.gpo.gov/fdsys/pkg/CFR-2001-title24-vol1/content-detail.html.

${ }^{2}$ Note that the retrofit window in the master bathroom was a single-hung (non-frosted) window because a single pane window was the factory-supplied window in the home (see Figure 4.1).
} 
aluminum frame sliders. ${ }^{1}$ These windows were installed by the GC with no special training or assistance, to represent a "typical" installation. ${ }^{2}$ Installation included removal of the existing windows, insertion of the new double-pane clear windows, and caulking of the opening. ${ }^{3}$ All window coverings in both Lab Homes were removed to assure that the homes were identically configured.

Table 6.1 provides the specifications for the factory-supplied windows, the baseline retrofit windows in Lab Home A and the highly insulating retrofit windows in Lab Home B. As can be seen in Table 6.1, the U-factor of the windows and patio doors in Lab Home B is $\sim 70 \%$ less than that of the standard windows in Lab Home B. Also the low-e coatings of the windows in Lab Home B significantly decrease the solar heat gain coefficient (SHGC) by $\sim 77 \%$ compared to the standard double-pane clear windows and patio doors. The visible transmittance (VT) of the highly insulating windows is approximately half that of the double-pane clear windows in Lab Home A.

Table 6.1. Window Performance Characteristics of the Factory-Installed, Baseline Retrofit, and Highly Insulating Retrofit Windows and Patio Doors Installed in the Lab Homes

\begin{tabular}{llccccc}
\hline & \multicolumn{2}{c}{ Lab Homes A \& B } & \multicolumn{2}{c}{ Lab Home A } & \multicolumn{2}{c}{ Lab Home B } \\
& \multicolumn{2}{c}{ Factory Installed Windows } & \multicolumn{2}{c}{ Standard Retrofit Windows } & Highly Insulating Retrofit Windows \\
\cline { 2 - 7 } Value & Windows & Patio Doors & Windows & Patio Doors & Windows & Patio Doors \\
\hline U-factor & 0.31 & 0.29 & 0.68 & 0.66 & 0.20 & 0.20 \\
SHGC & 0.3 & 0.31 & 0.7 & 0.66 & 0.19 & 0.19 \\
VT & 0.56 & 0.59 & 0.73 & 0.71 & 0.36 & 0.37 \\
\hline
\end{tabular}

The possible impact of the light levels in the homes from the reduced VT of the highly insulating windows was measured. Light levels were measured in both homes prior to the windows retrofit and after the windows retrofit. A description of those measurements and the results are given in Appendix F.

\subsection{Initiate Windows Field Evaluation}

After the highly insulating and standard windows were installed in Lab Home B and Lab Home A respectively, the air leakage of the two homes was again measured with a blower door to determine air leakage changes and differences due to the windows retrofit. The homes were then set up identically for data collection of the energy use and thermal performance and to characterize savings and comfort impacts of the highly insulating windows compared to the standard windows.

As part of the experimental plan, the homes were operated identically in a variety of scenarios to understand the importance of different variables. Specifically, the impact of additional energy use associated with occupancy patterns and heating system type (heat pump and electric resistance heat with central distribution system) was evaluated. The thermostat set points were set at $75^{\circ} \mathrm{F}$ early in the study

\footnotetext{
${ }^{1}$ The retrofit master bathroom window in Lab Home A (see Figure 4.1) is a single hung frosted (privacy) glass window with the same specifications and from the same manufacturer as the other retrofit windows in Lab Home A given that the single hung was the window type installed at the factory.

${ }^{2}$ The windows retrofit in Lab Home A could only approximate a representation of windows in typical existing homes given that the windows were new, the caulking was fresh and the windows were installed in a new home without the effects of aging.

${ }^{3}$ The Lab Homes were constructed without an air barrier as an air barrier was not a requirement in the specifications nor required to meet the HUD code thermal performance.
} 
period and $80^{\circ} \mathrm{F}$ later in the study period to maximize the indoor/outdoor temperature difference as outdoor average temperatures began to increase toward the end of winter.

The field evaluation was run without and with simulated occupancy. The field evaluation was also performed with all appliances disabled to minimize any possible differences in appliance performance that might influence the heating of the homes. When run under simulated occupancy, the homes were run identically using the protocols described in Appendix B.

\subsection{Energy Modeling}

\subsubsection{Energy Simulation Tool}

The energy analysis for the lab homes was carried out in EnergyPlus. EnergyPlus is a whole-building detailed energy simulation engine capable of carrying out calculations at the hourly and sub-hourly level. It is the successor of powerful building energy modeling programs DOE-2 and BLAST. It combines the strong points of both programs and adds some more of its own. It is one of the most powerful wholebuilding energy modeling programs available today and is publically available. ${ }^{1}$ The model requires a text input file (.idf) with information about the building and a weather file (.epw) to generate an annual energy simulation.

EnergyPlus lacks a graphical user interface and the building information is input to the program through a text input file. This makes it difficult to define complicated parts of the energy model such as building geometry. Various plug-in and add-on utilities are available that act as a front end to the engine, allowing the user to define geometry and mechanical systems without directly interfacing with the text format of EnergyPlus. While these programs are very useful in some ways, they limit the strength and flexibility of EnergyPlus in some others.

OpenStudio, ${ }^{2}$ developed by the National Renewable Energy Laboratory (NREL) is used to specify building geometry. OpenStudio allows the user to visualize and modify building geometry and creates an EnergyPlus input file (.idf) for the whole building. It was desirable to use OpenStudio's graphical abilities while still maintaining the freedom of using all of EnergyPlus' mechanical systems capability. In order to achieve this, the building geometry was created in OpenStudio and exported in the form of an idf. This idf was then modified directly in EnergyPlus to model all the mechanical systems.

\subsubsection{Building Energy Model}

EnergyPlus requires detailed building geometry input in order to simulate a total heat balance. The dimensions of the walls, windows and doors were measured after the Lab Homes were sited and the data used in OpenStudio were used to create the outer shell of the building.

\subsubsection{Building Geometry}

Lab Home A and Lab Home B are identical in terms of building geometry, internal gains and mechanical systems. The retrofitted windows are the only differentiating factor between the two homes. Building geometry is created in OpenStudio and the resulting EnergyPlus input file is modified to model

\footnotetext{
${ }^{1}$ http://apps1.eere.energy.gov/buildings/energyplus/

${ }^{2}$ http://apps1.eere.energy.gov/buildings/energyplus/openstudio_suite.cfm
} 
mechanical systems and internal gains. Figure 6.2 is an image of the house model exported from OpenStudio.

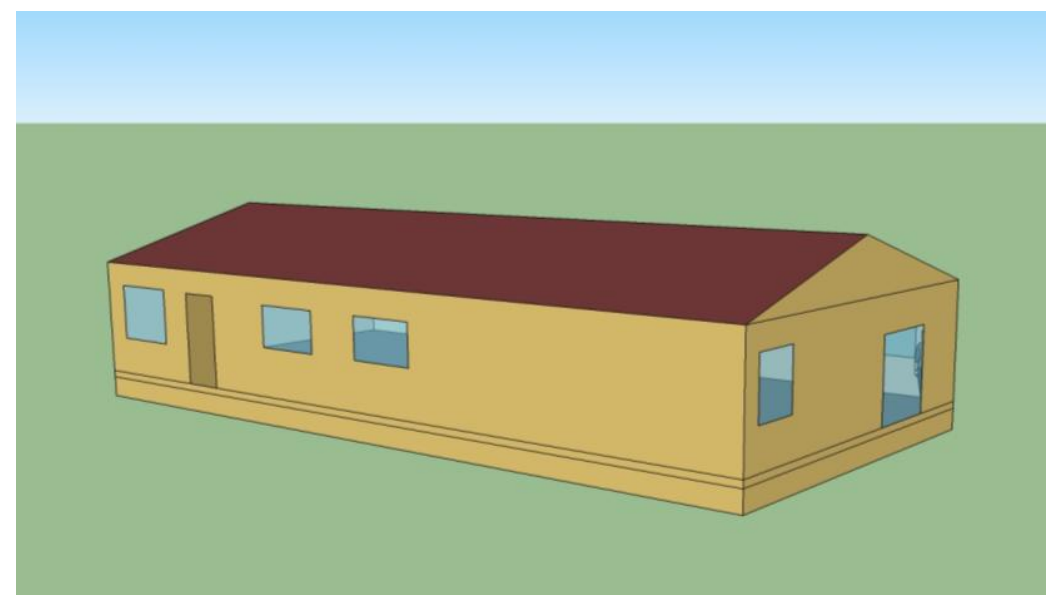

Figure 6.2. Building Geometry Exported from OpenStudio

\subsubsection{Building Envelope}

The building envelope is summarized in Table 6.2 below:

Table 6.2. Envelope Insulation Levels

\begin{tabular}{lcc}
\hline & Lab Home A & Lab Home B \\
\hline Ceiling Insulation & R-22 & R-22 \\
Wall Insulation & R-11 & R-11 \\
Floor insulation & R-22 & R-22 \\
Window U-factor & 0.68 & 0.20 \\
Window SHGC & 0.70 & 0.19 \\
Window VT & 0.73 & 0.36 \\
\hline
\end{tabular}

\subsubsection{Internal Gains}

EnergyPlus models internal gains using a peak power value and an associated schedule. Figure 6.3 through Figure 6.6 show various daily schedules used in the model. Table 6.4 summarizes the peak power value associated with each schedule. 


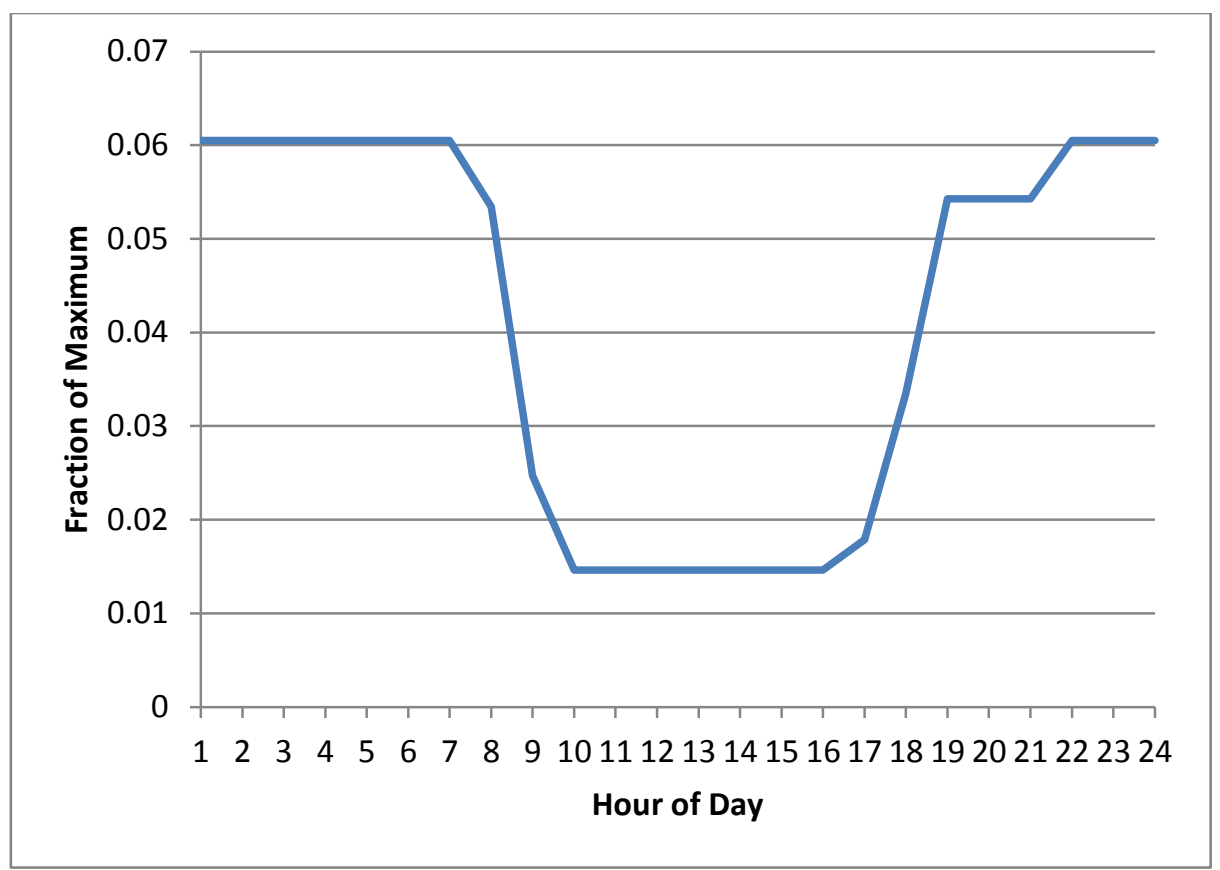

Figure 6.3. Occupancy Schedule

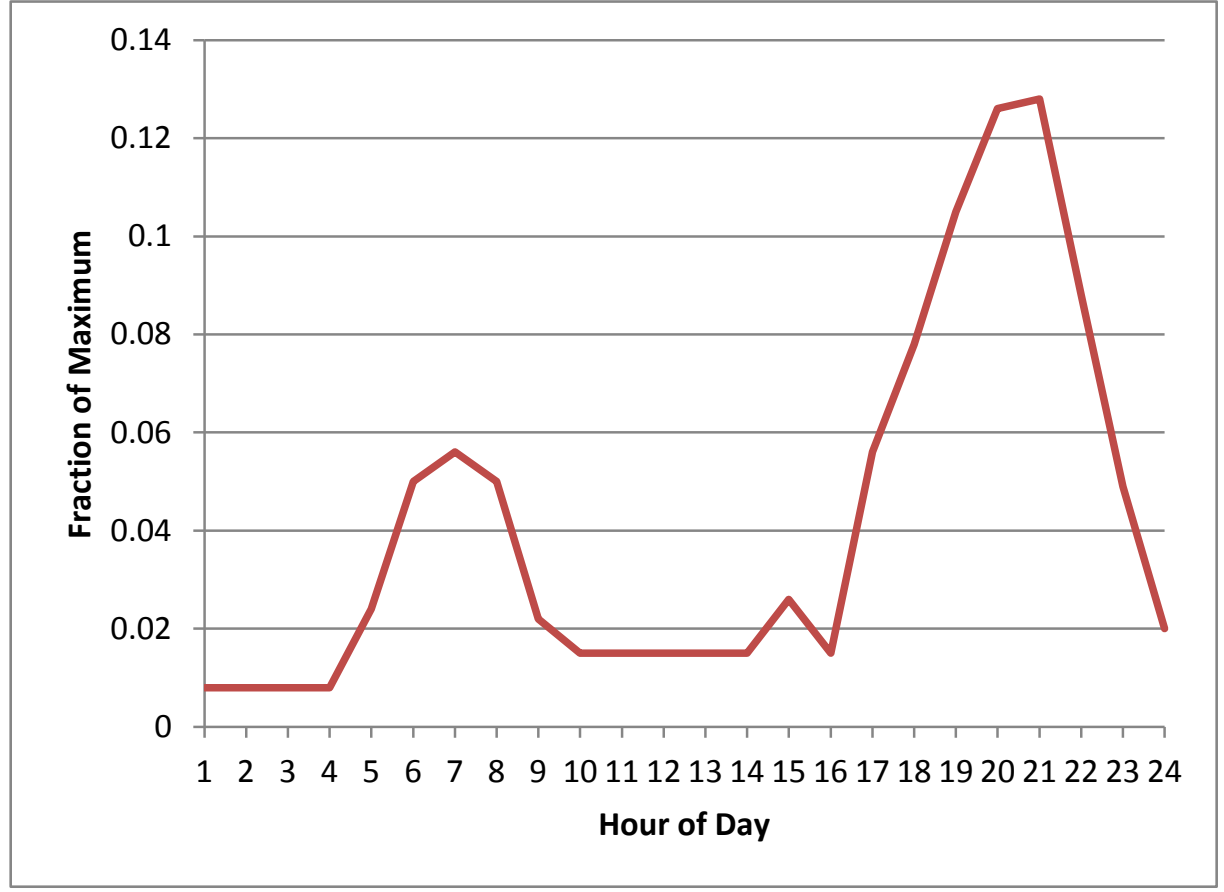

Figure 6.4. Lighting Schedule 


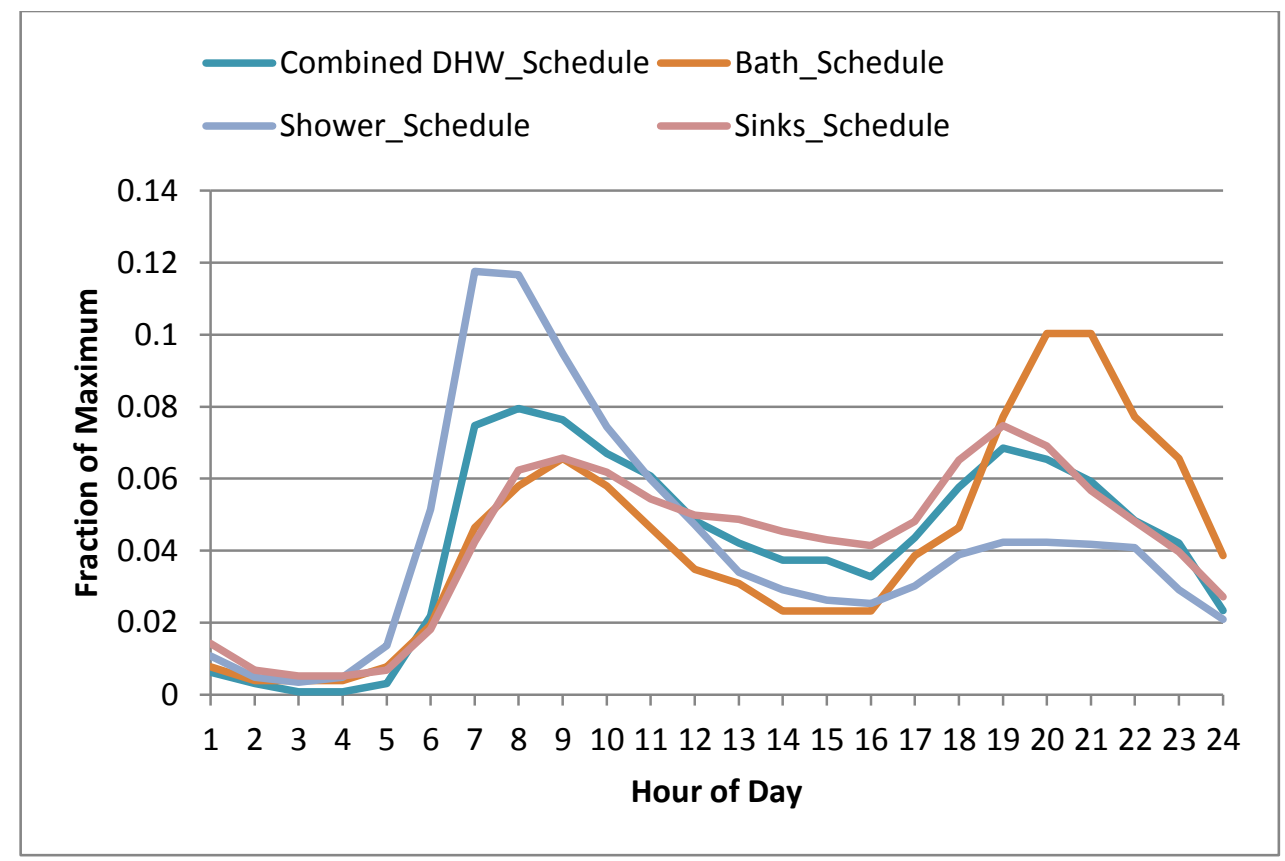

Figure 6.5. Domestic Hot Water Use Schedules

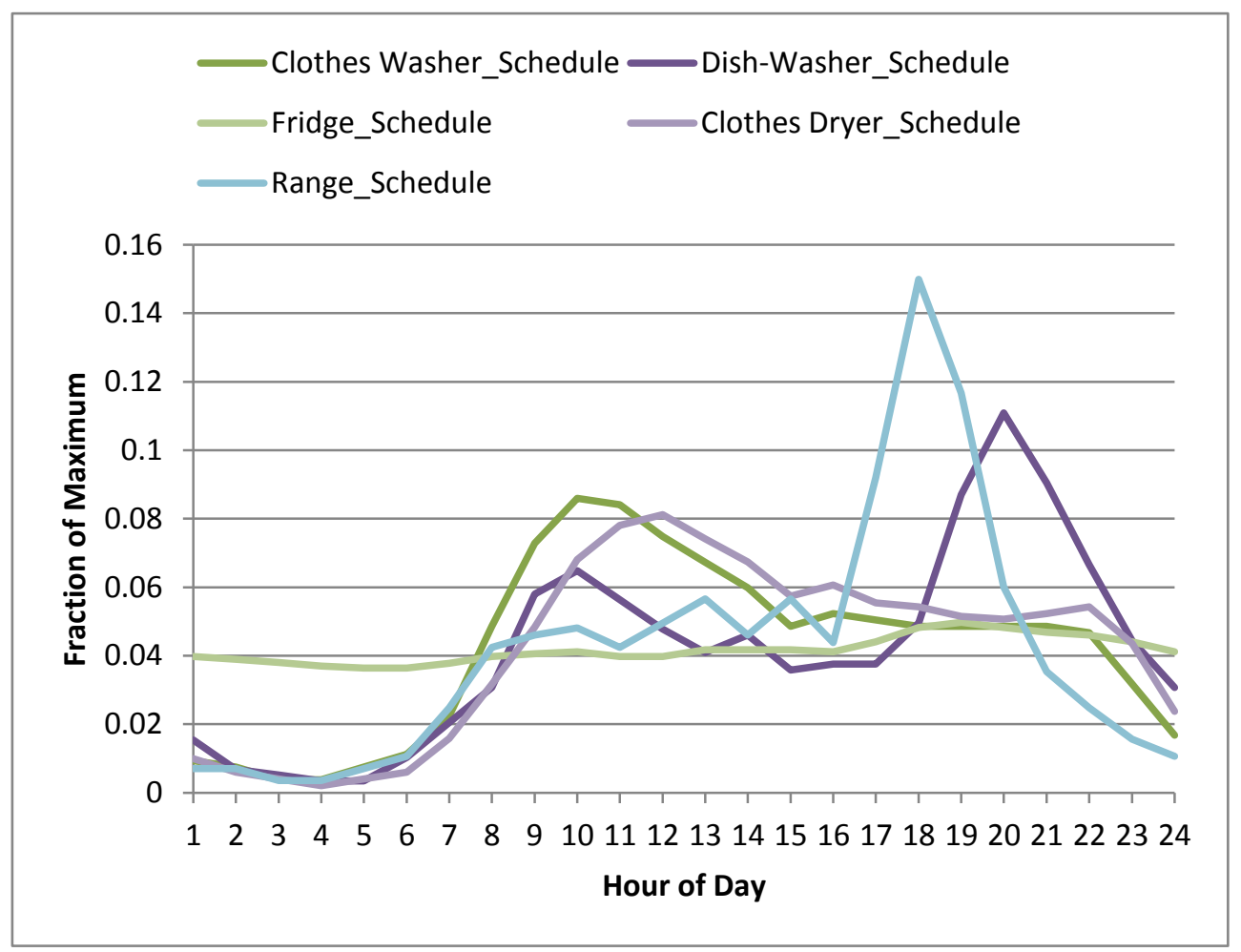

Figure 6.6. Appliance Use Schedules 
Table 6.3. Peak Power Value for Each Internal Gains Component

\begin{tabular}{lccrr}
\hline \multicolumn{1}{c}{ Appliance } & $\begin{array}{c}\text { Sensible } \\
\text { (Btu/day) }\end{array}$ & $\begin{array}{c}\text { Latent } \\
\text { (Btu/day) }\end{array}$ & Total & $\begin{array}{c}\text { Total } \\
\text { (W) }\end{array}$ \\
\hline Clothes Washer & 614 & 0 & 614 & 7.50 \\
Dishwasher & 848 & 212 & 1,060 & 12.94 \\
Combined Domestic Hot Water & 3,113 & 0 & 3,113 & 38.02 \\
Bath & 371 & 0 & 371 & 4.53 \\
Shower & 1,482 & 1,408 & 2,890 & 35.29 \\
Sinks & 619 & 281 & 900 & 10.99 \\
Refrigerator & 6,272 & 0 & 6,272 & 76.59 \\
Clothes Dryer & 1,447 & 482 & 1,930 & 23.56 \\
Range & 3,508 & 2,631 & 6,139 & 74.96 \\
\hline
\end{tabular}

\subsubsection{Envelope Air Leakage}

The Lab Homes were tested for air leakage by a blower door test. These measured values were used directly in energy simulations and are described in Section 7.9 below.

EnergyPlus' "Airflownetwork" was used to model infiltration. The model uses a detailed nodal structure to compute infiltration due to wind and stack effect. The model requires effective leakage area (ELA) to be specified for each surface in the model. It is difficult to pinpoint the exact location and ELA for each surface via a blower door test. Hence, it is assumed that the leakages are spread out on all four walls, the ceiling and the floor proportional to the surface area. This is an oversimplification which may not be an accurate representation of these homes and result in a small error.

The ELA can be derived from the results of the blower door tests. The values used in the model are representative of the measured building leakage after the windows installation. Blower door test results are converted to EnergyPlus inputs using the equations below. Table 6.4 below summarizes the total house ELA for the baseline and the experimental home.

Conversion equations: ${ }^{1}$

$$
\begin{gathered}
C_{e l a}=\frac{c f m 50}{50 * * 0.65} \\
E L A=0.2833 * C_{\text {ela }} *(4 * * 0.65)
\end{gathered}
$$

Table 6.4. ELA Input to EnergyPlus

\begin{tabular}{ccc}
\hline & Baseline Home & Experimental Home \\
\hline C_ela & 55.66 & 51.51 \\
ELA (sq. in) & 38.83 & 35.93 \\
E+ input (sq. m) & 0.0449 & 0.0416 \\
\hline
\end{tabular}

\footnotetext{
${ }^{1}$ EnergyGauge Technical Reference Manual
} 


\subsubsection{Mechanical System}

The HVAC system is modeled as a single speed heat pump with SEER 13 with electric resistance backup heat.

\subsubsection{Weather Data and Simulation Period}

In order to do an annual simulation, EnergyPlus needs weather data in form of an .epw file. NREL developed and maintains weather files for over 1200 locations in the US. ${ }^{1}$ The closest typical meteorological year (TMY) site available is Pasco, Washington (airport) and this was used for energy simulation.

Energy use for the high-performance windows test was recorded from February 2 to April 13, 2012. The 'runperiod' field in EnergyPlus was set to this exact period for comparison. Additional runs were conducted to get the annual energy savings from using the high-performance windows.

1

http://apps1.eere.energy.gov/buildings/energyplus/cfm/weather_data3.cfm/region=4_north_and_central_america_w mo region $4 /$ country $=1$ usa/cname=USA\#WA 



\subsection{Results}

\subsection{Highly Insulating Windows Retrofit Installed Costs}

The costs for purchasing and installing the highly insulating windows for Lab Home B were not provided as a separate cost to PNNL by the GC given these costs were included in the fixed-price bid for the package of work undertaken by the GC. A delivered (to the PNW) cost range for highly insulating slider windows and patio glass doors in small quantities for retrofit was therefore obtained from the vendors in the DOE windows volume purchase program who sell a product line of sliders and patio doors. ${ }^{1}$

These costs ranged from $\$ 21 /$ square foot to $\$ 40$ /square foot for windows and $\$ 23 /$ square foot to $\$ 36 /$ square foot for sliding glass doors. Installation and materials costs were estimated at $\$ 3 /$ square foot based on observed retrofit of the windows by subcontractors at the Lab Homes. Therefore total installed cost for the windows and sliding glass doors in Lab Home B was estimated to range from $\$ 4,300$ to $\$ 7,600$.

\subsection{Data Analysis}

Data were averaged over 15 minute intervals and hourly time steps for data visualization and trends analysis. Data analysis was performed in Microsoft Excel and R statistical software. Error around each variable was calculated as the instrument error specific to each measurement instrument, if available, plus the $95 \%$ confidence interval around the geometric mean (average) value, assuming a normal distribution about the mean. Data were checked for completeness and accuracy prior to use in the analysis. Error analysis was only conducted on relevant data.

\subsection{Lab Homes Thermal Performance}

After the homes were set up on the PNNL campus and prior to the installation of the metering equipment and sensors, a home energy assessment was conducted on both homes to verify similar construction as built and sited. The results of these tests are given below.

\subsubsection{Infrared Testing}

Thermal imaging with an IR camera showed very similar thermal characteristics of the floor, ceiling, and exterior walls in both homes. However, the images can only be compared qualitatively due to differences in the interior temperature of each home. The baseline home average interior temperature was between 74.1 and $74.8^{\circ} \mathrm{F}$, while the experimental home's average interior temperature ranged between 71.6 and $71.8^{\circ} \mathrm{F}$. The exterior scans on the experimental home were taken from 7:09 p.m. to 7:18 p.m. while those on the baseline home were taken between 7:50 p.m. and 7:58 p.m. The night sky was clear, and the outside temperature was $22^{\circ} \mathrm{F}$ during the scans. The time difference allowed the baseline home's

\footnotetext{
${ }^{1}$ The window vendors selected for estimating costs from the qualified vendors in the windows volume purchase program were vendors who offered horizontal sliders and patio doors and who sold products in the PNW. An average cost/square foot across the multiple sizes of windows in Lab Home B was determined.
} 
outer surfaces to cool longer than the outside of the experimental home. Figure 7.1 shows two images of the baseline and experimental homes from the outside. Each image has a box drawn on it with the maximum, average and minimum temperature in the box; however conclusions should not be drawn from the temperature differentials presented in the images, as explained above. In Figure 7.1, the increased thermal conductivity of the studs is evident, shown as brighter vertical lines on the wall. Heat also appears to be escaping from the top of the wall at the joint where the wall meets the ceiling.
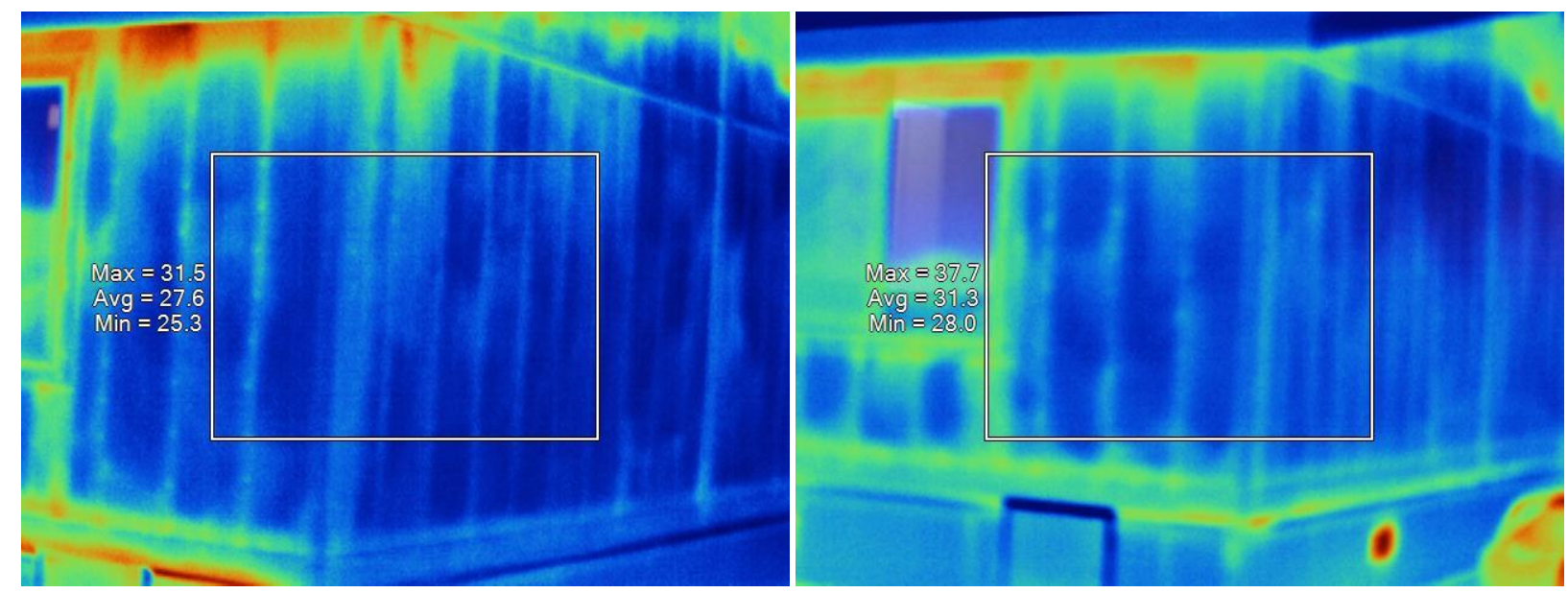

Figure 7.1. Baseline (left) and Experimental (right) Homes Exterior Side/Endwall Corner Thermal Images

Other thermal images indicate infiltration at electrical outlets and building joints, and inconsistency in wall insulation. The exterior scans indicate increased heat transfer at the joints between the ceiling and floor as well as above the windows where a solid structural heater exists (see Figure 7.1). Also the temperature of the wall surface on each home varies as if there are inconsistencies in the insulation. This insulation inconsistency is particularly evident in the east- and west-facing end walls, as shown in Figure 7.2. In this image, insulation appears to not be in contact with this interior wall in the master bedroom near the foot of the wall, as indicated by the greater than $10^{\circ} \mathrm{F}$ temperature differential. This insulation inconsistency is probably caused by movement and slumping of the R-11 batt insulation, which does not completely fill the 2 x 6 stud cavity and may not be well-attached. Much of this movement may have occurred during transportation of the homes from the factory to the site. 


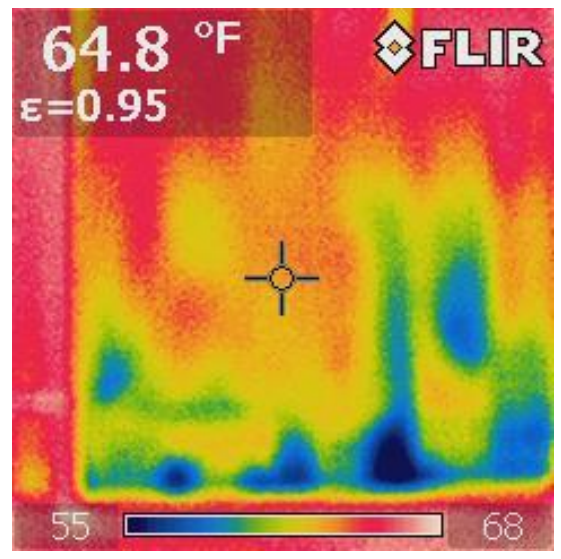

Figure 7.2. Thermal Image of Experimental Home East End Wall from the Master Bedroom. This image was taken with a FLIR b60 IR camera; image resolution is that of the instrument.

The scans focused mainly on the walls and joints. Where the ceiling and floors were included in scans they appear to be much more consistent in temperature across the assembly than the walls.

\subsubsection{Pre-Windows-Retrofit Building Shell Air Leakage}

Blower door tests were taken after siting of the homes to document air leakage of the homes as procured from the manufacturer and after installation of the metering equipment but prior to the retrofit of the windows to verify all penetrations were adequately sealed in both homes and that they had nearidentical air leakage. It is important that both homes have similar air leakage, since the amount of air leakage will impact HVAC energy use in each home. Differences in air leakage will thus confound determination of energy savings due to the highly insulating windows in Lab Home B.

As received, the two homes exhibited very similar building envelope leakage: both homes had measured natural air change per hour $\left(\mathrm{ACH}_{\mathrm{n}}\right)$ of 0.15 , as shown in Table 7.1.

Table 7.1. Building Envelope Air Leakage of Baseline and Experimental Home As-Received and Sited (prior to metering installation)

\begin{tabular}{lcc}
\hline & Baseline Home & Experimental Home \\
\cline { 2 - 3 } \multicolumn{1}{c}{ Parameter } & Average Value & Average Value \\
\hline CFM25 $^{(\text {a) }}$ & 429.3 & 436.4 \\
CFM50 $^{(b)}$ & 653.4 & 683.3 \\
ACH50 $^{\text {b) }}$ & 3.14 & 3.29 \\
ACHn & 0.15 & 0.15 \\
\hline
\end{tabular}

(a) cubic feet per minute at 25 Pascals depressurization

(b) air changes per hour at 50 Pascals depressurization

Following installation of metering equipment, the homes were retested for similar air leakage, because the installation of metering equipment required minor penetrations of the building envelope, which could increase leakage. After slight additional air sealing was performed, the blower door results showed the air leakage of the two homes is statistically the same, with $95 \%$ confidence. The homes are 
both fairly tight, which is typical of the manufactured housing industry in the PNW. The baseline home has leakage of $0.15 \pm 0.01 \mathrm{ACH}_{\mathrm{n}}$ and the experimental home has leakage of $0.16 \pm 0.01 \mathrm{ACH}_{\mathrm{n}}$. Detailed air leakage test results are given in Table 7.2.

Table 7.2. Building Envelope Leakage as Measured by Blower Door Tests in the Baseline and Experimental Home with Metering Equipment Installed.

\begin{tabular}{lcccc}
\hline & \multicolumn{2}{c}{ Baseline Lab Home A } & \multicolumn{2}{c}{ Experimental Lab Home B } \\
\cline { 2 - 5 } Parameter & Average Value & \pm Error & Average Value & \pm Error \\
\hline CFM25 & 491.6 & 30.4 & 492.8 & 30.5 \\
CFM50 & 657.6 & 27.8 & 701.4 & 26.7 \\
ACH50 & 3.16 & 0.13 & 3.38 & 0.13 \\
$\mathrm{ACH}_{\mathrm{n}}{ }^{(a)}$ & 0.15 & 0.01 & 0.16 & 0.01 \\
\hline
\end{tabular}

(a) $\mathrm{n}=21.5$, based on single-story home in climate zone 3 , minimal shielding

\subsubsection{Duct Leakage and Pressure Mapping}

Duct leakage and distribution performance was characterized in each home to verify similar performance. As shown in Table 7.3, Lab Home A has duct leakage of $203 \pm 6$ CFM at 25 Pascals depressurization with respect to the house (CFM25) and duct leakage to outside ${ }^{1}$ of $70 \pm 2$ CFM at 25 Pascals depressurization with respect to outside (CFM25 to out), while Lab Home B has duct leakage of $197 \pm 6$ CFM25 and duct leakage to outside of $57 \pm$ CFM25 to out. Overall duct leakage was shown to be reasonably similar between the two homes, with Lab Home A slightly leakier than Lab Home B but within measurement error. For duct leakage to outside, Lab Home A is leakier than Lab Home B by approximately 10 CFM25 to outside, which is statistically significant. This may indicate greater leakage from the belly into the crawlspace in Lab Home A. However, much care was taken to maintain the integrity of the belly pan in the manufactured homes in their original condition as extensive duct sealing and penetration of the belly could introduce additional leakage. This additional leakage could increase the difference between the homes, rather than improve it. Also, 10 CFM25 to outside is still a small difference and is not expected to significantly impact the measured energy performance. Thus, the team did not take measures to reduce the duct leakage in Lab Home A to make it statistically the same as Lab Home B. The duct systems were tested in the homes as sited at PNNL and the ducting has not been modified since.

\footnotetext{
${ }^{1}$ Duct leakage to outside quantifies the amount of air leakage from the duct work that exfiltrates to outside the building's air barrier (usually the same as the thermal boundary). Because some of the duct work is located in conditioned space, air that leaks out of the ducts is not "lost," as it is still (unintentionally) heating, cooling, or ventilating a conditioned space. Duct leakage that is outside the conditioned space causes heated or cooled air to be wasted and is more important than duct leakage inside the conditioned space. That is why it is calculated separately.
} 
Table 7.3. Duct Leakage Measurements in Lab Home A and Lab Home B

\begin{tabular}{|c|c|c|c|c|}
\hline \multirow[b]{2}{*}{ Measured Parameter } & \multicolumn{2}{|c|}{ Baseline Lab Home A } & \multicolumn{2}{|c|}{ Experimental Lab Home B } \\
\hline & Value & \pm Error & Value & \pm Error \\
\hline Total Duct Leakage, near $25 \mathrm{~Pa}(\mathrm{CFM})$ & 203 & 6.09 & 197 & 5.91 \\
\hline Total Duct Leakage, near $50 \mathrm{~Pa}(\mathrm{CFM})$ & 311 & 9.33 & 304 & 9.12 \\
\hline Duct Leakage to Outside, near $25 \mathrm{~Pa}$ (CFM) & 70 & 2.1 & 57 & 1.71 \\
\hline Duct Leakage to Outside, near $50 \mathrm{~Pa}$ (CFM) & 104 & 3.12 & 83 & 2.49 \\
\hline
\end{tabular}

The distribution system in each home also showed reasonably similar performance, with higher flow rates for supply registers near the air handler and lower flow rates farther away, as shown in Table 7.4. These results indicated that all ducts are connected and there are no large problems with the duct work. Error is not calculated for these static pressure and fan flows and their relative magnitude of concern and precise values are not necessary.

Table 7.4. Duct Distribution System Performance, Static Pressure and Flows in Baseline Lab Home A and Experimental Lab Home B.

\begin{tabular}{lcccc}
\hline & \multicolumn{2}{c}{ Baseline Lab Home A } & \multicolumn{2}{c}{ Experimental Lab Home B } \\
\cline { 2 - 5 } \multicolumn{1}{c}{ Location } & $\begin{array}{c}\text { Static Pressure } \\
\text { (Pa) }\end{array}$ & $\begin{array}{c}\text { Flow } \\
(\text { CFM })\end{array}$ & $\begin{array}{c}\text { Static Pressure } \\
\text { (Pa) }\end{array}$ & $\begin{array}{c}\text { Flow } \\
(\text { CFM })\end{array}$ \\
\hline Living Room (northwest corner) & 5.2 & 60 & 2.7 & 54 \\
North Entryway & 25.2 & 124 & 25.7 & 120 \\
Bedroom 1 & 25.9 & 124 & 28.0 & 138 \\
Bedroom 2 & 25.7 & 124 & 28.8 & 129 \\
Master Bath (northeast corner) & 26.1 & 103 & 28.2 & 116 \\
Master Bedroom (southeast corner) & 4.0 & 73 & 3.7 & 100 \\
Hall Bath & 50.9 & 176 & 61.0 & 172 \\
Utility Room & 2.2 & 62 & 5.1 & 65 \\
Kitchen & 14.8 & 92 & 10.7 & 85 \\
Dining Room (southwest corner) & 3.0 & 90 & 1.8 & 69 \\
Total Flow, sum of register flows & - & 1028 & - & 1048 \\
Average Static Pressure and Register Flow & 18.3 & 103 & 19.6 & 105 \\
\hline
\end{tabular}

\subsubsection{Ventilation Fan Flow Rate}

Flow rates of the whole-house ventilation fan and two bathroom exhaust fans showed very similar flow rates, which were lower than their rated value as shown in Table 7.5. The bathroom fans were rated as $50 \mathrm{CFM}$ and the whole-house fan was rated as $90 \mathrm{CFM}$. These values were taken from the manufactured home manufacturer literature (Burdette/Boylan, 2011). 
Table 7.5. Flow Rate of Bath and Whole-House Ventilation Exhaust Fans Measured in the Baseline and Experimental Homes

\begin{tabular}{lcc}
\hline \multicolumn{1}{c}{ Ventilation Fan } & $\begin{array}{c}\text { Baseline Lab Home A } \\
\text { (CFM) }\end{array}$ & $\begin{array}{c}\text { Experimental Lab Home B } \\
\text { (CFM) }\end{array}$ \\
\hline Hall Bath Fan, Broan 655 & 38 & 41 \\
Whole-House Fan, Active Ventilation EC-25 & 49 & 50 \\
Master Bath Fan, Broan 655 & 35 & 39 \\
\hline
\end{tabular}

\subsection{Heat Pump and Air Handler Performance}

The performance of both homes' heat pumps was verified by measuring the temperature differential across the coil in both homes when heating was called for. The measured temperature differential using a hand-held thermometer was very similar for both homes, which suggests similar performance of the units. Error is not provided on these readings as the accuracy of the thermometer is not known.

Table 7.6. Heat Pump Temperature Differential Across Coil

\begin{tabular}{lcccc}
\hline & \multicolumn{2}{c}{ Baseline Lab Home A } & \multicolumn{2}{c}{ Experimental Lab Home B } \\
\cline { 2 - 5 } \multicolumn{1}{c}{ Measurement } & $\begin{array}{c}\text { Return Air Temp. } \\
\left({ }^{\circ} \mathrm{F}\right)\end{array}$ & $\begin{array}{c}\text { Supply Air Temp } \\
\left({ }^{\circ} \mathrm{F}\right)\end{array}$ & $\begin{array}{c}\text { Return Air Temp. } \\
\left({ }^{\circ} \mathrm{F}\right)\end{array}$ & $\begin{array}{c}\text { Supply Air Temp. } \\
\left({ }^{\circ} \mathrm{F}\right)\end{array}$ \\
\hline $\begin{array}{l}\text { Air Temperature in Home and } \\
\text { Downstream from Coil }\end{array}$ & 74.45 & 96.35 & 71.7 & 94.3 \\
$\begin{array}{l}\text { Temperature Rise across Indoor Coil } \\
\text { in Heating Mode }\left({ }^{\circ} \mathrm{F}\right)\end{array}$ & 21.9 & & 22.6 & \\
\hline
\end{tabular}

Air flow across the coil was also measured to assess adequate and similar fan performance. As shown in Table 7.7, the measured flow rate through the air handler is statistically similar for Lab Home A and Lab Home B.

Table 7.7. Air Handler Flow and Static Operating Pressure

\begin{tabular}{lcc}
\hline \multicolumn{1}{c}{ Measurement } & $\begin{array}{c}\text { Baseline Home } \\
\text { Lab Home A }\end{array}$ & $\begin{array}{c}\text { Experimental } \\
\text { Lab Home B }\end{array}$ \\
\hline Air Handler Flow Measurement, TrueFlow Plate (CFM) & $927 \pm 65$ & $875 \pm 61$ \\
Normal System Operating Pressure (Pa) & 27.2 & 27.0 \\
\hline
\end{tabular}

\subsection{Pre-Windows-Retrofit Null Testing}

After instrumentation and the baseline assessments were completed in both Lab Homes, null testing was performed to compare energy use information over several days. Null testing with no occupancy or moisture generation showed exceptionally similar energy use between the two homes, within $0.5 \% \pm$ $0.5 \%$ over the six day period. Figure 7.3 shows a comparison of energy use between the experimental home (Lab Home A) and the baseline home (Lab Home B), for one day of the null test. The black 45 degree line indicates perfect agreement. This chart is indicative of the agreement observed on the other days of null testing. 


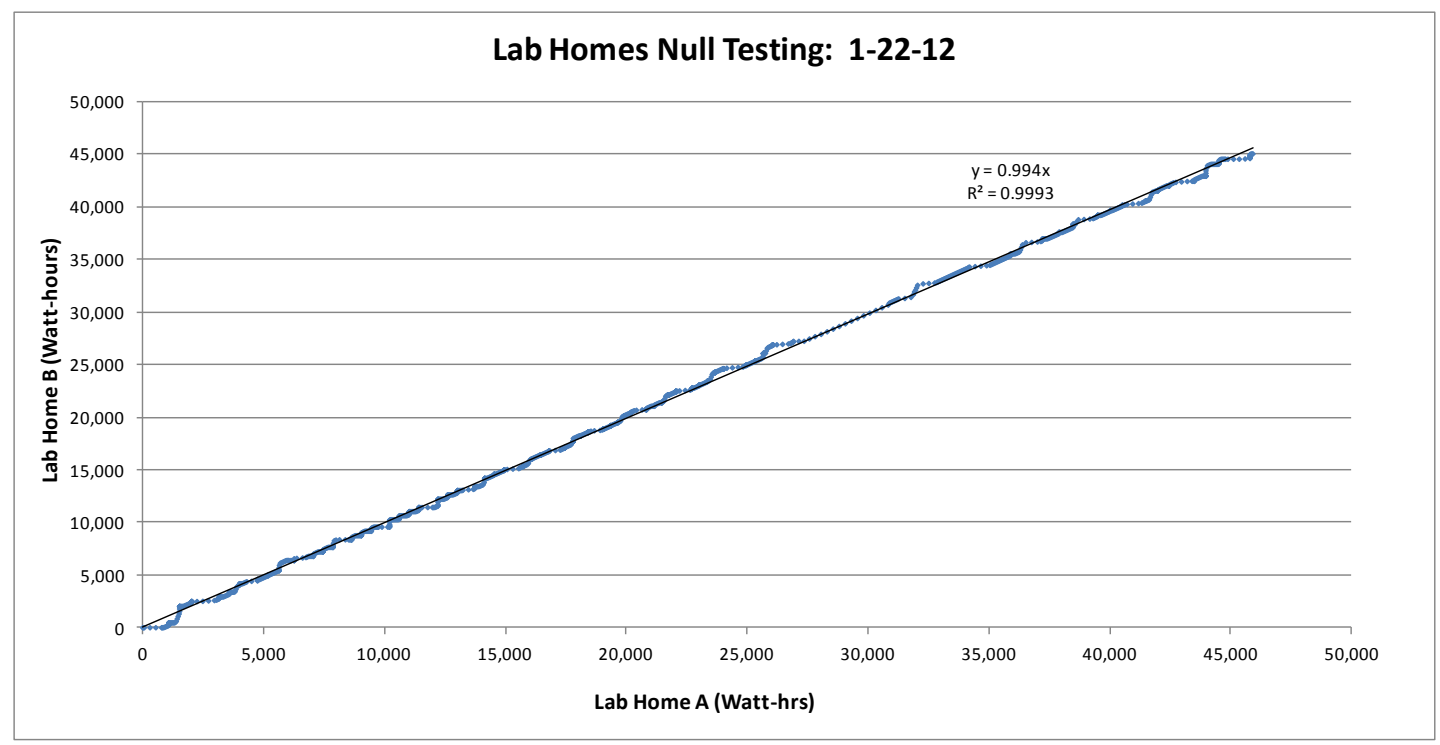

Figure 7.3. Comparison of Cumulative HVAC Energy Use of Lab Home A (Baseline Home; x-axis) versus Lab Home B (Experimental Home; y-axis).

\subsection{Post-Windows-Retrofit Building Shell Air Leakage}

Building shell air leakage was measured after the windows retrofit in the two homes to characterize the impact of the two installation techniques. Table 7.8 shows the null-test building leakage values, the building leakage after windows installation, and the difference achieved by the different installation practices. In the experimental home, air leakage, as characterized by the CFM50 depressurization with respect to the outside value, decreased by $46.4 \pm 34.9$ CFM50. Conversely, air leakage in the baseline home increased $50.3 \pm 34.1 \mathrm{CFM} 50$. While the error is large in comparison to the magnitude of the change, the overall impact of these changes was statistically significant. Improved installation technique of the highly insulating windows in Lab Home B comparison to the typical installation of the baseline windows in Lab Home A caused the experimental home to be measurably tighter, if only slightly so, than the baseline home. 
Table 7.8. Building Shell Leakage in the Baseline and Experimental Homes after Window Retrofits

\begin{tabular}{lcccc}
\hline & Baseline Home & \pm Error & Experimental Home & \pm Error \\
\hline Null Data & & & & \\
CFM25 & 491.6 & 30.4 & 492.8 & 30.5 \\
CFM50 & 657.6 & 27.8 & 701.4 & 26.7 \\
ACH50 & 3.16 & 0.13 & 3.38 & 0.13 \\
ACHn & 0.15 & 0.01 & 0.16 & 0.01 \\
Post-Windows Install & & & \\
CFM25 & 457.9 & 19.0 & 381.9 & 15.7 \\
CFM50 & 707.8 & 24.6 & 655.0 & 22.5 \\
ACH50 & 3.41 & 0.12 & 3.15 & 0.11 \\
ACHn & 0.16 & 0.01 & 0.15 & 0.01 \\
Difference & & & & \\
CFM25 & -33.7 & 35.9 & -110.9 & 34.3 \\
CFM50 & 50.3 & 37.1 & -46.4 & 0.17 \\
ACH50 & 0.24 & 0.18 & -0.22 & 0.01 \\
ACHn & 0.01 & 0.01 & -0.01 & \\
\hline
\end{tabular}

\subsection{Post-Windows Retrofit HVAC and Whole House Thermal Performance}

Following retrofit to the highly insulating and baseline windows, the experiment began in earnest. Data was collected from February 3, 2012 to April 13, 2012 to describe the energy and thermal performance of the windows over a range of temperature and operational scenarios. To assess the performance of the highly insulating windows as compared to the baseline windows, energy use as well as interior temperatures were compared daily. Comparison shows significant whole-house energy savings and comfort improvement in the Lab Home with the highly insulating windows (Lab Home B). Removing days for which data was incomplete or erroneous, the overall whole-house savings are $11.6 \% \pm 1.53 \%$ over the study period.

During the study period, the Lab Homes were operated in a number of configurations including with and without occupancy simulation, in heat pump (HP) and electric resistance (ER) heating modes, and at two different interior thermostat set points. Comparing the periods without occupancy simulation to comparable periods after occupancy simulation was introduced, the savings decrease approximately $2.5 \%$ when occupancy is introduced, as shown in Table 7.9. This decrease is logical, as you would expect increased energy use of equivalent magnitudes from the identical occupancy simulations in both homes and the resulting decrease in energy savings. However, this difference is not statistically significant due to the variation in savings based on other factors. 
Table 7.9. Average Energy Savings (\%) and 95\% Confidence Interval (\%) from Highly Insulating Windows in Different Operating Scenarios: With and without Occupancy Simulation and in HP versus ER Heating Modes.

\begin{tabular}{lcc}
\hline \multicolumn{1}{c}{ Operating Scenario } & $\begin{array}{c}\text { Average } \\
\text { Savings } \\
(\%)\end{array}$ & $\begin{array}{c}\text { 95\% Confidence } \\
\text { Interval } \\
(\%)\end{array}$ \\
\hline Without Occupancy Simulation & 14.3 & 5.23 \\
With Occupancy Simulation & 11.7 & 2.08 \\
Heat Pump Mode (with occupancy simulation) & 10.4 & 2.96 \\
Electric Resistance Mode (with occupancy simulation) & 11.7 & 2.08 \\
\hline
\end{tabular}

When comparing savings from periods when the HP was providing heating versus ER, no statistically significant difference was observed. In HP mode, the ER elements were still enabled and cycled to provide heating during extremely cold periods.

Changing the thermostat set point was performed to maintain a sufficient temperature differential between indoors and outdoors to drive heating system use. Changing the thermostat set point was also successful at maintaining a fairly uniform average temperature differential between indoors and outdoors on a daily basis. The average difference between the indoor and outdoor temperatures was $69.9^{\circ} \mathrm{F}$, with the maximum and minimum temperature differentials being $75.7^{\circ} \mathrm{F}$ and $63.3^{\circ} \mathrm{F}$, respectively.

Savings were also analyzed with respect to daily weather variation, including outdoor air temperature and degree of cloud cover. The magnitude of whole-house energy savings showed significant dependence on weather patterns.

Energy use of baseline and experimental both show a linear dependence to outdoor air temperature, as shown in Figure 7.4. In this Figure Lab Home A (blue diamonds) exhibits slightly greater average energy use (higher points) than Lab Home B (red squares).

A linear regression through the series yields a slope, which is representative of the homes' energy use in $\mathrm{kWh}$ with respect to the outdoor air temperature in ${ }^{\circ} \mathrm{F}$. Comparing the slopes of these two regressions is another way to analyze savings in the experimental home versus the baseline home. This comparison provides a temperature-independent statement of energy savings potential in the heating season. Comparing the slopes of these two least-squares linear regressions shows the highly insulating windows yield $12.9 \%$ energy savings in the experimental home versus the baseline home. This result is similar to, but slightly greater than, calculated average savings over the study period of $11.6 \%$. This suggests that another factor may be limiting savings to what would be achieved based on outdoor air temperature alone. 


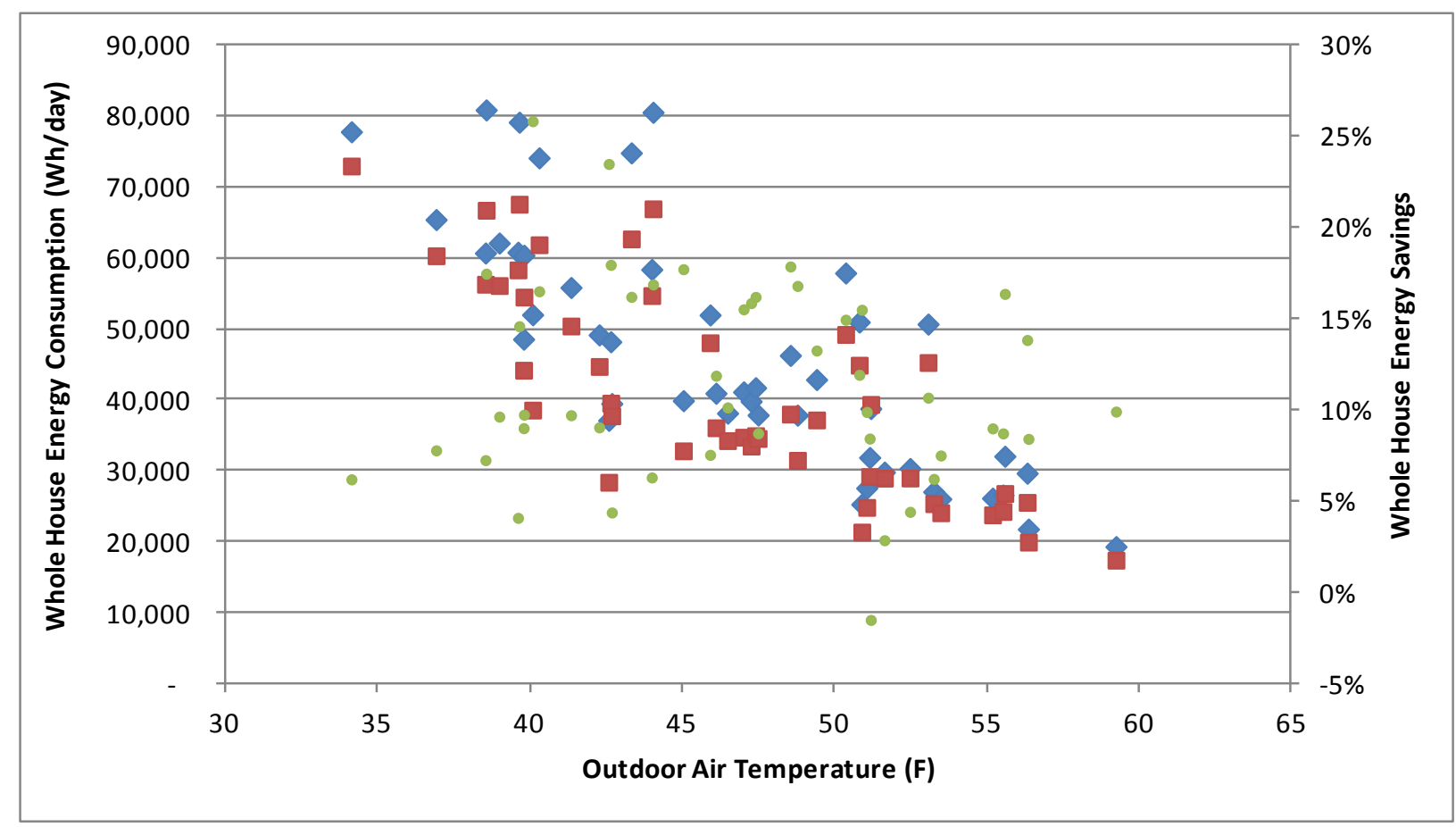

Figure 7.4. Whole-House Energy Use (Wh/day; left axis) and Whole-House Energy Savings (\%; right axis) versus Outdoor Air Temperature $\left({ }^{\circ} \mathrm{F}\right)$

However, the savings do not show the temperature dependence that the energy use does. This finding corroborated the hypothesis that actual measured savings is dependent on other variables in addition to outdoor temperature, for example solar insolation, which confounds the relationship between savings and outdoor air temperature.

Another key variable in understanding the variability and extent of savings is the degree of cloud cover. Over the study period, most days were either overcast or clear. These classifications are based on data recorded visually and verified by weatherunderground.com historical information. Figure 7.5 shows the savings achieved on each day grouped with respect to these two weather extremes. Days that were difficult to categorize into one of these definitions (i.e. widespread dust) were left out of the analysis, but are included on Figure 7.5 as separate data series. There is no relevance to the horizontal ordering of data. When depicted this way, once can see that the majority of high saving days are overcast days (green triangles), while the majority of low saving days are clear (blue diamonds). The average savings achieved on overcast days is $14.6 \% \pm 1.86 \%$ while the average savings on clear days is $8.9 \% \pm 1.42 \%$. The average savings and error are indicated on the figure by solid and dashed lines, respectively.

The decrease in savings on clear days is due to solar heat gain, which offset some heating system energy use. Since the baseline windows are not low-e coated and have a much higher SHGC, the baseline home is able to take advantage of the incident solar heat and offset more of the heating system energy use on sunny days. This effect is clearly seen in Figure 7.6, which shows a representative time series of whole-house energy use for the experimental home and the baseline home on a clear, sunny day. Data from February 12, 2012, are shown, with the Lab Homes in HP mode with a $75^{\circ} \mathrm{F}$ set point and no occupancy. The outside average temperature on this day was $39^{\circ} \mathrm{F}$. This graph is illustrative and conclusions shown in this graph are applicable to other similar sunny days. 


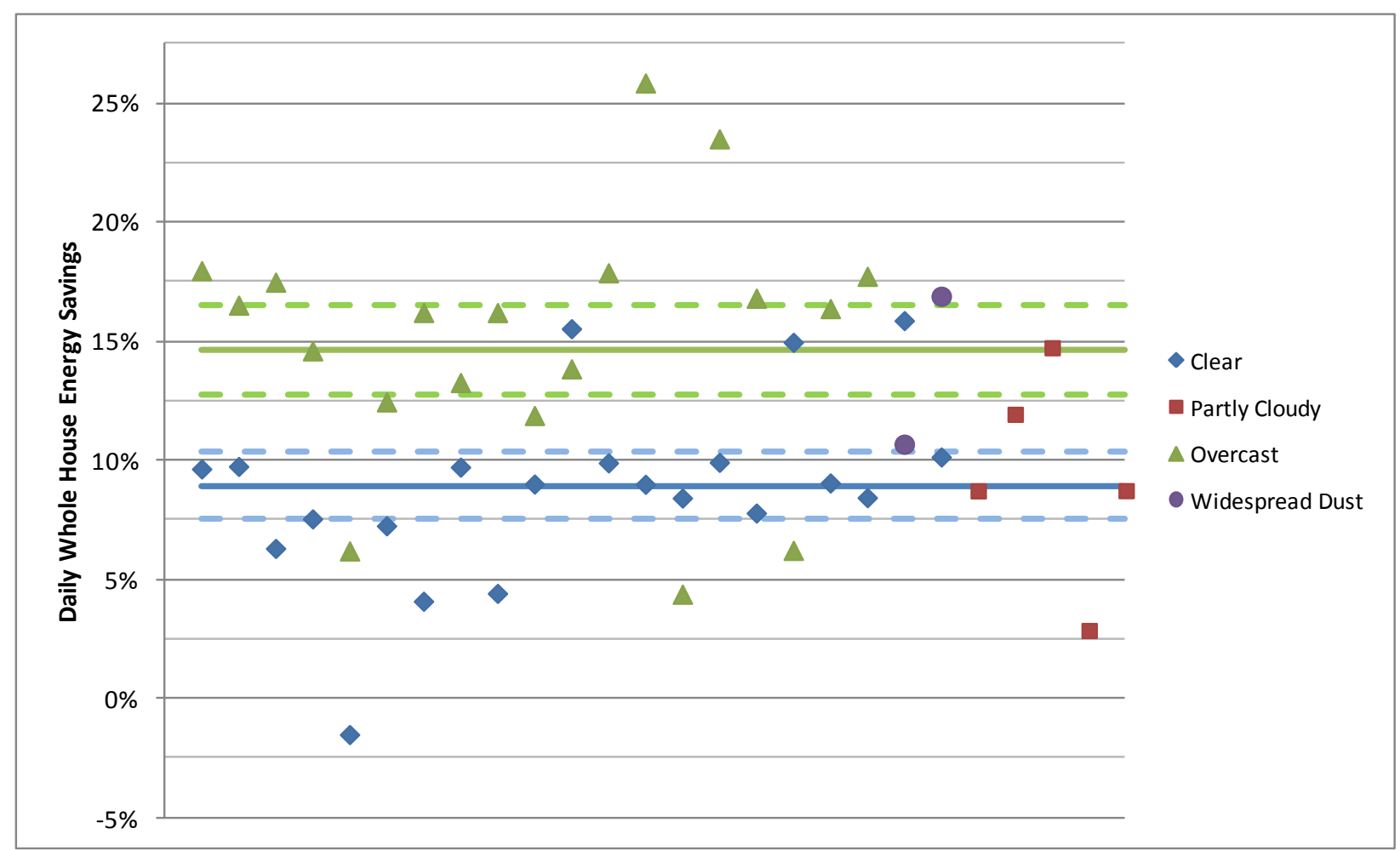

Figure 7.5. Daily Whole-House Energy Savings Due to Highly Insulating Windows for Overcast (green triangles), Clear (blue diamonds), Partly Cloudy (red squares), and Dusty (purple circles) Conditions. Blue and green solid lines indicate average savings, with $95 \%$ confidence interval indicated by the dashed lines.

The significant decrease in energy use in the middle of the day is due to solar heating and is experienced in both homes. However, the thermal properties and high SHGC (0.7) of the windows in the baseline home (blue line) take full advantage of this effect and the heat pump does not have to cycle on from 9:00 a.m. until 8:00 p.m. The heat pump in the experimental home (red line) is engaged until approximately 10:00 a.m. and is only off until 6:00 p.m. Although the HP in the experimental home cycles less frequently throughout the night, which achieves a significant level of savings, some of this decreased energy use is negated by increased heat pump operation during the day.

However, the impact of solar heat gain on indoor temperatures cannot be discounted. Indoor temperature in the kitchen of each home is also shown on Figure 7.6. As can be seen in the graph, Lab Home B maintains a much more consistent indoor temperature throughout the day due to both the high R-value and low SHGC (0.19) of the windows. In heating-only mode, interior temperatures in the baseline home climb to almost $84^{\circ} \mathrm{F}$. This would clearly cause a comfort problem for any occupants home during this time, even in these cold winter months.

This increased temperature is seen in all areas of the home in the baseline home, while the experimental home maintains a much more consistent temperature profile, as shown in Figure 7.7. 


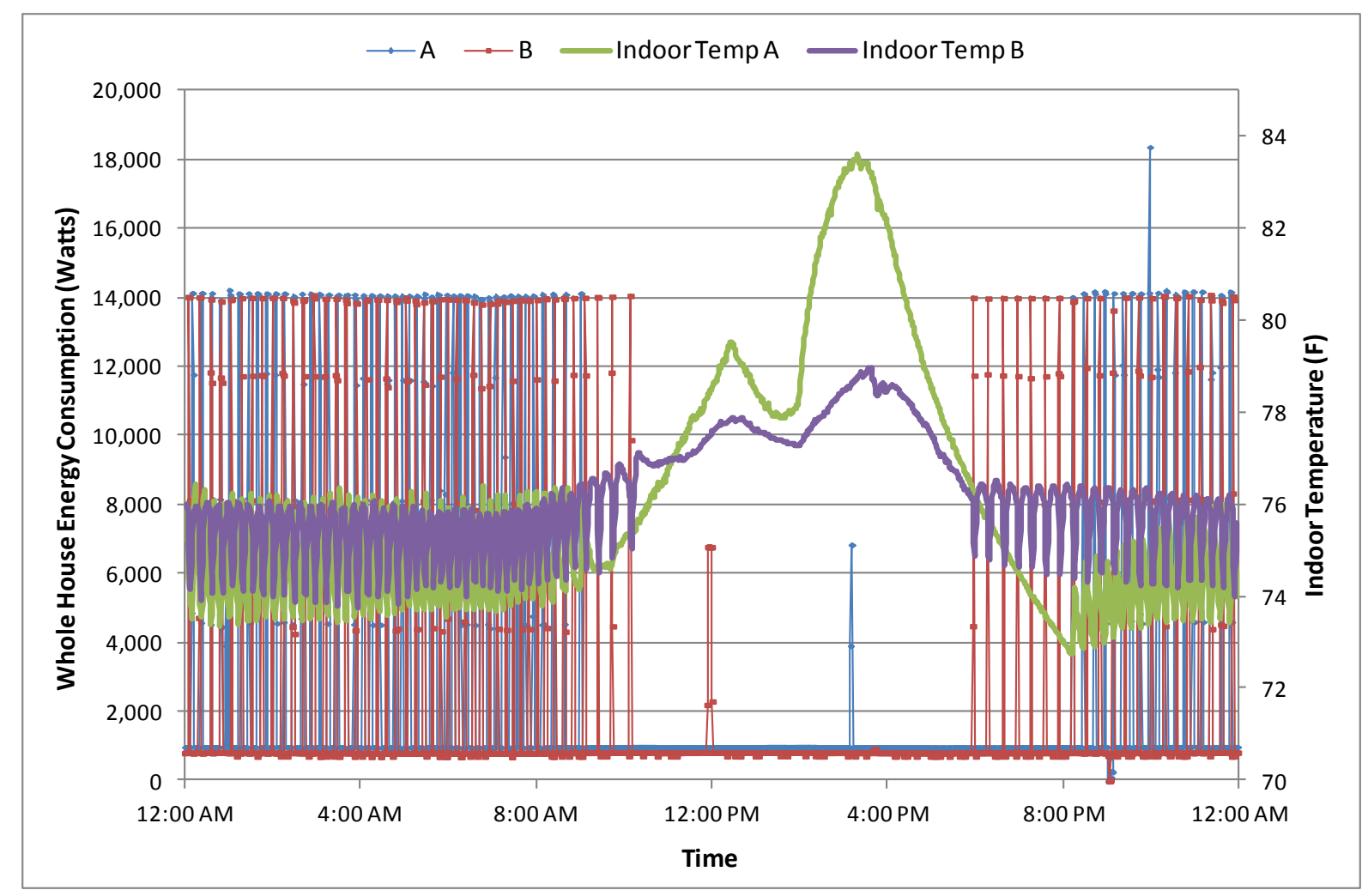

Figure 7.6. Whole-House Energy Use (Watts) and Indoor Temperature $\left({ }^{\circ} \mathrm{F}\right)$ for the Experimental Home (blue and green lines) and the Baseline Home (red and purple lines) on a Sunny Day

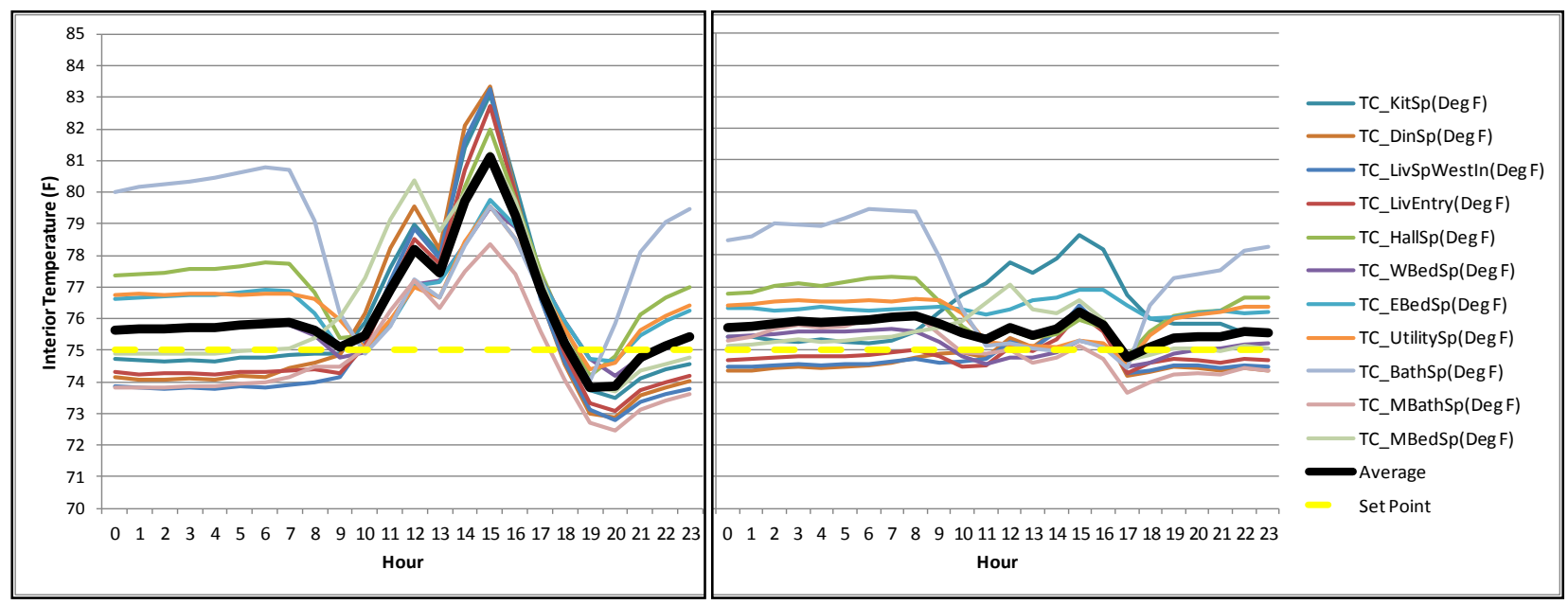

Figure 7.7. Interior Temperature Distribution for Lab Home A (left) and Lab Home B (right) on a Sunny Day

Not obvious from Figure 7.7 is the magnitude of energy use Figure 7.8 compares the cumulative energy use of Lab Home A versus that of Lab Home B on the same day. A whole-house savings of 9.6\% is achieved on this cold, sunny day. (The $45^{\circ}$ red line represents equal energy use by the two homes.) The impact of solar heat gain is evident in Figure 7.8 as well. The first change in slope just before Lab Home A consumes 40,000 Wh corresponds with 8:00 a.m. when the heat pump turns off in Lab Home A, but remains on until 9:00 a.m. in Lab Home B. Thus the line trends back towards the red line of equal energy 
use (losing savings). At 9:00 a.m., the slope of the blue line runs parallel the red line for a period, which corresponds with the middle of the day when the heating system is off in both homes. Just before 50,000 Wh on the X-axis, the slope of the blue line changes again when the heat pump in Lab Home B turns on again and remains off in Lab Home A. Additional savings are "lost" until the heat pump in Lab Home A turns on again and the improved thermal properties of the highly insulating windows in Lab Home B achieve additional savings in the evening via decreased HP energy use.

This hypothesis is confirmed by observing the energy use and thermal performance of the two homes on cloudy days. On cloudy days, whole-house energy savings for Lab Home B compared to Lab Home A of $14.6 \% \pm 1.86 \%$ are observed, due to the reduced impact of solar heating. Similar graphics to those presented above for a sunny day are presented in Figure 7.9 and Figure 7.10 for cloudy days. Data from February 13, 2012, are shown, with the Lab Homes in HP mode with a $75^{\circ} \mathrm{F}$ set point and no occupancy. The outside average temperature on this day was $40^{\circ} \mathrm{F}$. Figure 7.9 is illustrative and conclusions shown in this graph are applicable to other similar cloudy days. Without the impact of solar heat gain, the HP operates fairly consistently throughout the day in both homes, as shown in Figure 7.8. Also, the indoor temperatures are much more uniform, with the experimental home maintaining a slightly higher indoor temperature due to the improved thermal performance of the highly insulating windows.

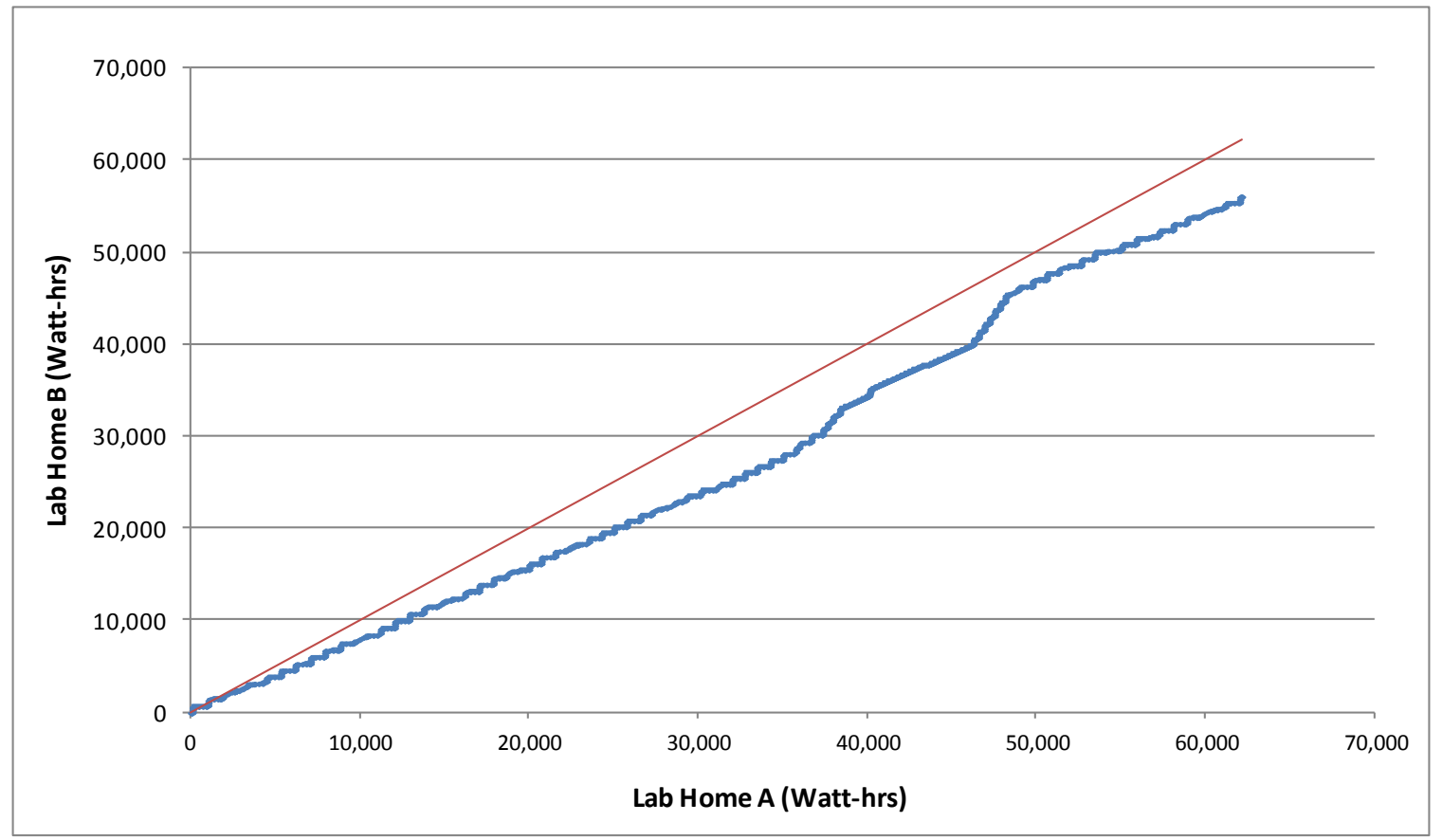

Figure 7.8. Cumulative Energy Use (Watt-hours) of Lab Home B (Experimental Home) versus Lab Home A (Baseline Home) on a Sunny Day. The $45^{\circ}$ red line represents equal energy use of the two homes.

Figure 7.10 shows a much more uniform slope and greater overall level of savings. Also note the overall increased energy use apparent from comparing Figure 7.10 to the previous Figure 7.8 (the other A vs. B chart). On this cloudy day, Lab Home A consumes approximately 74,200 Wh and Lab Home B consumes 61,900 Wh. On the previous sunny day, Lab Home A consumed 62,100 Wh and Lab Home B consumed 56,200 Wh. 


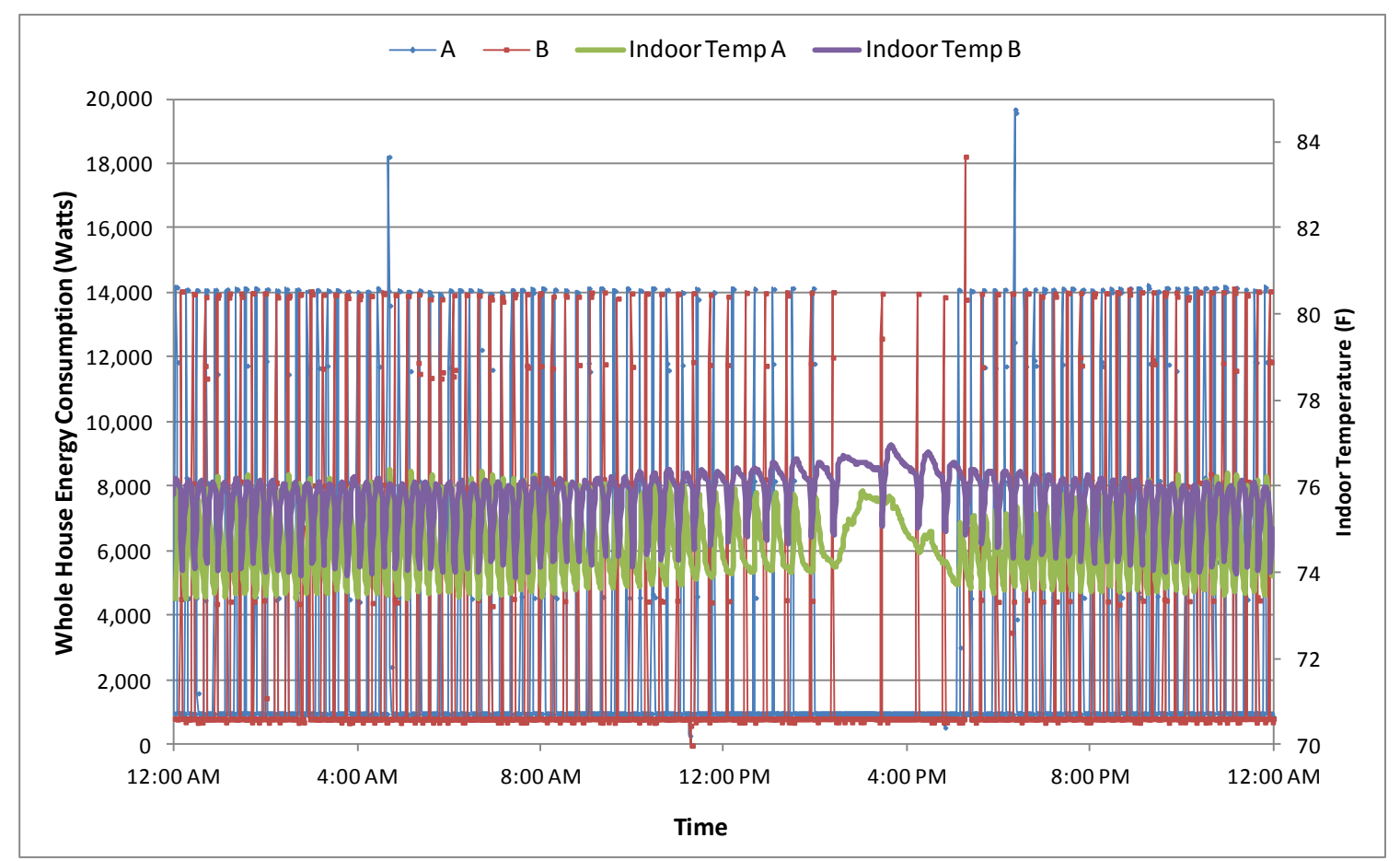

Figure 7.9. Whole-House Energy Use (Watts) and Indoor Temperature $\left({ }^{\circ} \mathrm{F}\right)$ for the Experimental Home (blue and green lines) and the Baseline Home (red and purple lines) on a Cloudy Day

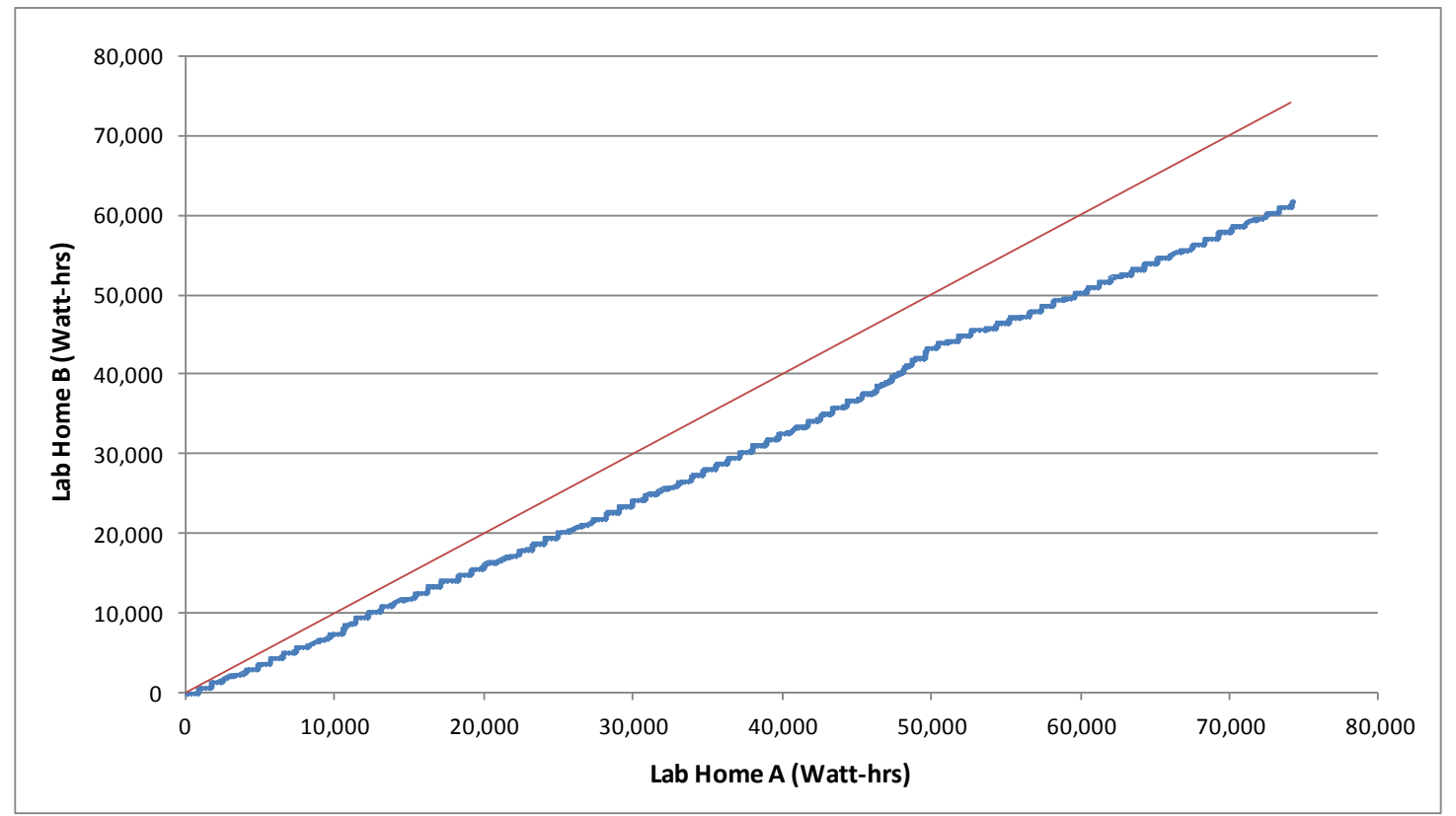

Figure 7.10. Cumulative Energy Use (Watt-hours) of Lab Home B (Experimental Home) versus Lab Home A (Baseline Home) on a Cloudy Day. The $45^{\circ}$ red line represents equal energy use of the two homes. 
This relationship between energy use and solar insolation is further illustrated by Figure 7.11 and Figure 7.12, which graph daily whole-house energy use in watt-hours (Wh) versus solar insolation in watts per square meter $\left(\mathrm{W} / \mathrm{m}^{2}\right)$ for Lab Home A and Lab Home B, respectively. In both homes, increased solar insolation decreased whole-house energy use. However, the difference in solar heat gain can clearly be seen by comparing the $\mathrm{x}$-axes of the two charts. The measured solar insolation through the window is $83.2 \% \pm 1.2 \%$ less through the low-e coated windows in Lab Home B than through the clear glass windows in Lab Home A. ${ }^{1}$

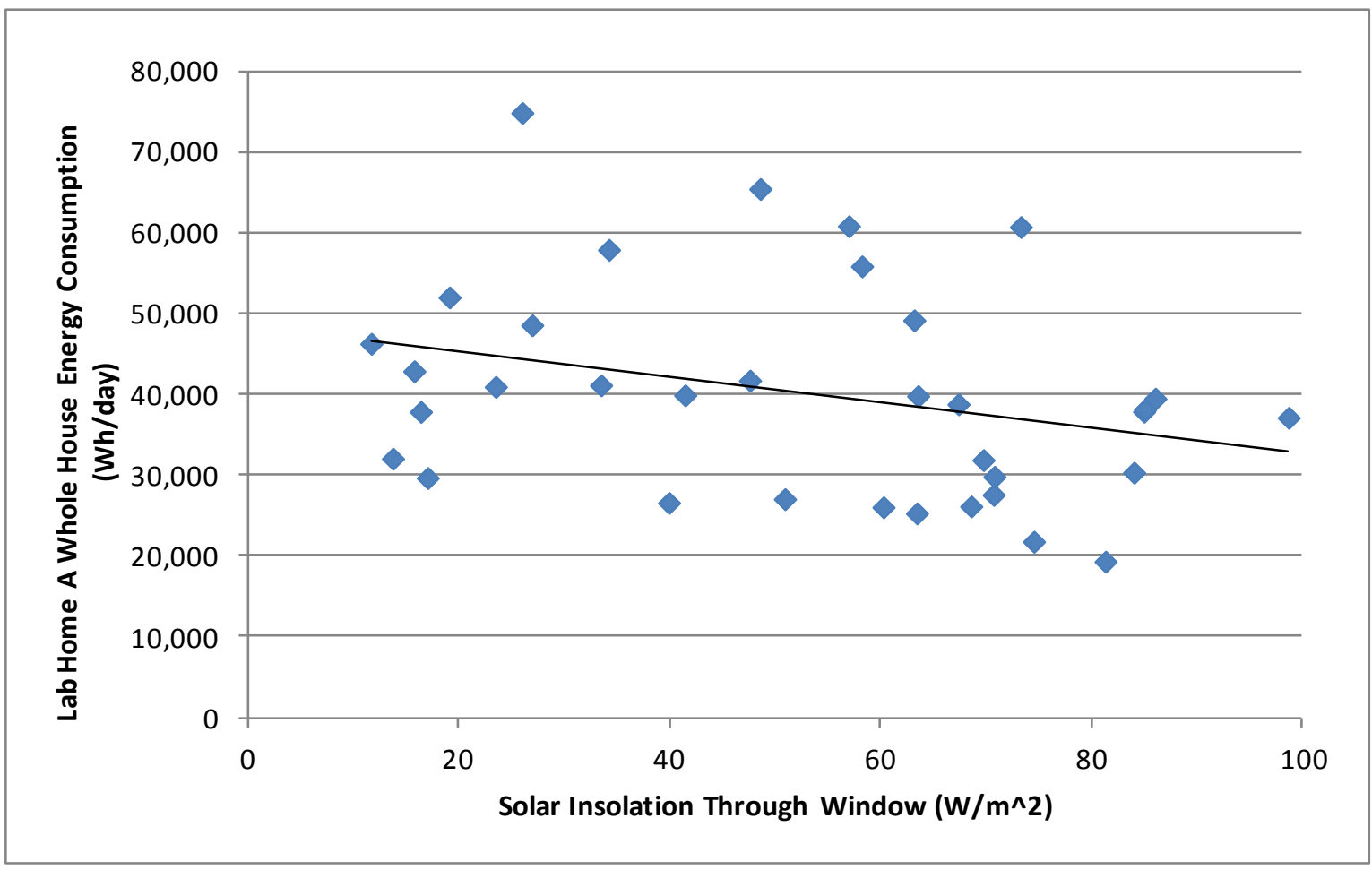

Figure 7.11. Whole-House Energy Use (Wh/day) in Lab Home A versus Solar Insolation $\left(\mathrm{W} / \mathrm{m}^{2}\right)$

\footnotetext{
${ }^{1}$ Note that the solar heat gain measurement reported here is in-situ and does not represent or replicate the measurement of the SHGC measurement that takes place in a highly controlled laboratory environment to certify a window. However, the magnitude of the solar insolation reduction is consistent with the magnitude of the difference in SHGC of the windows in Lab Homes A (SHGC=0.7) compared to the windows in Lab Home B (SHGC=0.19).
} 


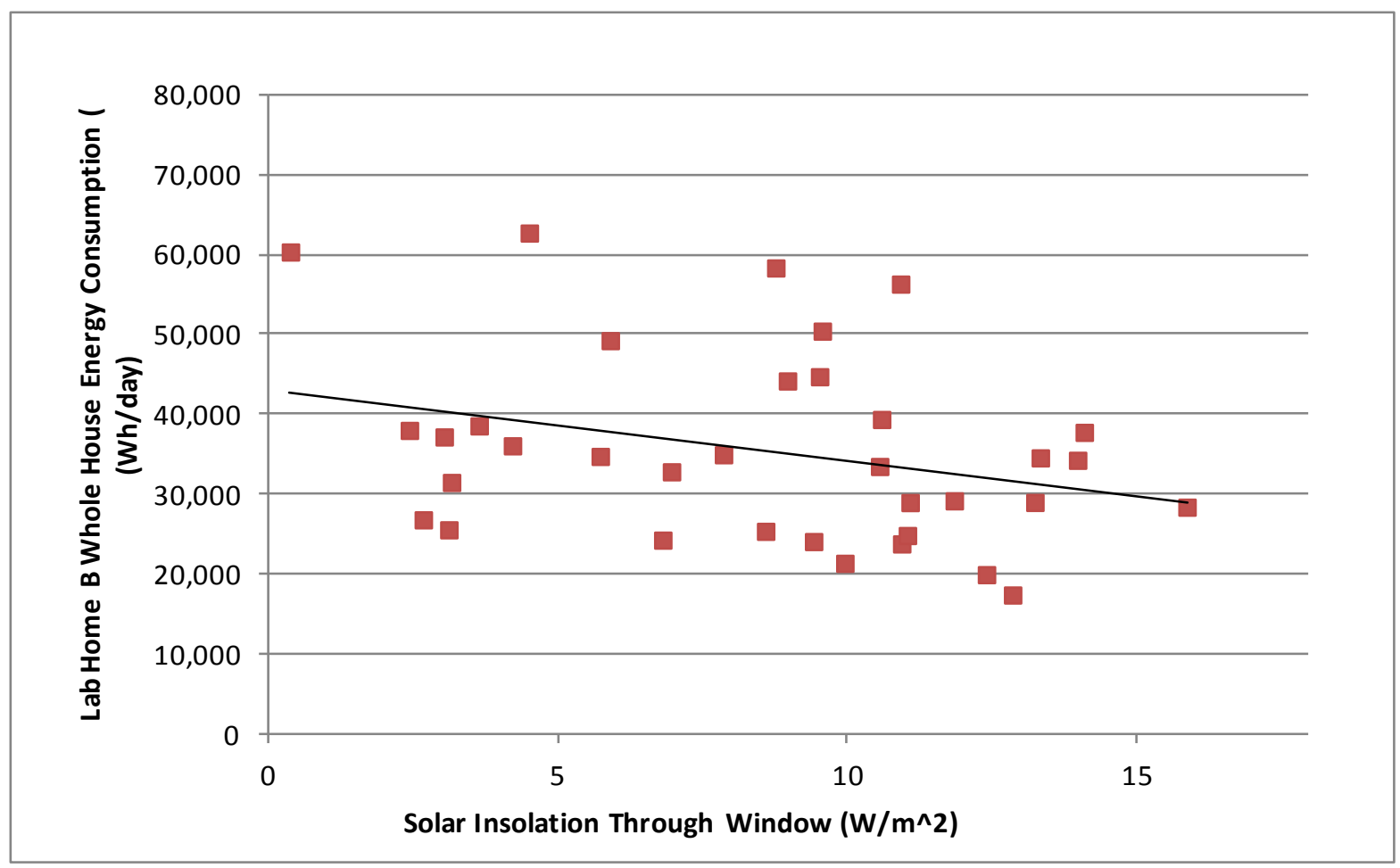

Figure 7.12. Whole-House Energy Use (Wh/day) in Lab Home B versus Solar Insolation (W/m²)

\subsubsection{Thermal Comfort and Condensation}

The increased thermal performance of highly insulating windows can also impact the health of a home. Poorly insulating windows, such as the double-pane clear glass windows installed in the baseline home (Lab Home A), can cause condensation to form on the window, which over time can contribute to mold growth on the window sill. While condensation was not observed with the low relative humidity in the homes, the thermal performance of the double-pane clear windows clearly indicated a propensity for condensation.

Figure 7.13 shows the interior temperature of all window surfaces in the baseline home (Lab Home A) and Figure 7.14 shows the interior temperature of all window surfaces in the experimental home (Lab Home B) during the period of March 11, 2012, through March 17, 2012. As the figures show, interior window temperature of the coolest window reaches $50^{\circ} \mathrm{F}$ on the west-facing dining room window in the baseline home, while the same window in the experimental home does not dip below $60^{\circ} \mathrm{F}$. With these temperatures and an interior room temperature of $75^{\circ} \mathrm{F}$ in both homes, the relative humidity of the air in the experimental home would have to exceed $70 \%$ to cause condensation on the highly insulating windows, while $40 \%$ relative humidity in the baseline would cause condensation and potential mold problems with the windows. ${ }^{1}$ For reference, the average relative humidity in the baseline home (Lab Home A) was $20.7 \%$, with a maximum of $31.7 \%$, and the average relative humidity observed in the experimental home (Lab Home B) was $21.7 \%$, with a maximum of $28.1 \%$.

\footnotetext{
${ }^{1}$ Based on data from a psychrometric chart.
} 


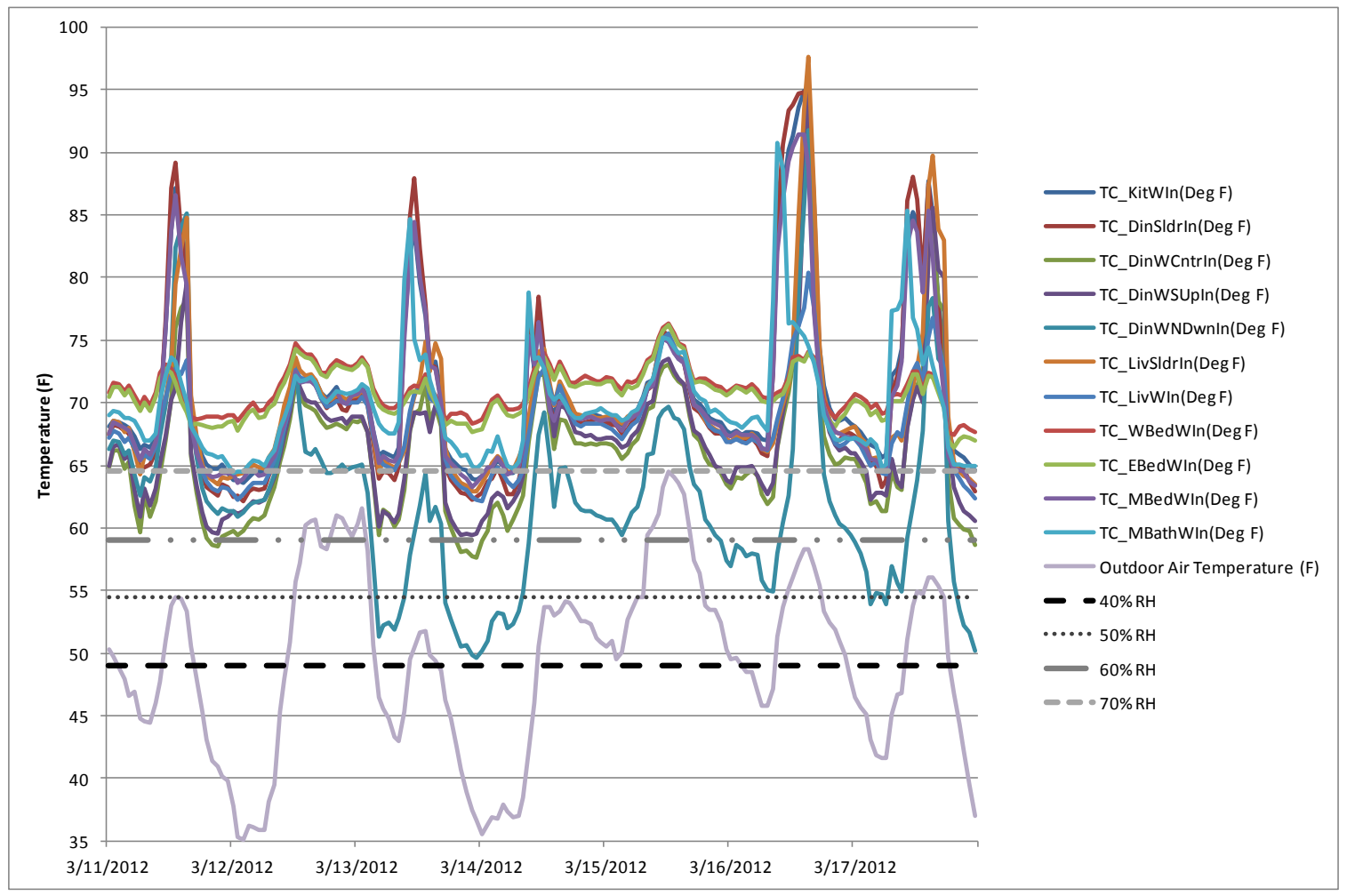

Figure 7.13. Interior Window Temperatures and Dew Point Temperatures Based on a $75^{\circ} \mathrm{F}$ Interior Air Temperature in the Baseline Home from March 11, 2012, through March 17, 2012

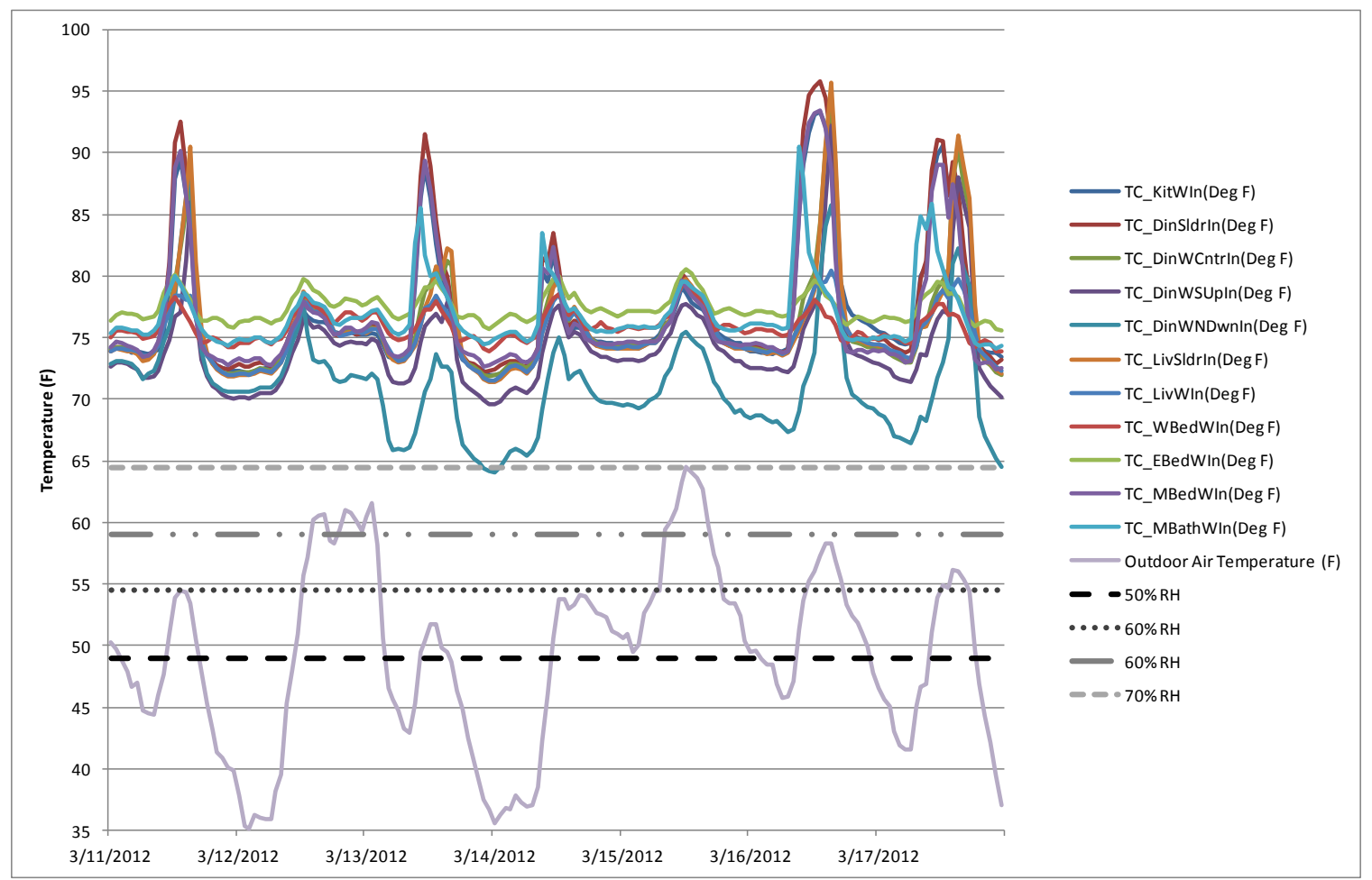

Figure 7.14. Interior Window Temperatures and Dew Point Temperatures based on a $75^{\circ} \mathrm{F}$ Interior Air Temperature in the Experimental Home from March 11, 2012, through March 17, 2012 
Figure 7.13 and Figure 7.14 also depict the difference in average interior glass surface temperature in the two homes. The average interior glass surface temperature measurement of all the windows over this period was $68.7 \pm 0.05^{\circ} \mathrm{F}$ in Lab Home A compared to $75.7 \pm 0.04^{\circ} \mathrm{F}$ in Lab Home B, nearly $7^{\circ} \mathrm{F}$ cooler. The colder window surface temperatures also affect comfort in the home felt by occupants. A window with a colder surface temperature will cause rooms to feel colder than the measured dry bulb temperature would suggest.

The MRT also was monitored in two locations in each Lab Home during the period of March 11, 2012, through March 17, 2012. In Figure 7.15, the average indoor air temperature and MRT are reported for both the homes.

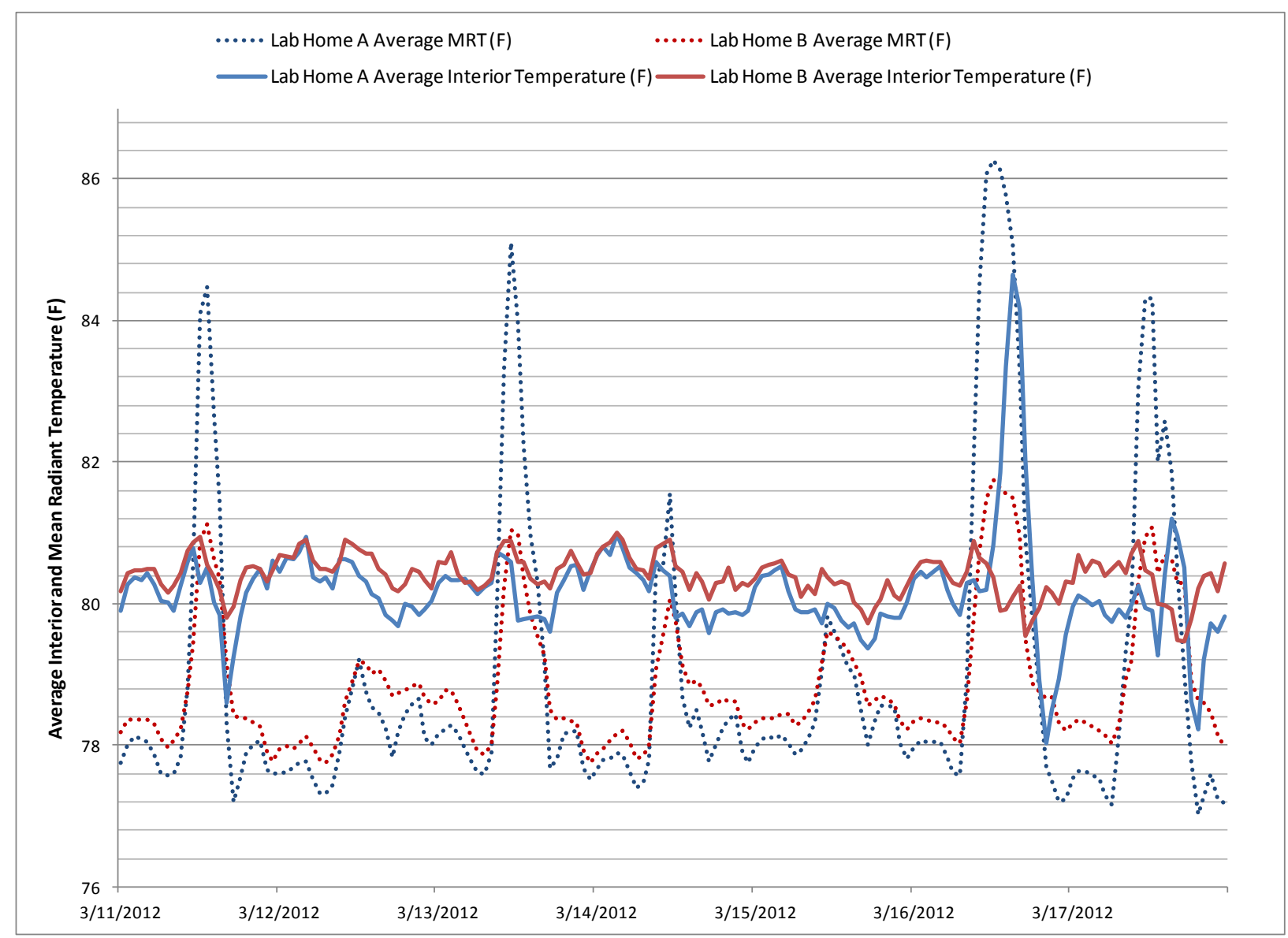

Figure 7.15. Average Indoor Air Temperature (solid line) and Mean Radiant Temperature (dotted line) in Lab Home A (blue) and Lab Home B (red)

The average MRT in Lab Home A during the nighttime period during the week when radiant heat loss was most extreme was $79.0 \pm 0.02^{\circ} \mathrm{F}$ in both the master bedroom and the living room compared to an average room temperature of $80.2 \pm 0.11^{\circ} \mathrm{F}$. The average MRT of both the living area and master bedroom was $1.63 \pm 0.01^{\circ} \mathrm{F}$ lower than the average interior room temperature in Lab Home A. The maximum MRT recorded in Lab Home A was $86.3^{\circ} \mathrm{F}$ and the minimum MRT was $77.0^{\circ} \mathrm{F}$. 
In contrast, in Lab Home B, the average MRT in the living area and master bedroom was $1.64 \pm$ $0.01^{\circ} \mathrm{F}$ lower than the average room temperature of $80.4 \pm 0.01^{\circ} \mathrm{F}$ in the living area and master bedroom. The maximum MRT recorded in Lab Home B was $81.7^{\circ} \mathrm{F}$ and the minimum MRT was $77.7^{\circ} \mathrm{F}$. Overall, the average nighttime MRT in Lab Home B was $0.345 \pm 0.004^{\circ} \mathrm{F}$ warmer than the average MRT in Lab Home A during the nighttime periods when radiant heat loss is most extreme. The very small temperature differences between the room temperature and MRT in Lab Home B compared to the larger difference in Lab Home A, as well as the higher average MRT in Lab Home B, suggest the highly insulating windows can provide a noticeably greater comfort level for occupants. Also, the MRT in Lab Home B was much more consistent, varying only $4.9^{\circ} \mathrm{F}$, while Lab Home A varied $9.2^{\circ} \mathrm{F}$.

\subsection{Peak Load}

Another impact of reduced energy use that is important to mention from a utility and resource planning perspective is the ability to reduce peak load $(\mathrm{kW})$. Figure 7.16 depicts peak load impacts due to installation of the highly insulating windows in the experimental home over a one-week time period. These impacts are nearly three times the heating season average energy $(\mathrm{kWh})$ savings, reducing the peak power consumed in the home with highly insulating windows (Lab Home B) by $33.9 \pm 0.6 \%$. This is because the peak load reduction represents a maximum real-time savings, rather than an average savings.

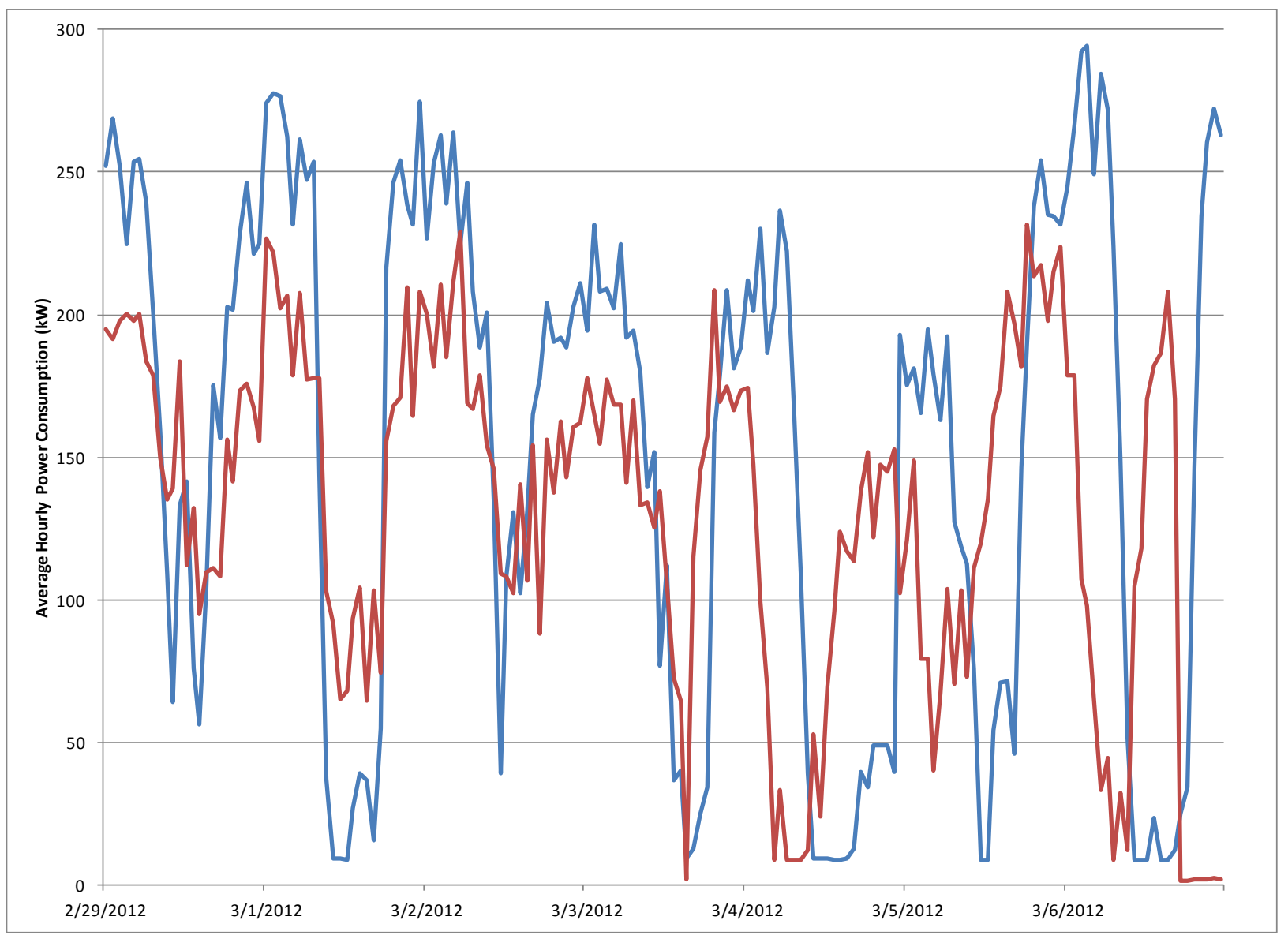

Figure 7.16. Average Hourly Power Use for Lab Home A (blue) and Lab Home B (red) During a OneWeek Period from February 29, 2012, to March 6, 2012 


\subsection{Energy Modeling}

An EnergyPlus model was created for the Lab Homes to compare modeled savings from the highly insulating windows to measured results. EnergyPlus analysis shows average whole-building energy savings in Lab Home B from the highly insulating windows to be $9.7 \%$ during the simulation period (February to April 2013). Part of the savings is due to the slightly tighter envelope of Lab Home B achieved as part of the windows retrofit (see Section 7.3.2). The general trends in energy use and savings are also comparable to, but slightly lower than, the measured data, which observed savings of $11.6 \pm 1.53 \%$ in Lab Home B compared to Lab Home A.

Figure 7.17 and Figure 7.18 show the modeled and measured energy use against outdoor air temperature for Lab Home A and Lab Home B, respectively. Figure 7.19 shows the modeled and measured energy savings versus outdoor air temperature of Lab Home B with respect to Lab Home A.

The modeled results track measured data well. The model predicts $\sim 15 \%$ annual energy savings from the highly insulating windows. This includes savings from the cooling season, which are expected to be greater than those observed during the heating season. However, the model needs to be calibrated before it can be used to accurately predict annual energy performance and savings. Future work will involve using on-site weather data in the energy simulation and matching daily load profiles exactly for the heating and cooling seasons.

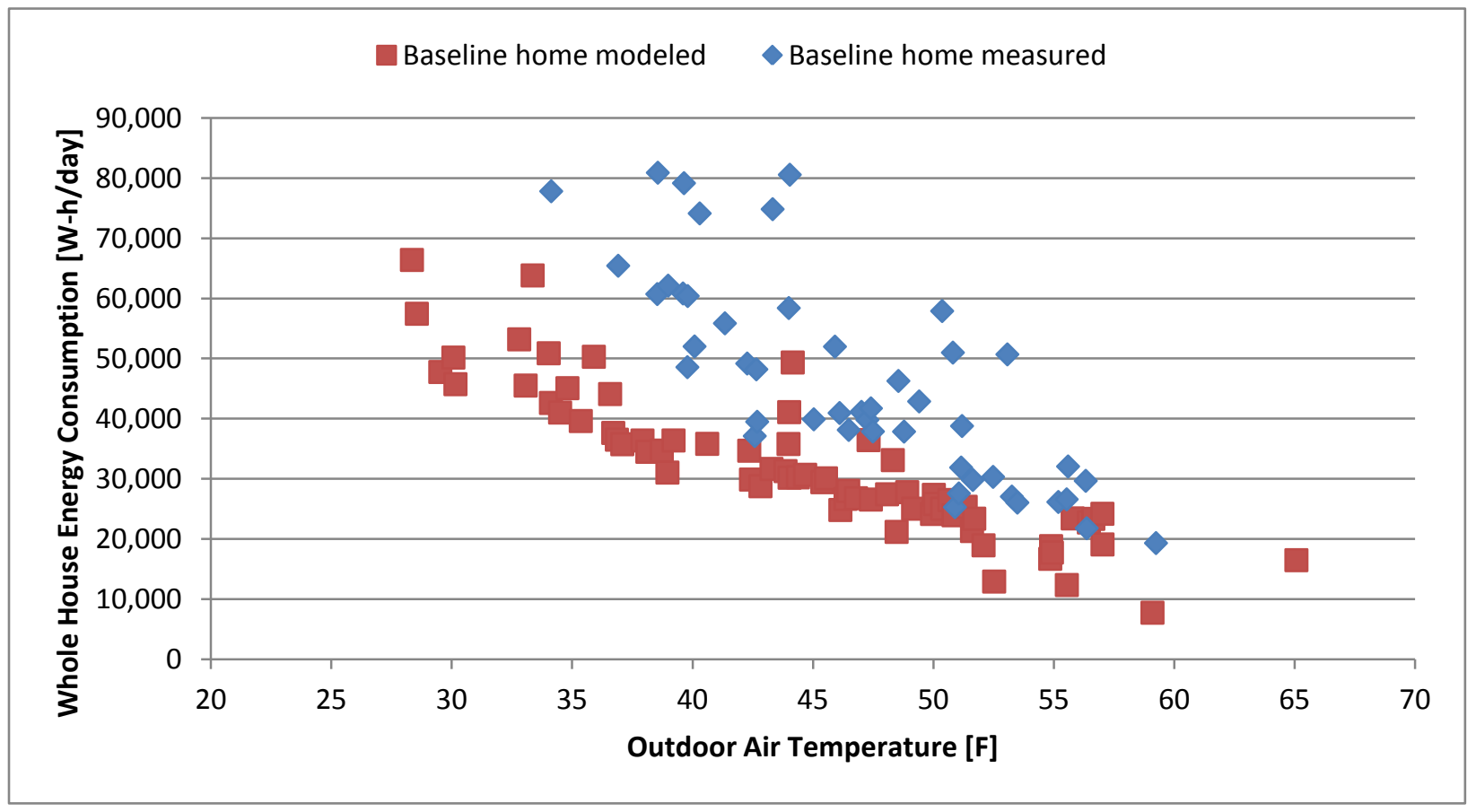

Figure 7.17. Modeled and Measured Whole-House Energy Use for Lab Home A (Baseline Home) 


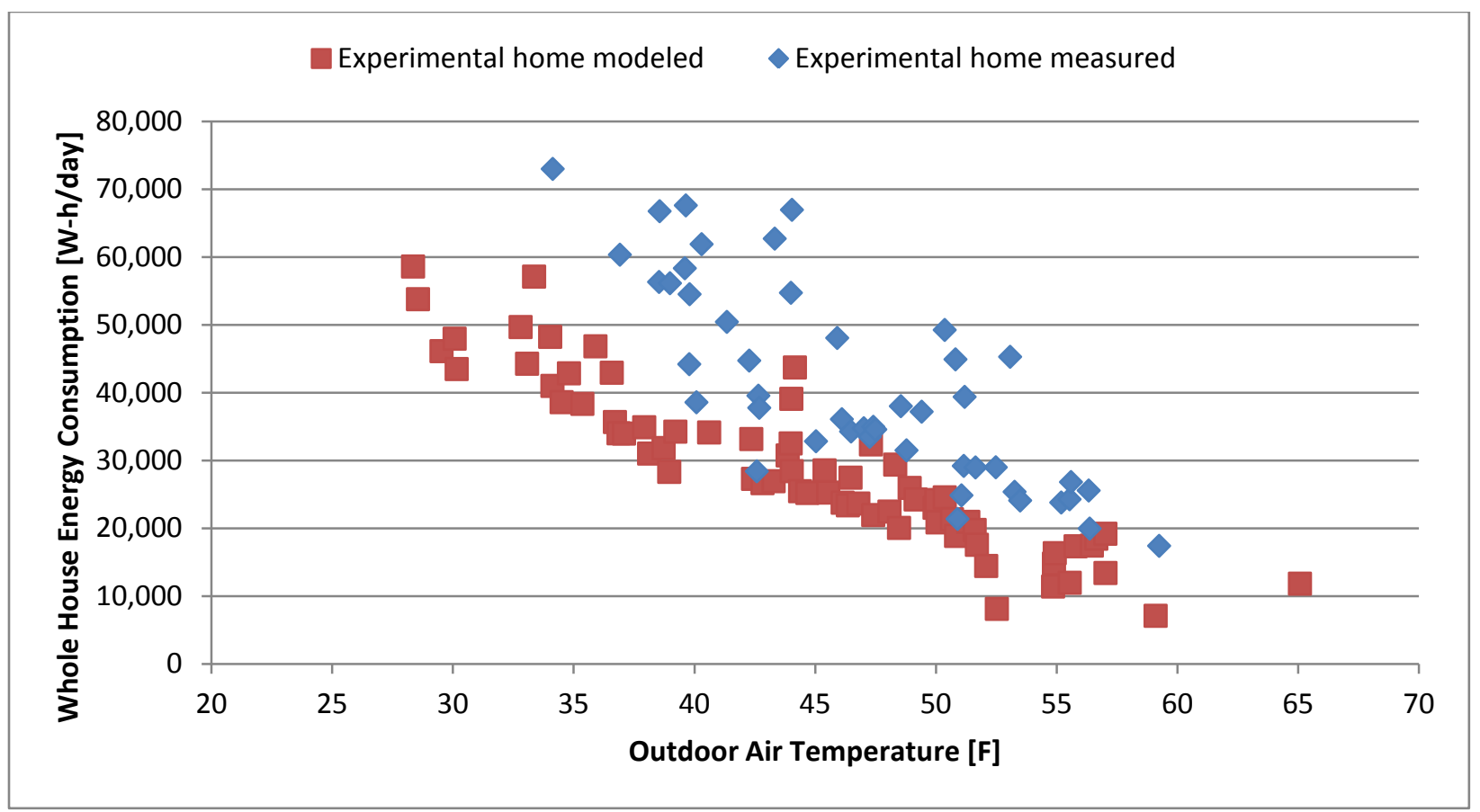

Figure 7.18. Modeled and Measured Whole House Energy Use for Lab Home B (Experimental Home)

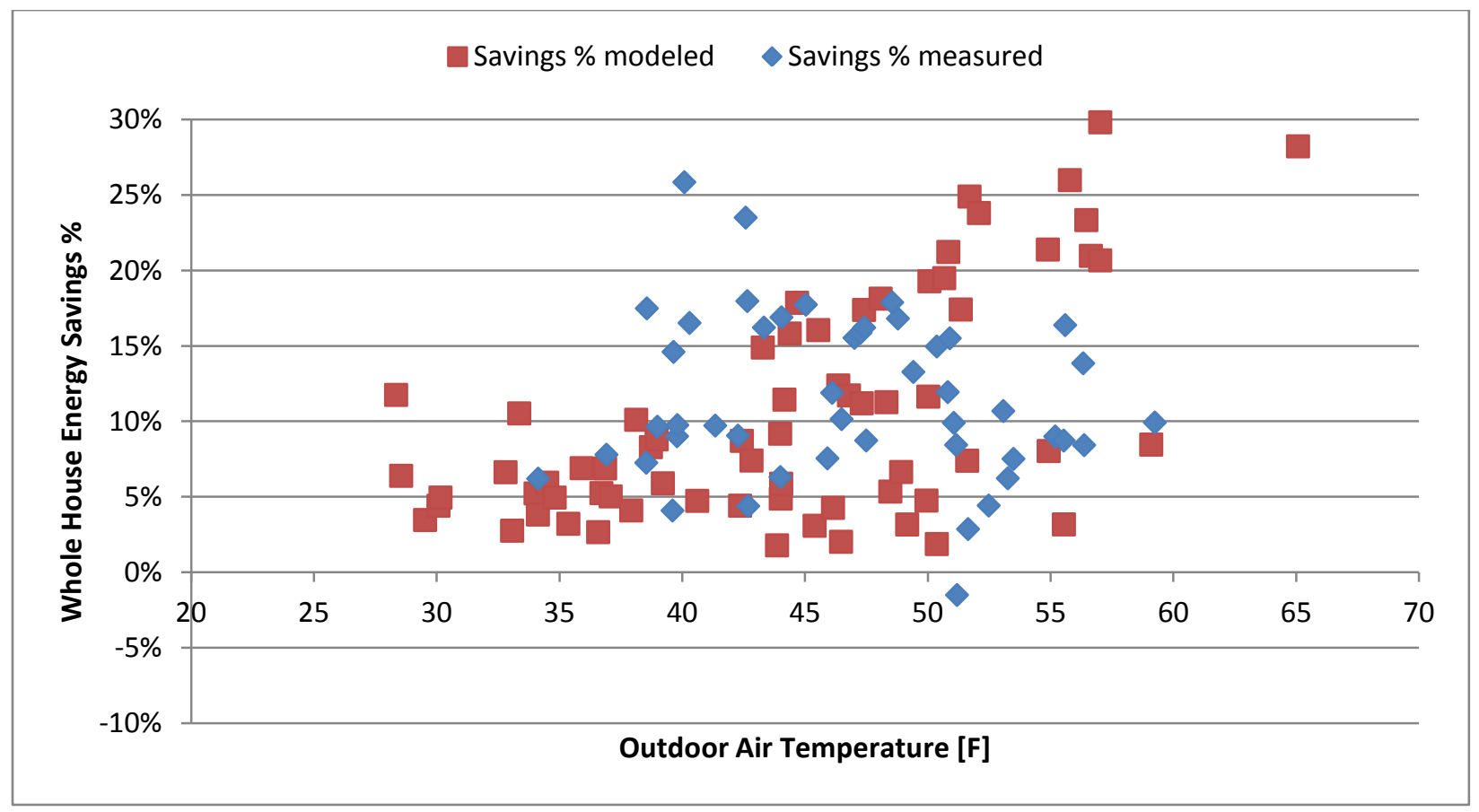

Figure 7.19. Modeled and Measured Energy Savings 



\subsection{Conclusions}

This experiment employed two side-by-side Lab Homes on the PNNL campus to measure the potential energy savings and thermal comfort impacts of highly insulating triple-pane windows (and patio doors) in the experimental home compared to the baseline home equipped with standard double-pane windows (and patio doors) representing windows in many existing homes across the PNW and much of the U.S. The homes were identical except for the windows. The U-factor of the highly insulating windows and patio doors in the experimental home (Lab Home B) is $\sim 70 \%$ lower than that of the standard windows in the baseline home (Lab Home A) and the SHGC of the highly insulating windows in the experimental home is $\sim 77 \%$ compared to the standard windows and patio doors in the baseline home.

The following conclusions are a result of the winter windows experiment in the Lab Homes.

\subsection{Lab Homes and Experimental Design}

The design of this field experiment in the Lab Homes was unique to the PNW. The experiment removed as many variables as possible that commonly impact other similar types of field experiments by having a nearly identical pair of homes, as verified by the null testing and by simulating occupancy identically in the two homes. The homes were oriented identically, experienced the same weather, had the same interior furnishings and equipment and were operated identically during the experiments. Thus the only differences between the two homes were the windows themselves (their inherent thermal properties) plus any impact from the windows' installation.

\subsection{Air Leakage}

The blower door measurements after the windows were retrofitted showed an increase of $50.3 \pm 34.1$ CFM50 in air leakage in Lab Home A, which is attributed to the combined effects of the air leakage of the window and air leakage around the window cavity resulting from the installation of the window. The air leakage of Lab Home B decreased by $46.4 \pm 34.9$ CFM50 or $6.9 \%$ after the windows retrofit. This decrease in air leakage is primarily due to the quality of the installation given that the air leakage of the highly insulating windows is similar to that of the factory-supplied windows. This is strong evidence of how important it is to properly install/retrofit windows.

\subsection{Pre-Windows Retrofit Performance During Null Testing}

The homes were initially null tested prior to the windows retrofit to verify similar construction and energy performance. Air leakage, duct leakage, ventilation fan flow, and HP performance testing was performed on both homes to compare construction of both homes' envelope construction and HVAC performance. This testing found the homes to be statistically the same, with blower door readings of $658 \pm 28$ CFM50 in Lab Home A and $701 \pm 27$ CFM50 in Lab Home B. For additional testing results see Section 7.0. Thermal imaging of the homes' envelopes also revealed similar construction, although some insulation settling had occurred in both homes, with slightly more in Lab Home A than Lab Home B. 
After baseline testing confirmed nearly identical construction of the homes, the energy use of the two homes was compared to verify similar energy performance. During this null test, no occupancy was simulated and the homes were operated in HP mode with the thermostat set point varied from $50^{\circ} \mathrm{F}$ to $85^{\circ} \mathrm{F}$ on a daily basis. Whole-house energy use was shown to be similar within $0.5 \% \pm 0.5 \%$ during the six days of null testing.

\subsection{Whole House Energy Performance}

The data from the two homes over the 70 days of testing show significant whole-house energy savings and comfort improvement in Lab Home B. The overall whole-house energy savings in Lab Home $\mathrm{B}$ with the high-performance windows are $11.6 \% \pm 1.53 \%$ compared to Lab Home A over the study period. The largest difference in energy performance between the homes was a result of solar insolation (solar heat gain) given the significant difference in SHGC of the windows in Lab Home A (0.7) compared to Lab Home B (0.19).

\subsection{Peak Electrical Load}

Due to the highly insulating windows, the peak load in Lab Home B was 33.9\% lower than the peak power consumed in Lab Home A during a selected one-week time period. The heating season peak load in both homes occurred during the evening hours after sunset. The home's peak load and subsequent peak savings due to the highly insulating windows are not necessarily associated with a servicing utility-level peak (or even the BPA peak) in the heating season. The impacts on peak load are anticipated to be even more significant in the summer, may better correspond with the servicing utility peak, and will be explored in the summer experiment.

Although there is currently no direct financial benefit to most residential customers of an electric utility for peak load reduction, this significant reduction in peak power can be of benefit to the utility depending upon the time of the utility or system peak.

\subsection{Solar Heat Gain Effects}

On sunny days, for almost any home, solar heat gain through windows contributes enough heat to the home that the heating systems may even turn off, even though the outdoor temperature is well below the balance point for the home. Given that neither home had window coverings, this condition was expected and observed more often in the baseline home (with high SHGC windows), with measured average whole-house indoor temperatures often increasing 5 to $10^{\circ} \mathrm{F}$ above the set point of the heating system thermostat due to solar heating. In the experimental home, temperatures remained much more consistent, but the heating system was required to turn on to supply heat much sooner in the evening, while the baseline home could typically coast well into the late evening before needing to call for heat. Overall, the low SHGC of the windows in the experimental home (Lab Home B) showed energy savings on sunny days of $8.9 \% \pm 1.42 \%$ compared to the baseline home (Lab Home A).

On cloudy days, the difference in the SHGC of the windows, and thus the solar heat gain contribution, is not as evident. Data showed that both homes maintained average interior temperatures near the thermostat set points throughout the day and that the heating systems were operating to maintain 
that set point throughout the day. The heat pumps cycle, as would be expected, and cycle less frequently in the afternoon when outdoor temperatures are the warmest. On overcast days, the average whole-house energy savings from the windows is $14.6 \% \pm 1.86 \%$.

\subsection{Thermal Comfort}

The thermal comfort implications of increased interior temperatures cannot be discounted. The team did not examine the effect of covering windows, opening windows/doors or turning on air conditioning in the home to compensate for the elevated afternoon temperatures, as may occur in occupied homes. Also, the impact of significant solar gain will be much more problematic in the summer.

The window surface temperatures also impact comfort in the home felt by occupants. A window with a colder surface temperature will cause the occupant to feel colder near the window due to the lower window surface temperature than the measured dry bulb room temperature would suggest. This effect is partially illustrated by the dramatically cooler window surface temperatures observed in the baseline home of as low as $50^{\circ} \mathrm{F}$ compared to the experimental home where the window surface temperature never dropped below $60^{\circ} \mathrm{F}$.

Overall, the average nighttime MRT in Lab Home B was $0.345 \pm 0.004^{\circ} \mathrm{F}$ warmer than the average MRT in Lab Home A. Also, Lab Home A exhibited higher high temperatures and lower low temperatures as measured by the MRT.

\subsection{Condensation/Moisture on Windows}

This experiment did not directly measure presence of condensation on the windows, nor was additional humidity from occupancy introduced into either home for this experiment. However, window condensation is a common occurrence in most homes during the heating season, and can be of concern to residents. In climates with elevated relative humidity levels such as in the PNW coastal climate, or in residences with significant interior moisture generation, window condensation on interior window surfaces would likely occur. At an average outdoor temperature of $49^{\circ} \mathrm{F}$, an interior window temperature was recorded as low as $50^{\circ} \mathrm{F}$ in Lab Home A, while the lowest interior window temperature recorded was $60^{\circ} \mathrm{F}$ in Lab Home B. ${ }^{1}$ With these temperatures and an average interior room temperature of $75^{\circ} \mathrm{F}$, the relative humidity of the air in Lab Home B would have to exceed $70 \%$ to cause condensation on the highly insulating performance windows, while a $40 \%$ relative humidity would cause condensation on the double-pane windows in Lab Home B. For reference, during the study period, the average relative humidity in Lab Home A was $20.7 \%$, with a maximum of $31.7 \%$, and the average relative humidity in Lab Home B was $21.7 \%$, with a maximum of $28.1 \%$.

\footnotetext{
${ }^{1}$ The highly insulating windows in Lab Home B have sealed cavities with desiccant material to eliminate any (visible) condensation on inside surfaces of the glass. As noted, the overall insulative properties of the window will minimize the potential for condensation on the interior-facing glass surface even with very cold outdoor temperatures.
} 


\subsection{Windows Cost}

Retrofitting homes with highly insulating windows has been shown to save $10.3 \%$ on total home energy use during this winter heating season experiment. The windows also provide additional non-quantifiable comfort levels. The cost for the highly insulating windows to retrofit these homes ranged from $\$ 21 /$ square foot to $\$ 40 /$ square foot for windows and $\$ 23 /$ square foot to $\$ 36 /$ square foot for sliding glass doors. Installation and materials costs were estimated at $\$ 3 /$ square foot based on observed retrofit of the windows at the Lab Homes. Therefore, total installed cost for the highly insulating windows and sliding glass doors in Lab Home B was estimated to be $\$ 4,300$ to $\$ 7,600$.

If the highly insulating windows were installed on the manufactured-homes factory floor, the incremental cost of the windows is estimated to be $\$ 4.00$ /square foot over today's PNW factory-installed windows, ${ }^{1}$ with no additional labor cost for installation and a $\$ 0.25 /$ square foot incremental cost for materials (sill plate + foam). Therefore, total incremental factory-installed cost for highly insulating windows is estimated to be $\$ 4.25 /$ square foot. For a home with the same window area as the Lab Homes $\left(195.7 \mathrm{ft}^{2}\right)$, this incremental cost would be $\$ 832$.

The payback or return on investment for retrofitting highly insulating windows or for installing highly insulating windows on the factory floor will be dependent upon the yearly savings. These savings will be determined and reported after the summer experiment is carried out.

\subsection{Energy Modeling}

The modeled results generated using EnergyPlus compare to the measured energy use and savings fairly well. The model shows $9.7 \%$ savings over the study period, from February to April, and predicts $\sim 15 \%$ annual energy savings when cooling season savings are included. Future work will involve using real weather data in the energy simulation and matching daily load profiles exactly for the heating and cooling seasons to create a calibrated model that represents the actual observed savings for heating and cooling seasons. This calibrated model can then be used to extrapolate the measured savings to different climate zones to predict performance of the high-performance windows regionally or nationally. Annual measured data and savings will also be compared to other modeling software, particularly the SEEM simulation tool ${ }^{2}$ which is used in the PNW for determining measure cost and benefits for utility energy efficiency programs.

\footnotetext{
${ }^{1}$ This incremental cost estimate for a highly insulating window is an average incremental cost above an ENERGY STAR window obtained from windows suppliers who are part of the DOE windows volume purchase program.

${ }^{2}$ A Simple Energy Efficiency Model. http://www.nwcouncil.org/energy/rtf/measures/support/SEEM/Default.asp
} 


\subsection{References}

ASTM International. 2010. "ASTM Standard E779-10: Standard Test Method for Determining Air Leakage Rate by Fan Pressurization.” ASTM International. West Conshohocken, PA.

Burdette/Boylan. 2011. Telephone call to Larry Burdette and Mike Boylan, Marlette Industries, by Greg Sullivan, Efficiency Solutions, December 20, 2011, confirming rated fan flows.

Hendron R and C Engebrecht. 2010. "Building America House Simulation Protocols." National Renewable Energy Laboratory. Golden, CO. Available at:

http://apps1.eere.energy.gov/buildings/publications/pdfs/building_america/house_simulation_revised.pdf

The Energy Conservatory. 2006. “TrueFlow Air Handler Flow Meter Operation Manual.” The Energy

Conservatory. Minneapolis, MN. Available at: http://www.energyconservatory.com/download/tfman.pdf

The Energy Conservatory. 2010. "Exhaust Fan Flow Meter Operation Manual.” The Energy

Conservatory. Minneapolis, MN. Available at:

http://www.energyconservatory.com/download/boxman.pdf

The Energy Conservatory. 2011. "Minneapolis Duct Blaster Operation Manual.” The Energy

Conservatory. Minneapolis, MN. Available at:

http://www.energyconservatory.com/download/dbmanual.pdf

The Energy Conservatory. 2012. "Minneapolis Blower Door Operation Manual for Model 3 and Model 4 Systems." The Energy Conservatory. Minneapolis, MN. Available at:

http://www.energyconservatory.com/download/bdmanual.pdf 



\section{Appendix A}

\section{Lab Home A and B Construction}

Specifications and Alterations 



\section{Appendix A}

\section{Lab Home A and B Construction Specifications and Alterations}

\section{A.1 Lab Home A Construction Specifications and Alterations ${ }^{1}$}

\section{A.1.1 Background}

Battelle Memorial Institute Pacific Northwest Division (Battelle) operates the Pacific Northwest National Laboratory (PNNL). The lab home to be altered is sited in Richland, Washington on Battelleowned land adjacent to $7906^{\text {th }}$ Street, just South of the Atmospheric Measurement Lab (AML) and Battelle Shipping/Receiving Facilities in Richland, Washington.

The home ("Lab Home A") will become a research and demonstration laboratory to demonstrate and evaluate retrofit and smart grid technologies. The home will be instrumented for data collection.

\section{A.1.2 Alteration Specifications for Lab Home A}

Below are the specifications/scope of alterations work for Lab Home A.

1. Windows and Sliding Glass Doors Retrofit: (Bid Alternate \#1)

a. At Battelle's direction, and within 4-8 weeks of the set up of the homes, Contractor shall perform a retrofit of all windows and sliding glass doors with double-pane, clear glass, aluminum frame with a National Fenestration Rating Council (NFRC)-certified U-factor no less than 0.60 and a solar heat gain coefficient (SHGC) no less than 0.30 .

b. The windows and sliding glass doors in the home will be retrofitted with the same type of window (e.g., a picture window will be retrofitted with a picture window and an operable window retrofitted with an operable window). The NFRC temporary label shall remain attached to all windows and the sliding glass doors.

c. All operable windows shall be horizontal sliders.

d. All windows and sliding glass doors will be from the same manufacturer and the same product line (brand).

e. All windows and sliding glass doors shall be secured to the home with stainless steel screws and trimmed with the windows/sliding glass door trim-board that was removed from the home to retrofit these windows and doors. The trim board shall be attached using stainless steel screws.

f. All windows and sliding glass doors shall be supplied with screens.

g. All windows and sliding glass doors removed for this retrofit shall be preserved in as good a condition as possible and will be transferred to Battelle for storage.

\footnotetext{
${ }^{1}$ Note that due to funding limitations, the alterations in Section 8: Alternative (Secondary) Hot Water Distribution System: (Bid Alternate \#3) was not implemented.
} 


\section{Interior Walls.}

a. Selected non load-bearing walls identified below shall be moved or removed to accommodate future equipment. These include moving a wall in the utility room to expand the furnace closet, building an exterior access door and wall with a door in the master bedroom closet to the water heater, and moving a wall in the kitchen to accommodate a larger refrigerator. The approximate total wall area to be modified or added as described below is $250 \mathrm{ft}^{2}$.

i. Any walls that are replaced or constructed shall be taped, finished and painted in the original wall color.

b. The space for the water heater (located in the master bedroom closet) shall be expanded to approximately 4 foot deep by moving the access wall in the closet. An insulated door shall be installed across this wall to access the water heater from the closet. This access door shall be 36 inches wide by 80 inches high and have a door sweep and hardware. Contractor shall also install a 36 inch wide $\mathrm{x} 80$ inch high insulated/solid core exterior access door to the water heater closet. This door shall have locking hardware with weatherstripping. All walls/wall cavities shall be insulated with fiberglass batt insulation. Wall area to be modified and insulated is approximately $112 \mathrm{ft}^{2}$.

c. The enclosure for the air handling unit for the heat pump shall be modified to approximately 6 foot deep x approximately 4 foot wide to allow room for the future installation of a heat recovery ventilation unit (e.g., air-to-air heat exchanger). A 36 inch wide access door with hardware shall be installed approximately midway along the (new) 6 foot wall. Note that the walls enclosing the furnace room do not need to be insulated. Wall area to be modified is approximately $112 \mathrm{ft}^{2}$.

d. The space for the refrigerator shall be expanded to accommodate a 36 inch wide refrigerator (as a retrofit). Therefore the short-wall adjacent to the dining room will need to be moved. Wall area to be modified is approximately $20 \mathrm{ft}^{2}$.

3. Heating/Cooling Systems and Ductwork.

a. Home shall be equipped with two heating/cooling systems (for experimental purposes). Only the heat pump heating/cooling system will be activated at the time of setup.

i. Install the factory provided heating/cooling system \#1: current minimum federal standard 2.5 ton heat pump (13.0 SEER/7.7 HSPF) with outdoor compressor/fan unit and inside air handler (blower) with backup strip resistance (per HUD code for Richland, Washington climate). The heat pump shall be installed during setup of the home.

ii. Heating system \#2: Cadet Model \#RMC151W 120V white-color electric resistance fan heaters. See http://www.cadetco.com/show_product.php?prodid=1001. Fan heaters shall be located in each bedroom, bathroom, and laundry room and in the kitchen/dining/living room/hallway area. The total wattage of this system shall be sized to meet the design load in Richland, Washington and shall be allocated to the areas according to their square footage. This heating system shall be separately circuited per the Electrical Panel/Electrical Wiring specifications given in Section 7 below.

b. The thermostat for the Cadet heaters shall be controlled by line voltage, wall-mounted thermostats for each heater. 


\section{Water Heater Closet}

a. The water heater closet/location shall have a water drain in the floor connected to the central wastewater drain for the home.

5. Exterior Stairs

a. Code-compliant stairs shall be provided for the front entry, back door and the 1 sliding glass door on the end of the home.

i. All stairs shall have a code-compliant platform/landing.

ii. Stairs to the front entry door and back door shall be Jack and Jill type stairs (steps on both sides of the landing) similar to those shown in http://www.mobilehomedepotmi.com/parts_pages/steps_wood.html

b. A code-compliant handicapped ramp shall be provided for the sliding glass door on the backside of the home. The ramp shall have a 4 foot $\mathrm{x} 6$ foot platform/landing.

c. All stairs (including railing, treads and landing) and the handicapped ramp shall be pre-formed plastic or constructed of recycled plastic lumber in a dark color

6. Skirting

a. Entire perimeter of home shall be covered with 'rapid-wall' type skirting (vinyl-clad over Styrofoam backing) of a color that is complimentary to the house color. For an example of this skirting, see http://rustiquerapidwall.com/. Contractor shall provide two (2) access panels with skirting: 1 in the front and 1 in the back of the home. Skirting shall also include twelve 8 "x16"manual vents: 4 on front of home, 4 on back of home, and 2 on each side of the home.

7. Electrical Panel/ Electrical Wiring: (Bid Alternate \#2)

The electrical panel and wiring diagram specified below are non-standard for most common manufactured homes. The electrical panel is a commercial-style panel and thus is larger than a standard residential panel. The breakers specified are of 2 types: standard and controllable. The controllable breakers are specified so that Battelle can simulate occupancy conditions in the home by turning on and off equipment remotely (via a signal) that is connected to the controllable (powered) breaker. The wiring specifications shall require significantly more wire than is common in manufactured homes given that these specifications require separating out circuits that are most times combined (e.g., lights and plugs in rooms) in standard home wiring configurations.

For the electrical panel, breakers and wiring the Contractor shall follow National Electrical Code (NEC) requirements throughout.

The following are general specifications for the electrical panels and breakers:

a. The main electrical/breaker panel in the home shall be a Square D Powerlink G3 3000 Level System with web-enabled control. See http://www.schneider-electric.us/productsservices/products/lighting-control/powerlink/3000-level-system/3000-level-g3-controller/. A file of a panelboard take-off sheet with a recommended circuit layout and required breakers (standard or controllable - see notations and descriptions below) is included as Attachment 2 with these specifications. It is however up to the discretion of the Contractor's electrician on how to best balance the load on either side of the split-phase service. 
b. The labels for the circuits shall be included on the panel. The labels are given on the circuit layout and are identified in the specifications below for each circuit using an identifier following the circuit description in parentheses and bolded as shown here: (Label)

c. The main electrical/breaker panel shall be 'flush-mounted' and located either in the location of the existing panel or adjacent to the existing panel. If possible, there shall be at least 3 feet of unobstructed wall on one side of the panel. Battelle is aware that the Square D panel is deeper than a standard residential panel and thus when this panel is 'flush-mounted' it will protrude several (3 to 4 ) inches beyond the finished drywall. No trim around the panel is required. Panel shall have a door.

d. The breakers for each circuit are identified by amperage and as either 'standard' or 'controllable'. These breakers shall be provided for the Powerlink G3 3000 Level System panel by Square D and thus shall be purchased from Square D.

e. For each 15 and 20 amp breaker installed in the panel, a double loop of conductor ( 2 circular loops of conductor approximately 2 " in diameter) shall be used prior to connection to the breaker. Loops shall be as far away from the actual breaker lug as possible, but within the confines of the panel enclosure. [Note that the panel box has been sized to accommodate this request.] These loops will be used with current transformers (CTs) installed by Battelle as part of the metering and thus are necessary to achieve higher accuracy on low-load circuits.

f. The second panel, to be used for a future Electric Vehicle Charging Station, shall have a 200A main breaker and the panel shall be wired with a conventional two-pole $30 \mathrm{amp}$ breaker and a single-pole 20A breaker. This panel shall be a small panel since only three breaker slots are needed. The load side of this panel shall include appropriately sized conductors running from the panel and terminating on the exterior of the home with two service disconnects, one for the $30 \mathrm{~A}$ circuit and one for the 20A circuit. The service disconnect shall be a weather tight variety and located on the front of the home (same side as front door) and near the corner/end of the home. This second panel shall be flush-mounted in the utility room near the main panel.

g. All switch plates, receptacle plates and light fixtures/ light fixture covers shall be labeled with the circuit number of the breaker controlling that circuit.

The following are the specifications for the circuits. Ground Fault Interrupter (GFI) receptacles shall be used where code requires they be used.

8. Bedrooms

a. Master bedroom will have 1 dedicated $120 \mathrm{~V}$ receptacle circuit on a separate 20 amp standard breaker. (M_Bedroom Rcpt)

b. Master bedroom will have 1 dedicated $120 \mathrm{~V}$ lighting circuit serving the single ceiling fixture on a separate 15 amp controllable breaker. (M_Bedroom Lights)

c. Bedroom 2 will have 1 dedicated receptacle circuit a 20 amp standard breaker. (Bedroom 2 Rcpt)

d. Bedroom 3 will have 1 dedicated receptacle circuit on a 20 amp standard breaker. (Bedroom 3 Rcpt)

e. Bedrooms 2 and 3 will be combined into 1 dedicated 120V lighting circuit serving the ceiling fixtures on a separate $15 \mathrm{amp}$ controllable breaker. (2 Bedroom Lights) 
9. Master Bathroom

a. 1 dedicated $120 \mathrm{~V}$ receptacle circuit on a $15 \mathrm{amp}$ standard breaker. This circuit shall include 1 standard receptacle installed under the sink. (M_Bath $R \boldsymbol{c p t})$

b. 1 dedicated $120 \mathrm{~V}$ lighting circuit on a 15 amp controllable breaker. (M_Bath Lights)

c. 1 dedicated $120 \mathrm{~V}$ circuit for the ventilation fan on a 15 amp controllable breaker. (M_Bath Vent Fan)

10. $2^{\text {nd }}$ Bathroom

a. 1 dedicated $120 \mathrm{~V}$ receptacle circuit on a 15 amp standard breaker. This circuit shall include 1 receptacle installed under the sink. (Bath $\boldsymbol{R} \boldsymbol{c p t}$ )

b. 1 dedicated $120 \mathrm{~V}$ lighting circuit on a $15 \mathrm{amp}$ controllable breaker. (Bath Lights)

c. 1 dedicated $120 \mathrm{~V}$ circuit for the ventilation fan on a $15 \mathrm{amp}$ controllable breaker. (Bath Vent Fan)

11. Kitchen

a. 1 dedicated $120 \mathrm{~V}$ circuit for convenience receptacles on a separate 20 amp standard breaker. (Kitchen Rcpt)

b. 1 dedicated $120 \mathrm{~V}$ circuit for the dishwasher on a 20 amp controllable breaker. (Dishwasher)

c. 1 dedicated $120 \mathrm{~V}$ circuit for the refrigerator receptacle on a 20 amp controllable breaker. (Refrigerator)

d. 1 dedicated $120 \mathrm{~V}$ circuit for the over-the-range ventilation fan on a $15 \mathrm{amp}$ controllable breaker. (Range Vent Fan)

e. 1 dedicated $240 \mathrm{~V}$ circuit for the range on standard circuit breakers sized to meet NEC requirements for a residential kitchen range. (Range)

12. Dining Room

a. 1 dedicated $120 \mathrm{~V}$ circuit for receptacles on a separate 20 amp standard breaker. (Dining Room
Rcpt)

b. 1 dedicated $120 \mathrm{~V}$ lighting circuit on a 15 amp controllable breaker. (Dining Room Lights)

13. Living Room
a. 1 dedicated $120 \mathrm{~V}$ circuit for receptacles on a separate $20 \mathrm{amp}$ standard breaker. (Living Room Rcpt)

b. 1 dedicated $120 \mathrm{~V}$ lighting circuit on a 15 amp controllable breaker. (Living Room Lights)

14. Hallway
a. 1 dedicated $120 \mathrm{~V}$ circuit for receptacles on a separate $20 \mathrm{amp}$ standard breaker. (Hallway Rcpt)
b. 1 dedicated $120 \mathrm{~V}$ lighting circuit on a $15 \mathrm{amp}$ controllable breaker. (Hallway Lights)

15. Utility Room

a. 1 dedicated $120 \mathrm{~V}$ circuit for receptacles on a $15 \mathrm{amp}$ standard breaker. One receptacle should be at panel height near electrical panel. (Utility Room Rcpt) 
b. 1 dedicated $120 \mathrm{~V}$ circuit serving the clothes washer receptacle on a $20 \mathrm{amp}$ controllable breaker. (Clothes Washer)

c. 1 dedicated $240 \mathrm{~V}$ circuit serving the clothes dryer plug on controllable breakers sized to meet NEC requirements for a standard residential-sized clothes dryer. (Clothes Dryer)

d. 1 dedicated $120 \mathrm{~V}$ lighting circuit on a $15 \mathrm{amp}$ controllable breaker. (Utility Room Lights)

e. 1 dedicated $120 \mathrm{~V}$ receptacle circuit located adjacent to the furnace air handler enclosure with at least 3 feet $\mathrm{x} 3$ feet of wall space above the receptacle on a $15 \mathrm{amp}$ controllable breaker. (Heat Ex. Rcpt)

16. Heating/Cooling

a. 1 dedicated $240 \mathrm{~V}$ circuit for air handler/back up heat unit on standard breakers sized to meet NEC requirements for the air handler/back up heat. (Furnace)

b. 1 dedicated $240 \mathrm{~V}$ circuit for the heat pump outside unit on standard breakers sized to meet NEC requirements for the heat pump unit. Install a disconnect at the heat pump outside unit per NEC requirements. (Heat Pump) (Air Conditioner)

c. Dedicated $120 \mathrm{~V}$ circuits for the alternative room wall heaters on 20 amp controllable breakers. 5 individual circuits are suggested:

i. Both bathrooms + utility room (Bathroom/Utility Htr)

ii. Master bedroom (M_Bedroom Heater)

iii. Two (2) remaining bedrooms (2_Bedroom Heater)

iv. Living room/hallway area (Living Room/Hall Htr)

v. Dining room/kitchen area (Dining/Kitchen Htr)

Note: If more circuits are needed for the room wall heaters per NEC requirements, contact PNNL for guidance.

17. Other Circuits

a. 1 dedicated $120 \mathrm{~V}$ circuit serving the whole-house ventilation fan on a 15 amp controllable breaker. (Whole House Vent)

b. 1 dedicated $120 \mathrm{~V}$ circuit serving the exterior lighting on a 15 amp controllable breaker. (Exterior Lights)

18. Additional (Spare) Controllable Breakers

Contractor shall supply (in a box) additional controllable breakers for the main panel as follows:

8 additional 20 amp controllable breakers; 8 additional 15 amp controllable breakers; and 2 additional controllable breakers of the same amperage for the clothes dryer circuit. 


\section{A.2 Lab Home B Construction Specifications and Alterations ${ }^{1}$}

\section{A.2.1 Background}

Battelle Memorial Institute Pacific Northwest Division (Battelle) operates the Pacific Northwest National Laboratory (PNNL). The lab home to be altered is sited in Richland, Washington on Battelleowned land adjacent to $7906^{\text {th }}$ Street, just South of the AML and Battelle Shipping/Receiving Facilities in Richland, Washington.

The home ("Lab Home B") will become a research and demonstration laboratory to demonstrate and evaluate retrofit and smart grid technologies. The home will be instrumented for data collection.

\section{A.2.2 Alteration Specifications for Lab Home B}

Below are the specifications for Lab Home B alterations.

1. Windows and Sliding Glass Doors Retrofit (Bid Alternate \#1)

a. At Battelle's direction, and within 4-8 weeks of the setup of the homes, Contractor shall perform a retrofit of all windows and sliding glass doors with triple-pane low-e vinyl framed windows with a National Fenestration Rating Council (NFRC)-certified U-factor no greater than 0.22 for operable windows and the sliding glass doors, no greater than 0.20 for fixed (picture) windows, and a solar heat gain coefficient (SHGC) of no less than 0.20.

b. The windows and sliding glass doors in the home will be retrofitted with the same type of window (e.g., a picture window will be retrofitted with a picture window and an operable window retrofitted with an operable window). The NFRC temporary label shall remain attached to all windows and the sliding glass doors.

c. All operating windows shall be single-hung type windows with white vinyl frames.

d. All windows and sliding glass doors will be from the same manufacturer and the same product line (brand). The recommended vendor for the triple pane windows and sliding glass doors is Jeld-Wen Premium ESMK Vinyl White. The NFRC certified products directory number (CPD \#) for these windows and sliding glass doors is: JEL-A-543-09065-00001 retrofit single hung windows; JEL-A-757-01694-00001 retrofit fixed windows; and JEL-A-697-03919-00001 retrofit sliding glass doors. These windows shall be purchased from the vendor (Jeld-Wen) through the DOE windows volume purchase web site (www.windowsvolumepurchas.org)

e. All windows and sliding glass doors shall be secured to the home with stainless steel screws and trimmed with the windows/sliding glass door trim-board that was removed from the home to retrofit these windows and doors. The trim board shall be attached using stainless steel screws.

f. All windows and sliding glass doors shall be supplied with screens.

g. All windows and sliding glass doors removed for this retrofit shall be preserved in as good a condition as possible and will be transferred to Battelle for storage.

\footnotetext{
${ }^{1}$ Note that due to funding limitations, the alterations in Section 8: Alternative (Secondary) Hot Water Distribution System: (Bid Alternate \#3) was not implemented.
} 
2. Interior Walls.

a. Selected non load-bearing walls identified below shall be moved or removed to accommodate future equipment. These include moving a wall in the utility room to expand the furnace closet, building an exterior access door and wall with a door in the master bedroom closet to the water heater, and moving a wall in the kitchen to accommodate a larger refrigerator. The approximate total wall area to be modified or added as described below is $250 \mathrm{ft}^{2}$.

i. Any walls that are replaced or constructed shall be taped, finished and painted in the original wall color.

3. The space for the water heater (located in the master bedroom closet) shall be expanded to approximately 4 foot deep by moving the access wall in the closet. An insulated door shall be installed across this wall to access the water heater from the closet. This access door shall be 36 inches wide by 80 inches high and have a door sweep and hardware. Contractor shall also install a 36 inch wide $x 80$ inch high insulated/solid core exterior access door to the water heater closet. This door shall have locking hardware with weatherstripping. All walls/wall cavities shall be insulated with fiberglass batt insulation. Wall area to be modified and insulated is approximately $112 \mathrm{ft}^{2}$.

4. The enclosure for the air handling unit for the heat pump shall be modified to approximately 6 foot deep x approximately 4 foot wide to allow room for the future installation of a heat recovery ventilation unit (e.g., air-to-air heat exchanger). A 36 inch wide access door with hardware shall be installed approximately midway along the (new) 6 foot wall. Note that the walls enclosing the furnace room do not need to be insulated. Wall area to be modified is approximately $112 \mathrm{ft}^{2}$.

5. The space for the refrigerator shall be expanded to accommodate a 36 inch wide refrigerator (as a retrofit). Therefore the short-wall adjacent to the dining room will need to be moved. Wall area to be modified is approximately $20 \mathrm{ft}^{2}$.

6. Heating/Cooling Systems and Ductwork

a. Home shall be equipped with two heating/cooling systems (for experimental purposes). Only the heat pump heating/cooling system will be activated at the time of setup.

i. Install the factory provided heating/cooling system \#1: current minimum federal standard 2.5 ton heat pump (13.0 SEER/7.7 HSPF) with outdoor compressor/fan unit and inside air handler (blower) with backup strip resistance (per HUD code for Richland, Washington climate). The heat pump shall be installed during setup of the home.

ii. Heating system \#2: Cadet Model \#RMC151W 120V white-color electric resistance fan heaters. See http://www.cadetco.com/show_product.php?prodid=1001. Fan heaters shall be located in each bedroom, bathroom, and laundry room and in the kitchen/dining/living room/hallway area. The total wattage of this system shall be sized to meet the design load in Richland, Washington and shall be allocated to the areas according to their square footage. This heating system shall be separately circuited per the Electrical Panel/Electrical Wiring specifications given in Section 7 below.

b. The thermostat for the Cadet heaters shall be controlled by line voltage, wall-mounted thermostats for each heater. 


\section{Water Heater Closet}

a. The water heater closet/location shall have a water drain in the floor connected to the central wastewater drain for the home.

8. Exterior Stairs

a. Code-compliant stairs shall be provided for the front entry, back door and the 1 sliding glass door on the end of the home.

i. All stairs shall have a code-compliant platform/landing.

ii. Stairs to the front entry door and back door shall be Jack and Jill type stairs (steps on both sides of the landing) similar to those shown in http://www.mobilehomedepotmi.com/parts_pages/steps_wood.html

b. A code-compliant handicapped ramp shall be provided for the sliding glass door on the backside of the home. The ramp shall have a 4 foot $\mathrm{x} 6$ foot platform/landing.

c. All stairs (including railing, treads and landing) and the handicapped ramp shall be pre-formed plastic or constructed of recycled plastic lumber in a dark color

9. Skirting

a. Entire perimeter of home shall be covered with 'rapid-wall' type skirting (vinyl-clad over Styrofoam backing) of a color that is complimentary to the house color. For an example of this skirting, see http://rustiquerapidwall.com/. Contractor shall provide two (2) access panels with skirting: 1 in the front and 1 in the back of the home. Skirting shall also include twelve 8 "x16"manual vents: 4 on front of home, 4 on back of home, and 2 on each side of the home.

10. Electrical Panel/ Electrical Wiring: (Bid Alternate \#2)

The electrical panel and wiring diagram specified below are non-standard for most common manufactured homes. The electrical panel is a commercial-style panel and thus is larger than a standard residential panel. The breakers specified are of 2 types: standard and controllable. The controllable breakers are specified so that Battelle can simulate occupancy conditions in the home by turning on and off equipment remotely (via a signal) that is connected to the controllable (powered) breaker. The wiring specifications shall require significantly more wire than is common in manufactured homes given that these specifications require separating out circuits that are most times combined (e.g., lights and plugs in rooms) in standard home wiring configurations.

For the electrical panel, breakers and wiring the Contractor shall follow National Electrical Code (NEC) requirements throughout.

The following are general specifications for the electrical panels and breakers:

a. The main electrical/breaker panel in the home shall be a Square D Powerlink G3 3000 Level System with web-enabled control. See http://www.schneider-electric.us/productsservices/products/lighting-control/powerlink/3000-level-system/3000-level-g3-controller/. A file of a panelboard take-off sheet with a recommended circuit layout and required breakers (standard or controllable - see notations and descriptions below) is included as Attachment 2 with these specifications. It is however up to the discretion of the Contractor's electrician on how to best balance the load on either side of the split-phase service. 
b. The labels for the circuits shall be included on the panel. The labels are given on the circuit layout and are identified in the specifications below for each circuit using an identifier following the circuit description in parentheses and bolded as shown here: (Label)

c. The main electrical/breaker panel shall be 'flush-mounted' and located either in the location of the existing panel or adjacent to the existing panel. If possible, there shall be at least 3 feet of unobstructed wall on one side of the panel. Battelle is aware that the Square D panel is deeper than a standard residential panel and thus when this panel is 'flush-mounted' it will protrude several (3 to 4 ) inches beyond the finished drywall. No trim around the panel is required. Panel shall have a door.

d. The breakers for each circuit are identified by amperage and as either 'standard' or 'controllable'. These breakers shall be provided for the Powerlink G3 3000 Level System panel by Square D and thus shall be purchased from Square D.

e. For each 15 and 20 amp breaker installed in the panel, a double loop of conductor ( 2 circular loops of conductor approximately 2 " in diameter) shall be used prior to connection to the breaker. Loops shall be as far away from the actual breaker lug as possible, but within the confines of the panel enclosure. [Note that the panel box has been sized to accommodate this request.] These loops will be used with current transformers (CTs) installed by Battelle as part of the metering and thus are necessary to achieve higher accuracy on low-load circuits.

f. The second panel, to be used for a future Electric Vehicle Charging Station, shall have a 200A main breaker and the panel shall be wired with a conventional two-pole $30 \mathrm{amp}$ breaker and a single-pole 20A breaker. This panel shall be a small panel since only three breaker slots are needed. The load side of this panel shall include appropriately sized conductors running from the panel and terminating on the exterior of the home with two service disconnects, one for the $30 \mathrm{~A}$ circuit and one for the 20A circuit. The service disconnect shall be a weather tight variety and located on the front of the home (same side as front door) and near the corner/end of the home. This second panel shall be flush-mounted in the utility room near the main panel.

g. All switch plates, receptacle plates and light fixtures/ light fixture covers shall be labeled with the circuit number of the breaker controlling that circuit.

The following are the specifications for the circuits. Ground Fault Interrupter (GFI) receptacles shall be used where code requires they be used.

11. Bedrooms

a. Master bedroom will have 1 dedicated $120 \mathrm{~V}$ receptacle circuit on a separate 20 amp standard breaker. (M_Bedroom Rcpt)

b. Master bedroom will have 1 dedicated $120 \mathrm{~V}$ lighting circuit serving the single ceiling fixture on a separate 15 amp controllable breaker. (M_Bedroom Lights)

c. Bedroom 2 will have 1 dedicated receptacle circuit a 20 amp standard breaker. (Bedroom 2 Rcpt)

d. Bedroom 3 will have 1 dedicated receptacle circuit on a 20 amp standard breaker. (Bedroom 3 Rcpt)

e. Bedrooms 2 and 3 will be combined into 1 dedicated $120 \mathrm{~V}$ lighting circuit serving the ceiling fixtures on a separate 15 amp controllable breaker. (2 Bedroom Lights) 


\section{Master Bathroom}

a. 1 dedicated $120 \mathrm{~V}$ receptacle circuit on a $15 \mathrm{amp}$ standard breaker. This circuit shall include 1 standard receptacle installed under the sink. (M_Bath $R \boldsymbol{c p t})$

b. 1 dedicated $120 \mathrm{~V}$ lighting circuit on a 15 amp controllable breaker. (M_Bath Lights)

c. 1 dedicated $120 \mathrm{~V}$ circuit for the ventilation fan on a 15 amp controllable breaker. (M_Bath Vent Fan)

13. $2^{\text {nd }}$ Bathroom

a. 1 dedicated $120 \mathrm{~V}$ receptacle circuit on a $15 \mathrm{amp}$ standard breaker. This circuit shall include 1 receptacle installed under the sink. (Bath $\boldsymbol{R c p t}$ )

b. 1 dedicated $120 \mathrm{~V}$ lighting circuit on a $15 \mathrm{amp}$ controllable breaker. (Bath Lights)

c. 1 dedicated $120 \mathrm{~V}$ circuit for the ventilation fan on a $15 \mathrm{amp}$ controllable breaker. (Bath Vent Fan)

14. Kitchen

a. 1 dedicated $120 \mathrm{~V}$ circuit for convenience receptacles on a separate 20 amp standard breaker. (Kitchen Rcpt)

b. 1 dedicated $120 \mathrm{~V}$ circuit for the dishwasher on a 20 amp controllable breaker. (Dishwasher)

c. 1 dedicated $120 \mathrm{~V}$ circuit for the refrigerator receptacle on a $20 \mathrm{amp}$ controllable breaker. (Refrigerator)

d. 1 dedicated $120 \mathrm{~V}$ circuit for the over-the-range ventilation fan on a $15 \mathrm{amp}$ controllable breaker. (Range Vent Fan)

e. 1 dedicated $240 \mathrm{~V}$ circuit for the range on standard circuit breakers sized to meet NEC requirements for a residential kitchen range. (Range)

15. Dining Room

a. 1 dedicated $120 \mathrm{~V}$ circuit for receptacles on a separate 20 amp standard breaker. (Dining Room Rcpt)

b. 1 dedicated $120 \mathrm{~V}$ lighting circuit on a 15 amp controllable breaker. (Dining Room Lights)

16. Living Room
a. 1 dedicated $120 \mathrm{~V}$ circuit for receptacles on a separate $20 \mathrm{amp}$ standard breaker. (Living Room Rcpt)

b. 1 dedicated $120 \mathrm{~V}$ lighting circuit on a 15 amp controllable breaker. (Living Room Lights)

17. Hallway
a. 1 dedicated $120 \mathrm{~V}$ circuit for receptacles on a separate $20 \mathrm{amp}$ standard breaker. (Hallway Rcpt)
b. 1 dedicated $120 \mathrm{~V}$ lighting circuit on a $15 \mathrm{amp}$ controllable breaker. (Hallway Lights)

18. Utility Room

a. 1 dedicated $120 \mathrm{~V}$ circuit for receptacles on a $15 \mathrm{amp}$ standard breaker. One receptacle should be at panel height near electrical panel. (Utility Room Rcpt) 
b. 1 dedicated $120 \mathrm{~V}$ circuit serving the clothes washer receptacle on a $20 \mathrm{amp}$ controllable breaker. (Clothes Washer)

c. 1 dedicated $240 \mathrm{~V}$ circuit serving the clothes dryer plug on controllable breakers sized to meet NEC requirements for a standard residential-sized clothes dryer. (Clothes Dryer)

d. 1 dedicated $120 \mathrm{~V}$ lighting circuit on a $15 \mathrm{amp}$ controllable breaker. (Utility Room Lights)

e. 1 dedicated $120 \mathrm{~V}$ receptacle circuit located adjacent to the furnace air handler enclosure with at least 3 feet $\mathrm{x} 3$ feet of wall space above the receptacle on a 15 amp controllable breaker. (Heat Ex. Rcpt)

19. Heating/Cooling

a. 1 dedicated $240 \mathrm{~V}$ circuit for air handler/back up heat unit on standard breakers sized to meet NEC requirements for the air handler/back up heat. (Furnace)

b. 1 dedicated $240 \mathrm{~V}$ circuit for the heat pump outside unit on standard breakers sized to meet NEC requirements for the heat pump unit. Install a disconnect at the heat pump outside unit per NEC requirements. (Heat Pump) (Air Conditioner)

c. Dedicated $120 \mathrm{~V}$ circuits for the alternative room wall heaters on 20 amp controllable breakers. 5 individual circuits are suggested:

i. Both bathrooms + utility room (Bathroom/Utility Htr $)$

ii. Master bedroom (M_Bedroom Heater)

iii. Two (2) remaining bedrooms (2_Bedroom Heater)

iv. Living room/hallway area (Living Room/Hall Htr)

v. Dining room/kitchen area (Dining/Kitchen Htr)

Note: If more circuits are needed for the room wall heaters per NEC requirements, contact PNNL for guidance.

20. Other Circuits

a. 1 dedicated $120 \mathrm{~V}$ circuit serving the whole-house ventilation fan on a 15 amp controllable breaker. (Whole House Vent)

b. 1 dedicated $120 \mathrm{~V}$ circuit serving the exterior lighting on a 15 amp controllable breaker. (Exterior Lights)

21. Additional (Spare) Controllable Breakers

Contractor shall supply (in a box) additional controllable breakers for the main panel as follows:

8 additional $20 \mathrm{amp}$ controllable breakers; 8 additional $15 \mathrm{amp}$ controllable breakers; and 2 additional controllable breakers of the same amperage for the clothes dryer circuit.

22. Alternative (Secondary) Hot Water Distribution System: (Bid Alternate \#3)

The alternative (second) hot water distribution system (See Figure 1 below) is a parallel hot water supply system for all of the home's hot-water water-using fixtures and will be used in a future experiment in this home (Lab Home B). The purpose of the alternative hot water supply system is to test out a hot water delivery system that minimizes the use of hot water in the home and thus saves 
water and energy. Battelle will install a circulation pump in the system when this experiment is undertaken. The goal of this system is to draw no more than $1 / 2$ to 1 cup of water at each fixture until there is hot water available at the given fixture at the water heater set temperature and to have as little flow resistance as possible to minimize circulation pumping energy.

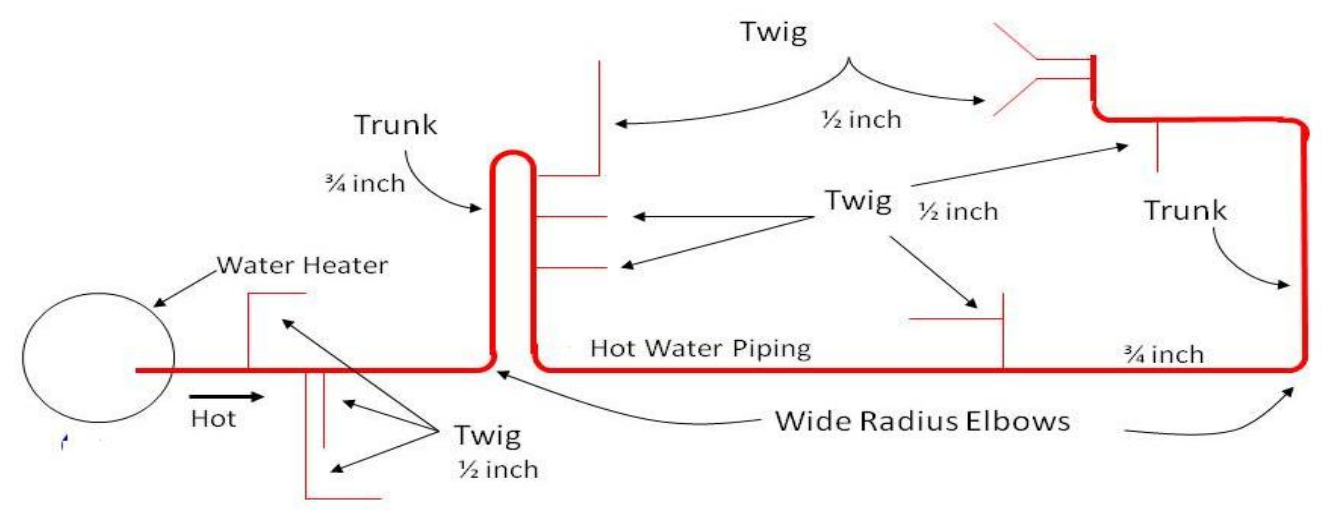

Figure A.1. Diagram of Alternative Hot Water Supply Distribution System

In the description below and in Figure 1 above, the hot water supply lines are referred to as "trunk" and "twigs". The trunk carries the hot water from the water heater to locations where the twigs branch out from the trunk to serve the individual fixtures.

For both the trunk and twigs, the material used shall be PEX tubing because this tubing is highly flexible, and Contractor shall use this flexibility to make wide radius bends that minimize the use of fittings and reduce flow restrictions, especially 90 degree elbows wherever feasible - see detailed specifications below under Hot Water Distribution System.

The trunk shall be $3 / 4$ inch PEX (cross-linked polyethylene) tubing.

The twigs shall be $1 / 2$ inch PEX tubing unless applicable standards require that $3 / 4$ inch PEX be used throughout.

This alternative hot water supply system shall be inactive (not connected) and dry at the time the home is delivered. At a later time for experimental purposes, Battelle will attach the alternative hot water supply line to the water heater and turn on the valves at those fixtures.

There is only one 'standard' cold water distribution system and this should be run with the 'standard' primary hot water distribution system (see $\mathbf{1 3}$ above), as it is typically configured in a manufactured home.

23. At the Water Heater

An easily accessible 2-way ball valve shall be installed at the water heater on the hot water supply from the water heater. The hot water supply system for the 'standard' hot water distribution system (see 13 above) shall be connected to the outlet of this 2-way ball valve. 
The alternative hot water supply tubing will run from the water heater location to the fixtures as shown in Figure 1 and described below. An additional length of the hot water "trunk" 3/4 inch tubing $\sim 8$ feet long shall be coiled and secured near the water heater for later connection by Battelle. The end of this pipe will have a brass PEX connection for (later) connection to the 2-way ball valve at the water heater and be sealed after the system is commissioned (tested for leaks)- see System

Commissioning below.

24. Alternative Hot Water Distribution System (see Figure 1)

a. The alternative hot water supply tubing shall supply hot water to all the same fixtures in the home that are connected to the 'standard' hot water distribution system.

b. The alternative hot water supply tubing shall be run separately from the 'standard' hot and cold water system tubing.

c. For all the alternative hot water supply tubing, keep the flow restrictions to a minimum by limiting the number of connections, particularly the number of 90 degree elbows.

i. Use wide-sweeping turns where possible rather than elbows and particularly 90 degree elbows.

ii. Minimize the use of couplings.

iii. Minimize the use of insert fittings.

iv. Use an open style manifold (or mini-manifold) ${ }^{1}$ without valves from the trunk for the twigs to serve hot water fixtures that are close together.

v. For the trunk $3 / 4$ inch tubing, minimize the number of fittings. In particular, minimize the use of any elbow fittings.

d. The supply lines (twigs) to the fixtures shall be plumbed in the following way:

i. The length of the tubing to each fixture should be as short as possible and thus the $3 / 4$ inch hot water trunk tubing should be run as close as possible to the fixture or group of fixtures.

ii. To serve a single fixture (e.g., clothes washer), a $3 / 4 \times 3 / 4 \times 1 / 2$ tee connection shall be used (with the $1 / 2$ inch line (twig) serving the clothes washer).

iii. To serve multiple fixtures, a manifold (or mini-manifold) without valves shall be used on the trunk line to reduce the number of field joints. The length of an individual hot water supply twig to the fixture should not exceed 6-8 feet to the valve or angle stop. In some locations, primarily where fixtures in a group are supplied with twigs from a manifold, some of these supply lines may need to be longer than others. If more than 8 feet, Contractor will consult with Battelle staff who will be on-site during the installation of the hot water distribution systems.

25. Connections of the Alternative Hot Water Supply Lines at the Fixtures

a. Upstream of the standard and alternative hot water supply tubing (trunk line) to each bath/shower fixture and to the clothes washer hot water supply, ball valves shown in Figure 2 shall be

\footnotetext{
${ }^{1}$ An example of an open-style $3 / 4 \times 3 / 4 \times 1 / 2$ manifold/mini-manifold can be found at http://www.pexuniverse.com/store/product/434. Note that this example is not an endorsement of this particular brand of manifold.
} 
installed. These ball valves shall be accessible through a panel with dimensions of approximately 16 inches wide x 12 inches above the valves and 12 inches below the valves. The opening shall be covered with a removable (screwed) cover. The ball valves shall be set to provide hot water to the bath/shower and clothes washer from the standard hot water supply system when the home is delivered.

b. The alternative and standard hot water supply (trunk) lines to each bathroom sink shall be connected under the sinks using ball valves as shown in Figure 2 upstream of the standard shut off (angle) valves. Both valves must be accessible through an opening in the wall under the sinks. The wall opening shall be covered with a removable (screwed) door.

c. The alternative and standard hot water supply (trunk) lines to the kitchen sink shall be under the sink as shown in Figure 2. The line after the $\mathrm{T}$ will go on to serve both kitchen hot water tap and the dishwasher. The sink and dishwasher hot water lines shall also be provided with standard shut off (angle) valves. Both ball valves must be accessible through an opening in the wall under the sinks. The wall opening shall be covered with a removable (screwed) door.

d. The ball valves for the clothes washer and under the bathroom and kitchen sinks shall be set to provide hot water from the standard hot water system when the home is delivered.

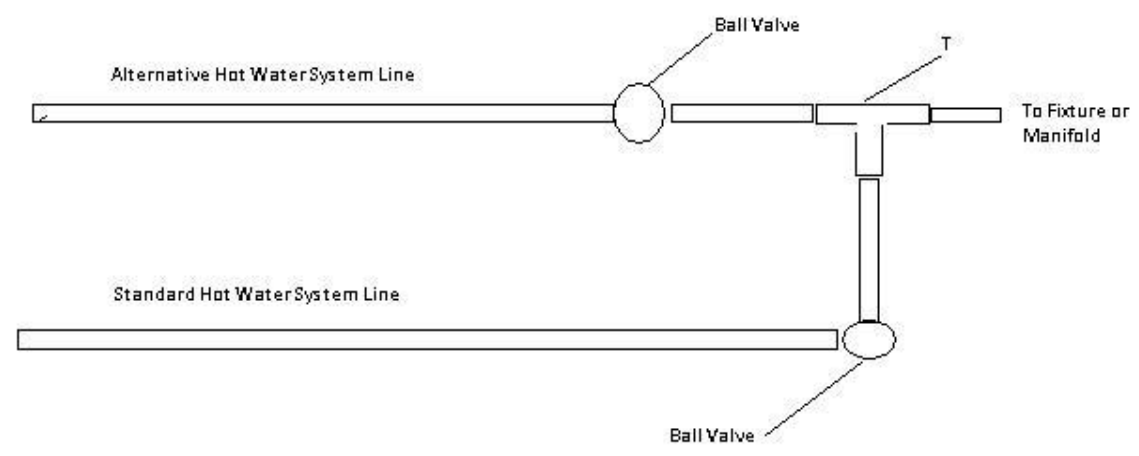

Figure A.2. Diagram of Alternative Hot Water System Fixture Connection

26. Tubing Insulation

a. All hot water tubing (trunk and twigs) of the alternative hot water delivery system shall be insulated. This includes the fittings/manifolds where possible.

b. Self-sealing closed-cell polyethylene (PE) pipe insulation shall be used. Use $3 / 4$ inch thick PE insulation for $3 / 4$ inch tubing and $1 / 2$ inch PE insulation shall be used for $1 / 2$ inch tubing. Tape endto-end joints and around fittings with acrylic tape appropriate for PE pipe.

c. The tubing (twigs) to the fixtures should be insulated as near as possible to the fixture.

d. The extra/coiled tubing at the water heater shall not be insulated.

\section{System Commissioning}

The alternative system shall be tested for leaks in a similar manner to how the 'standard' water distribution system is tested. 



\section{Appendix B}

Photographs of the Exterior and Interior of the Lab Homes 



\section{Appendix B}

\section{Photographs of the Exterior and Interior of the Lab Homes}

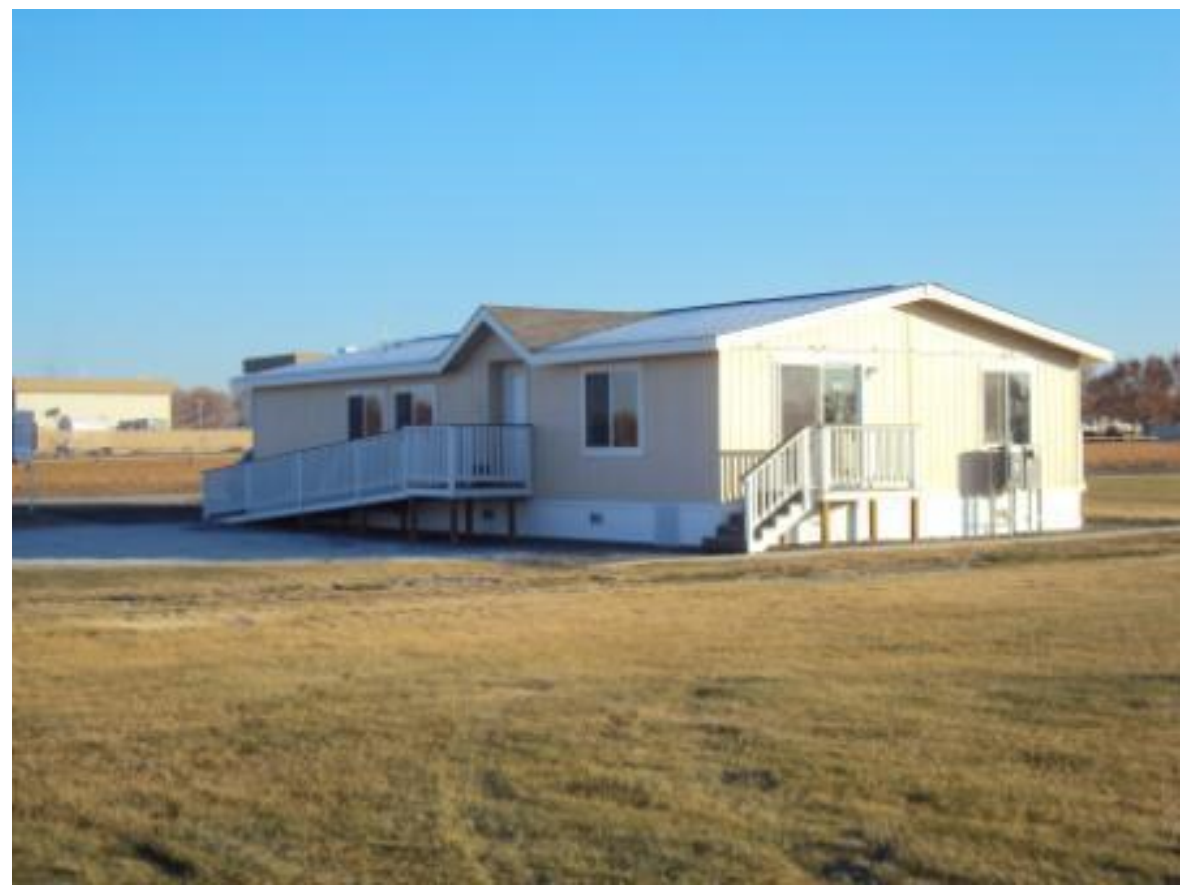

Figure B.1. Lab Home A Home on a Cold and Clear December Afternoon

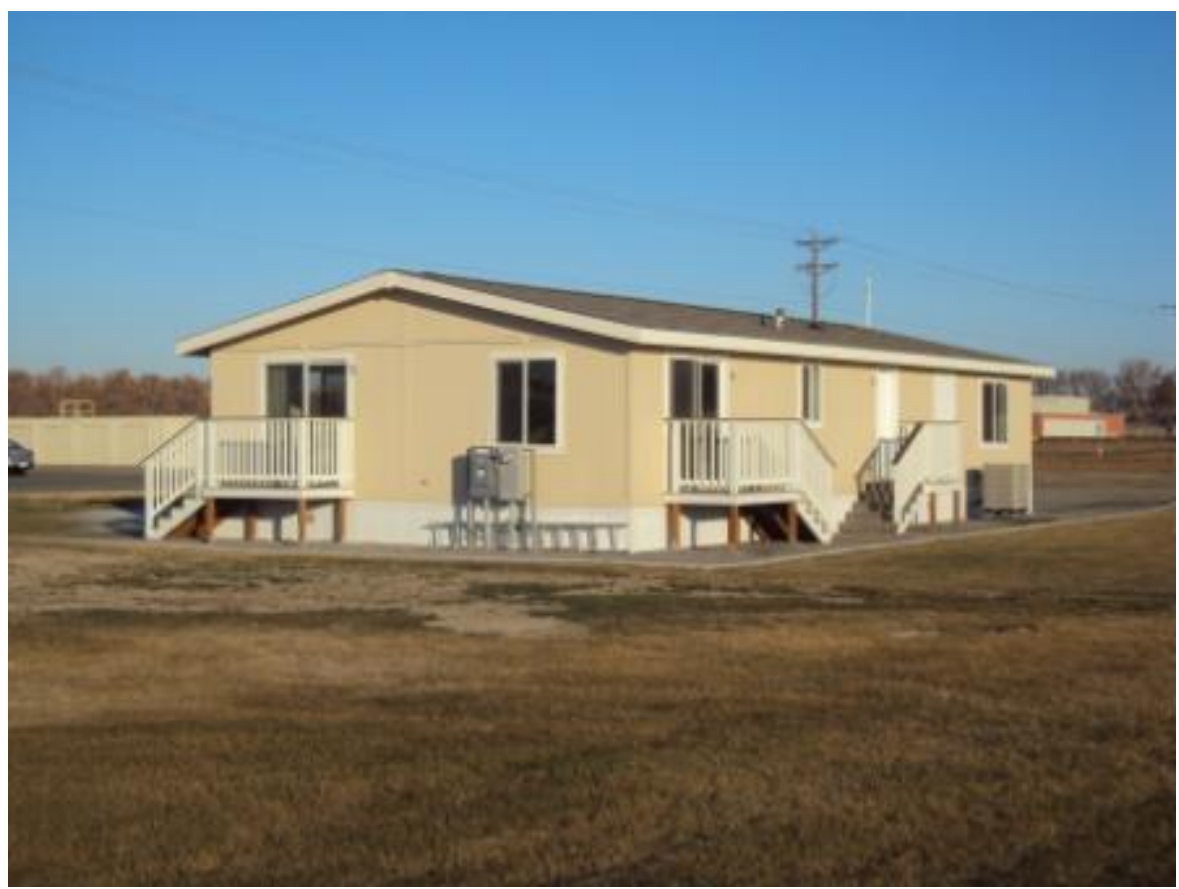

Figure B.2. Lab Home B Home on a Cold and Clear December Afternoon 


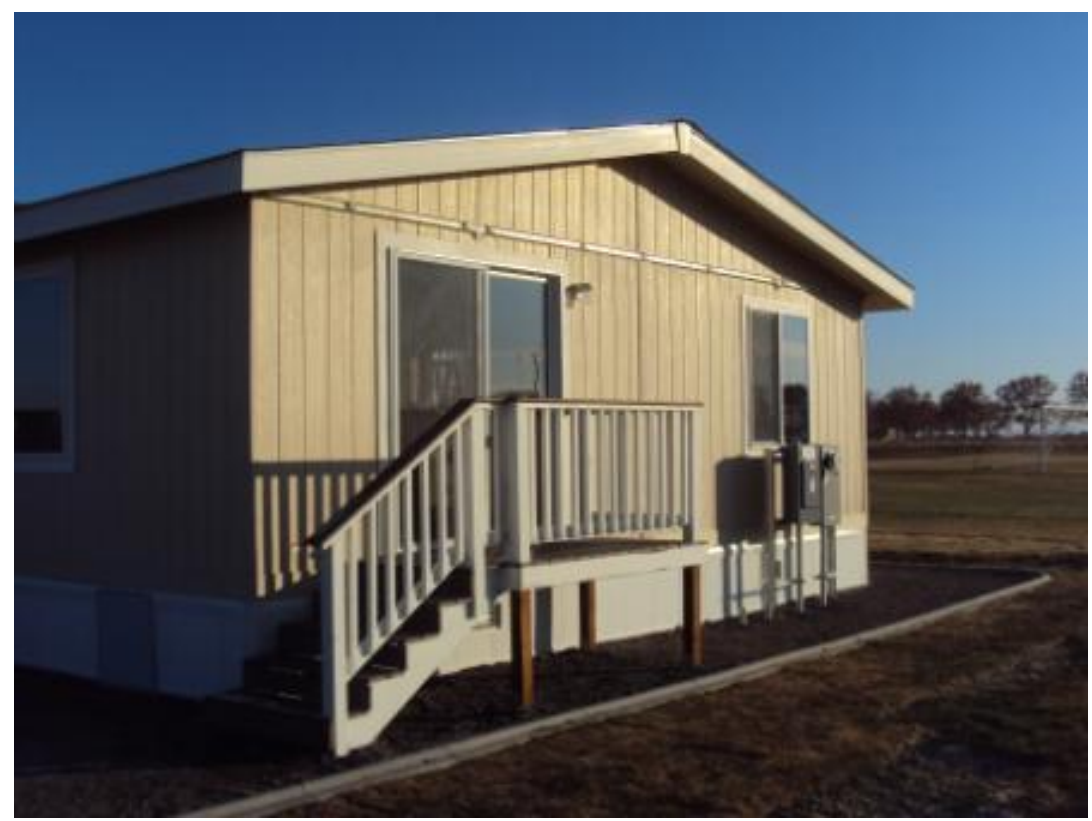

Figure B.3. West End of Lab Home A. Note conduit tray (above slider and window) to hold exterior thermocouple wiring.

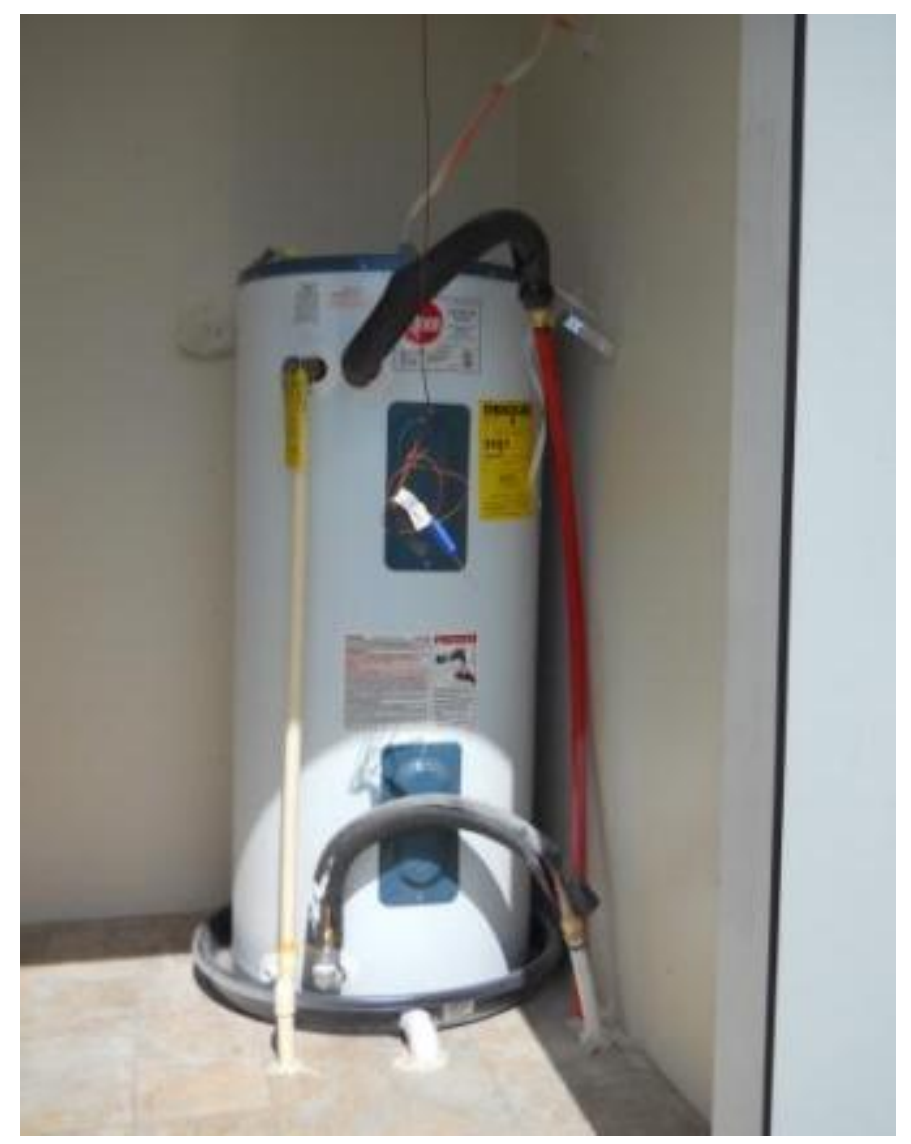

Figure B.4. Electric Water Heater As Installed in Exterior Accessed (insulated) Closet 


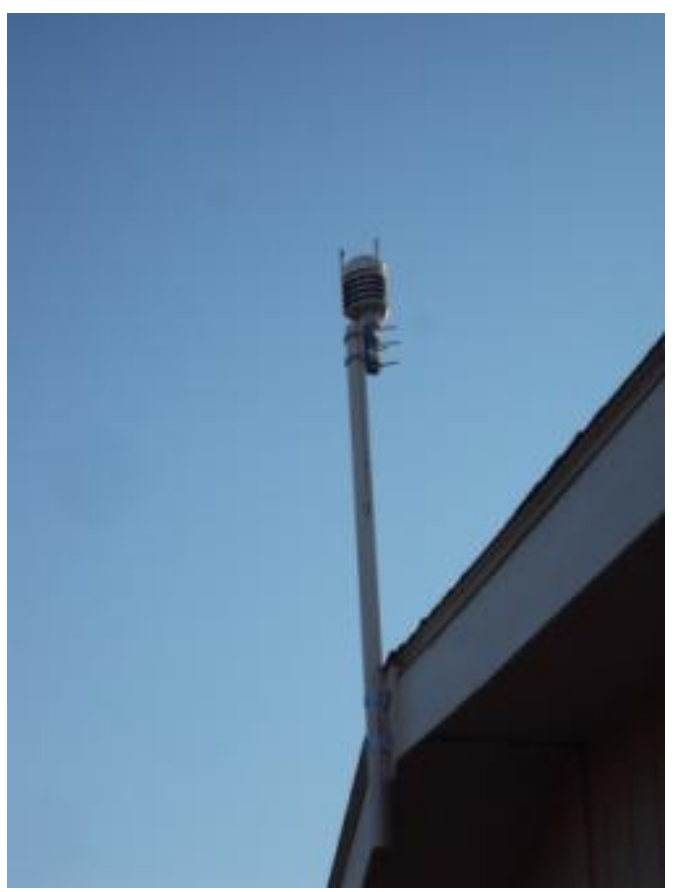

Figure B.5. Weather Station on East End of Lab Home B

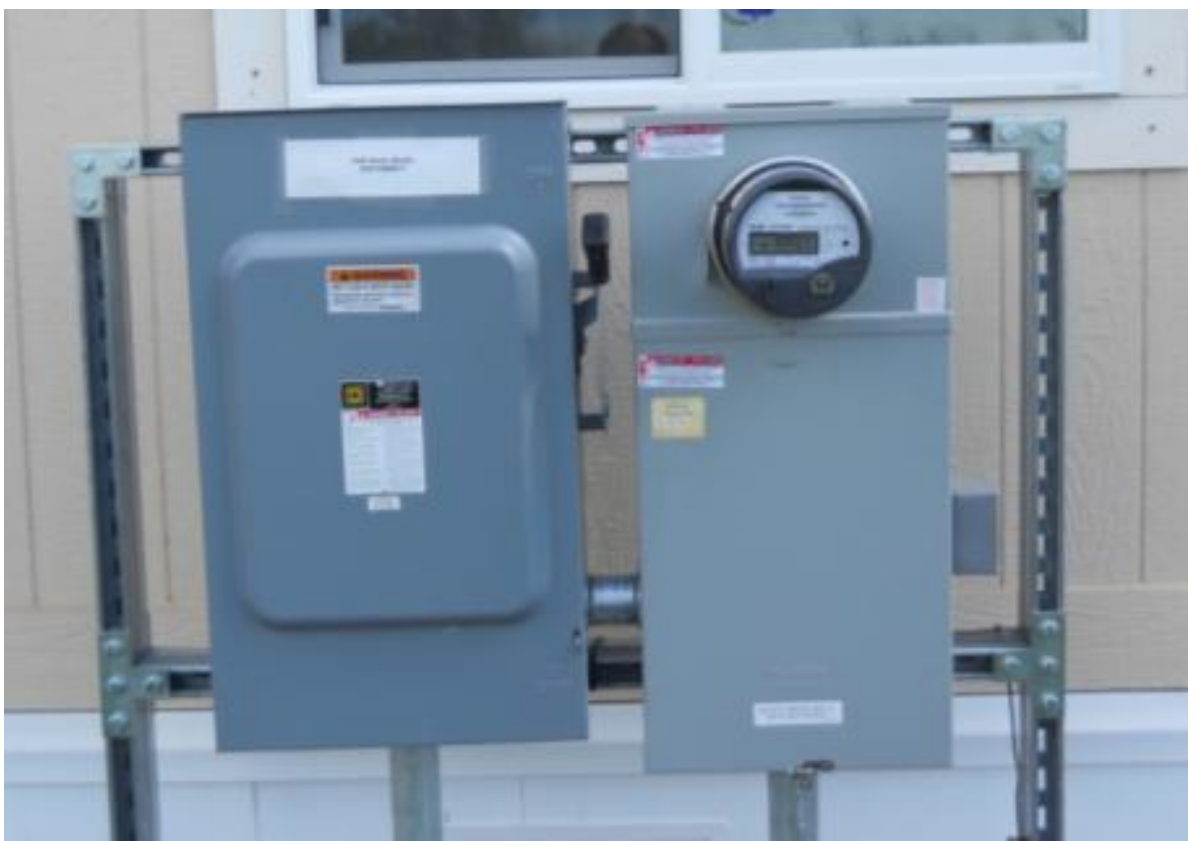

Figure B.6. Electrical Service Connection Complete With Disconnect and Utility-Provided Smart Meter 


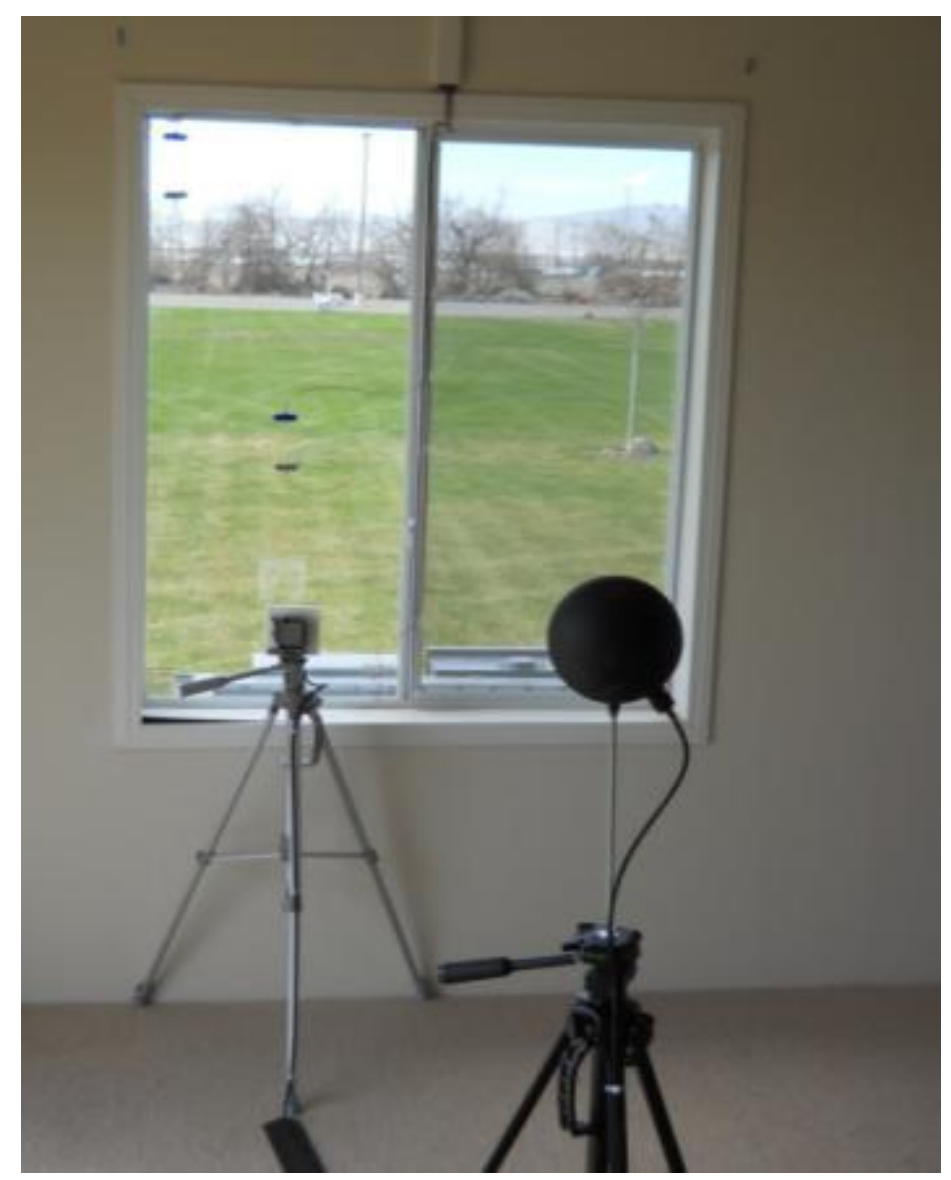

Figure B.7. Window on West End of Home B. Mean radiant temperature sensor (tripod mount in foreground), pryranometer (tripod mount next to window), and surface-mounted thermocouples attached to interior/exterior of window

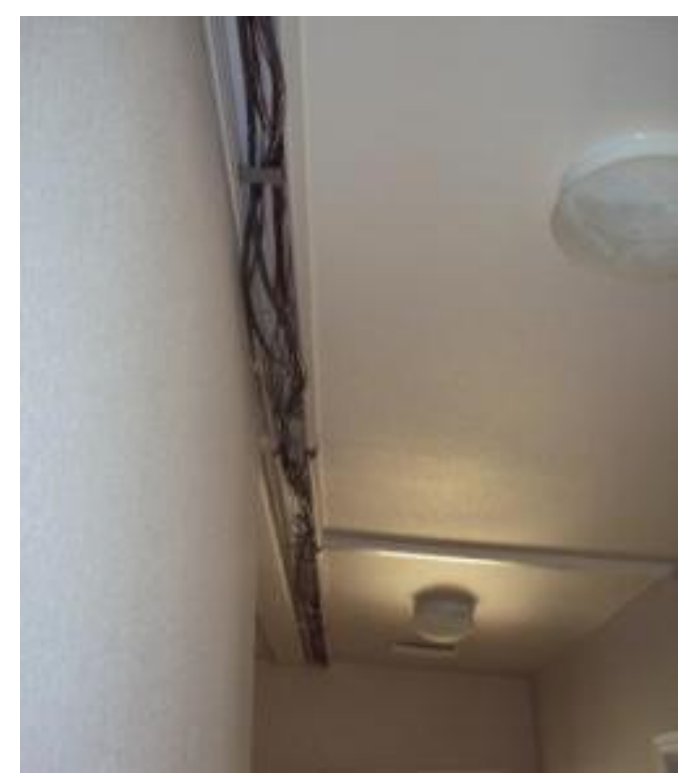

Figure B.8. Conduit Race (uncovered) in Hallway Showing Thermocouple and Control Wiring 


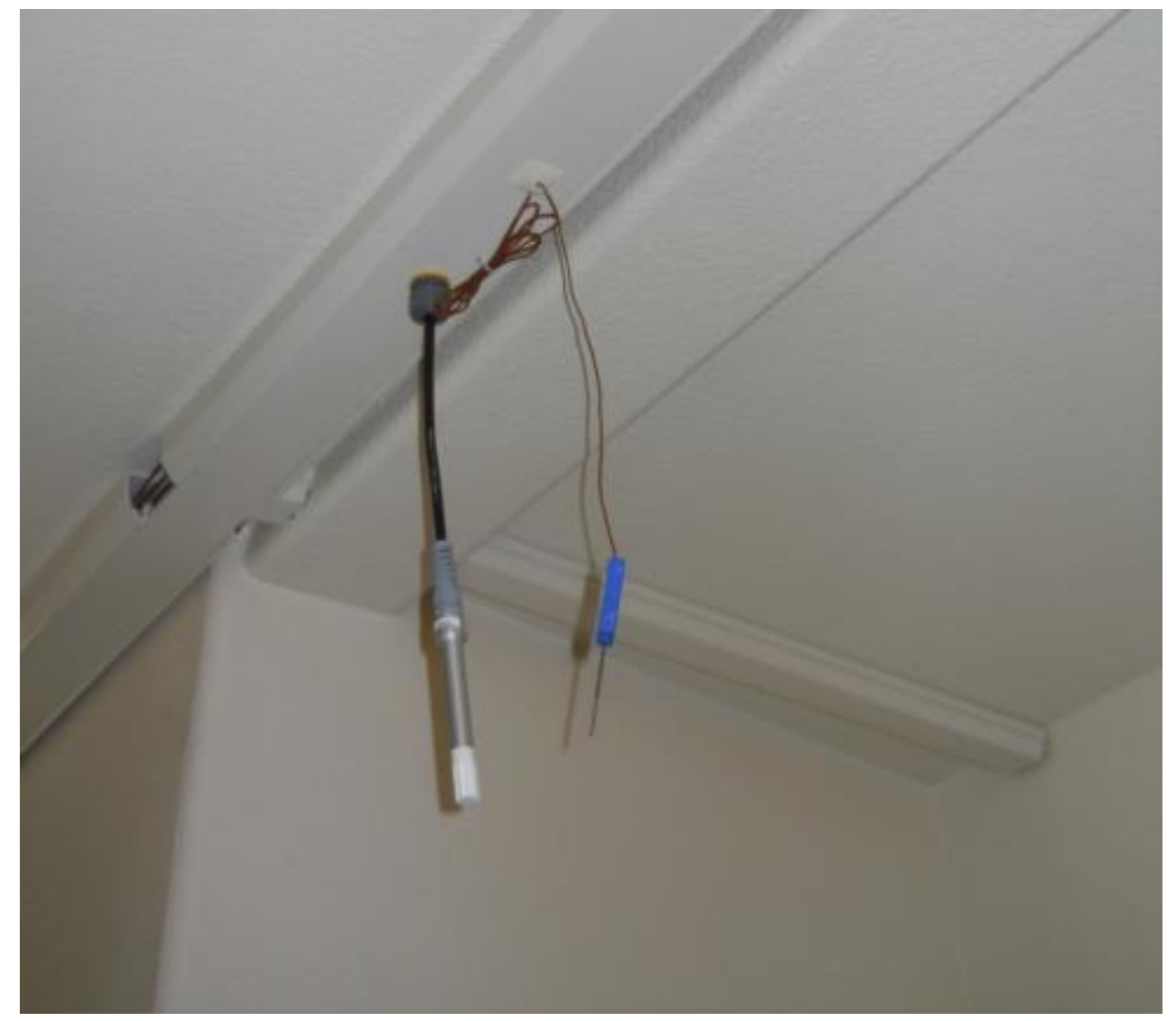

Figure B.9. Ceiling Mounted Humidity Sensor (device on left) and Thermocouple as Installed in Main Living Area 


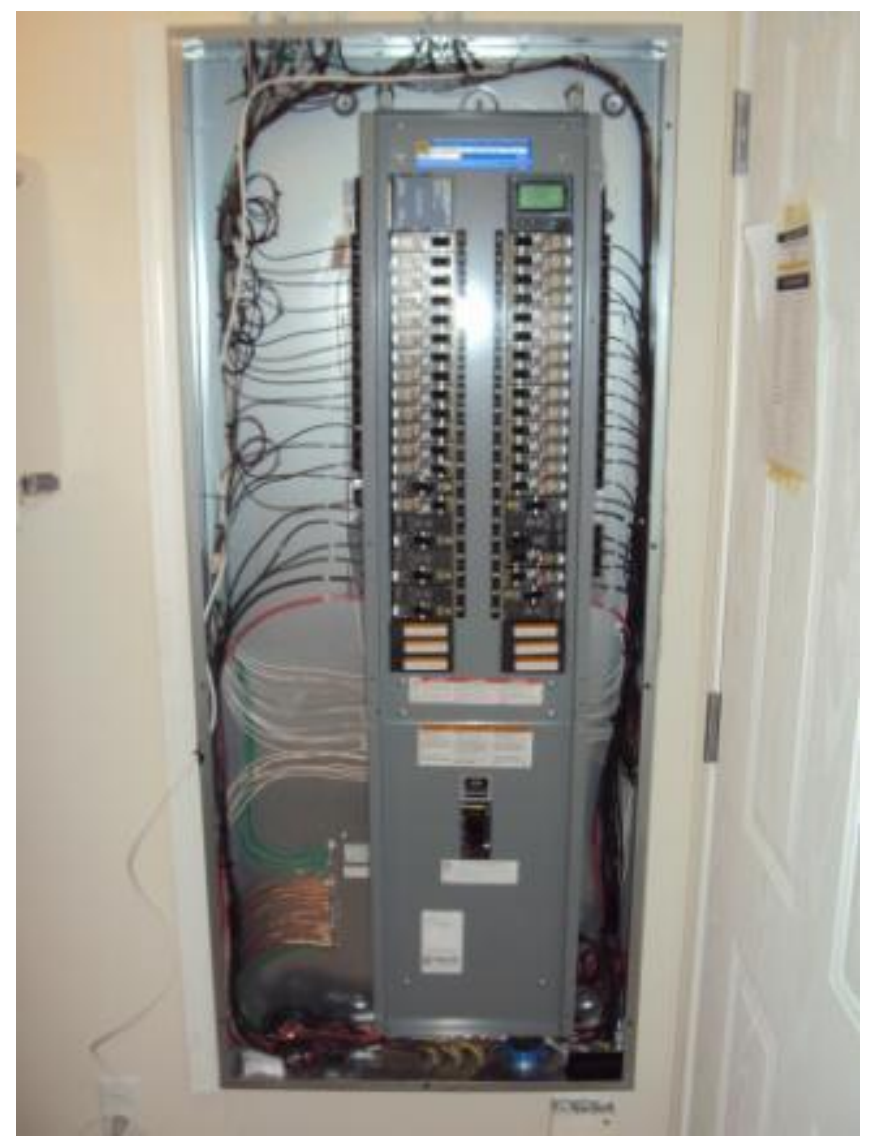

Figure B.10. Full 42-Breaker Controllable Commercial Lighting Panel as Installed. Note loops of conductor on left to achieve higher sensitivity on amperage readings.

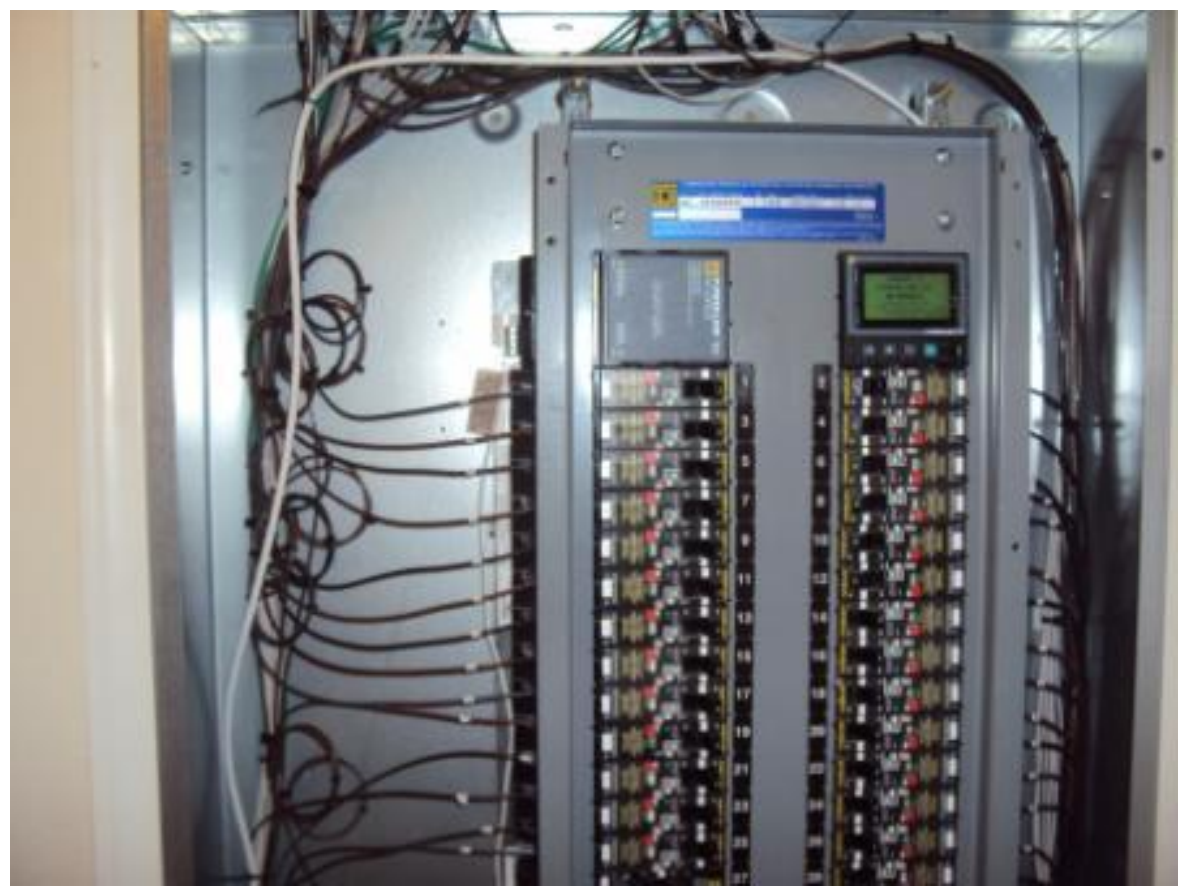

Figure B.11. Close-Up of Panel and Conductor Loops 


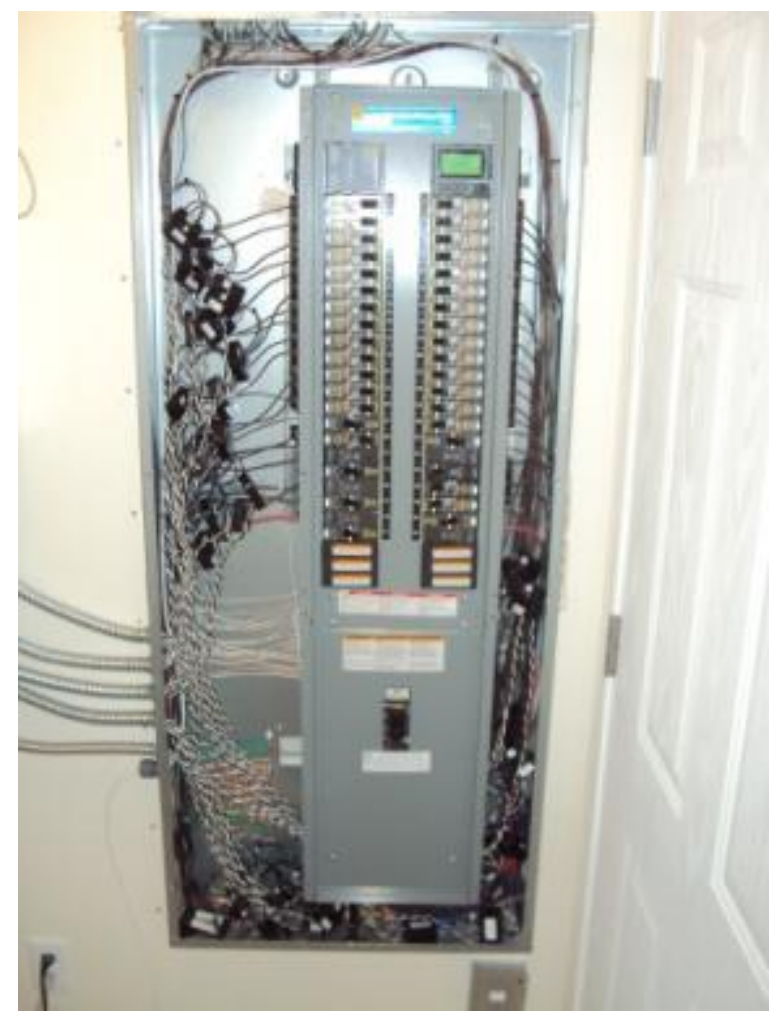

Figure B.12. Fully Instrumented Breaker Panel. Note every breaker/conductor is instrumented with current transformers (CTs - black devices).

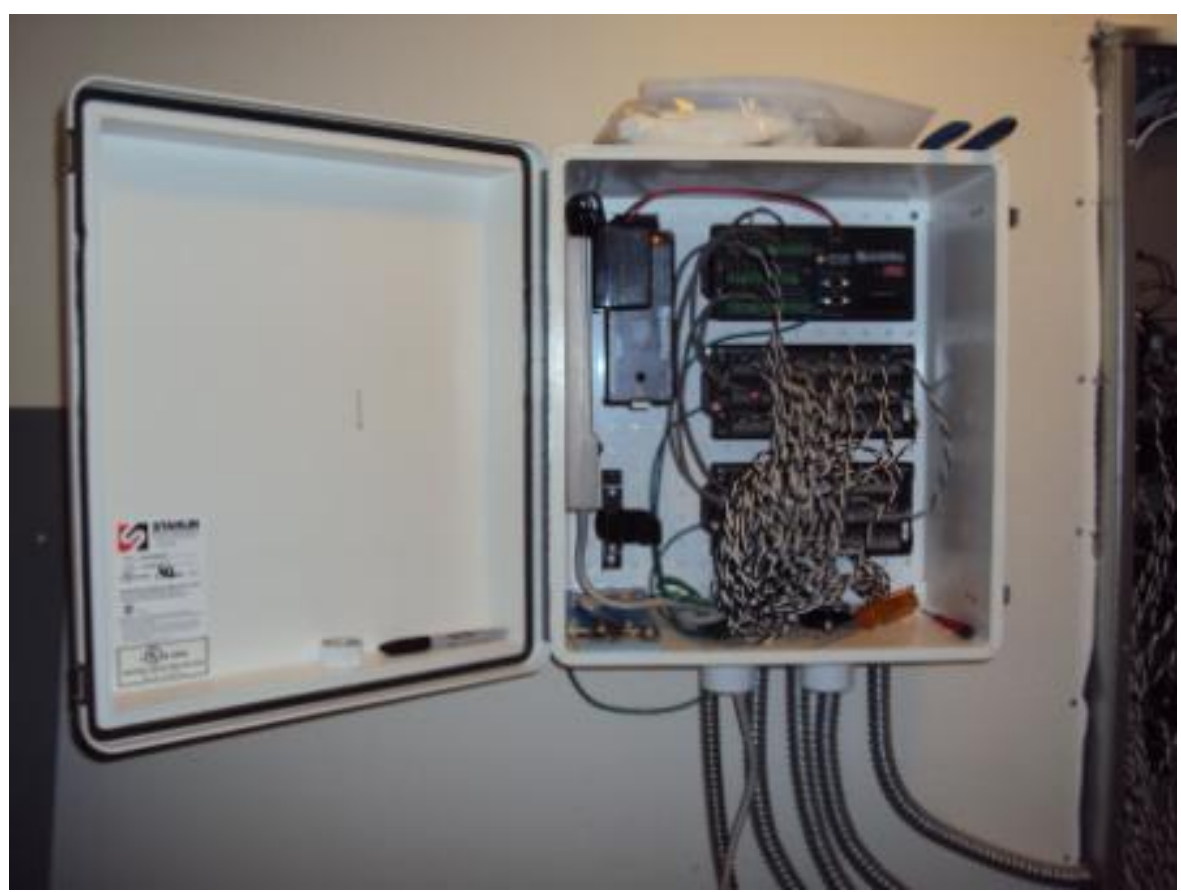

Figure B.13. Campbell Scientific Data Logger Use for Power Measurements. Note CT leads to logger terminals used for true power calculation. 


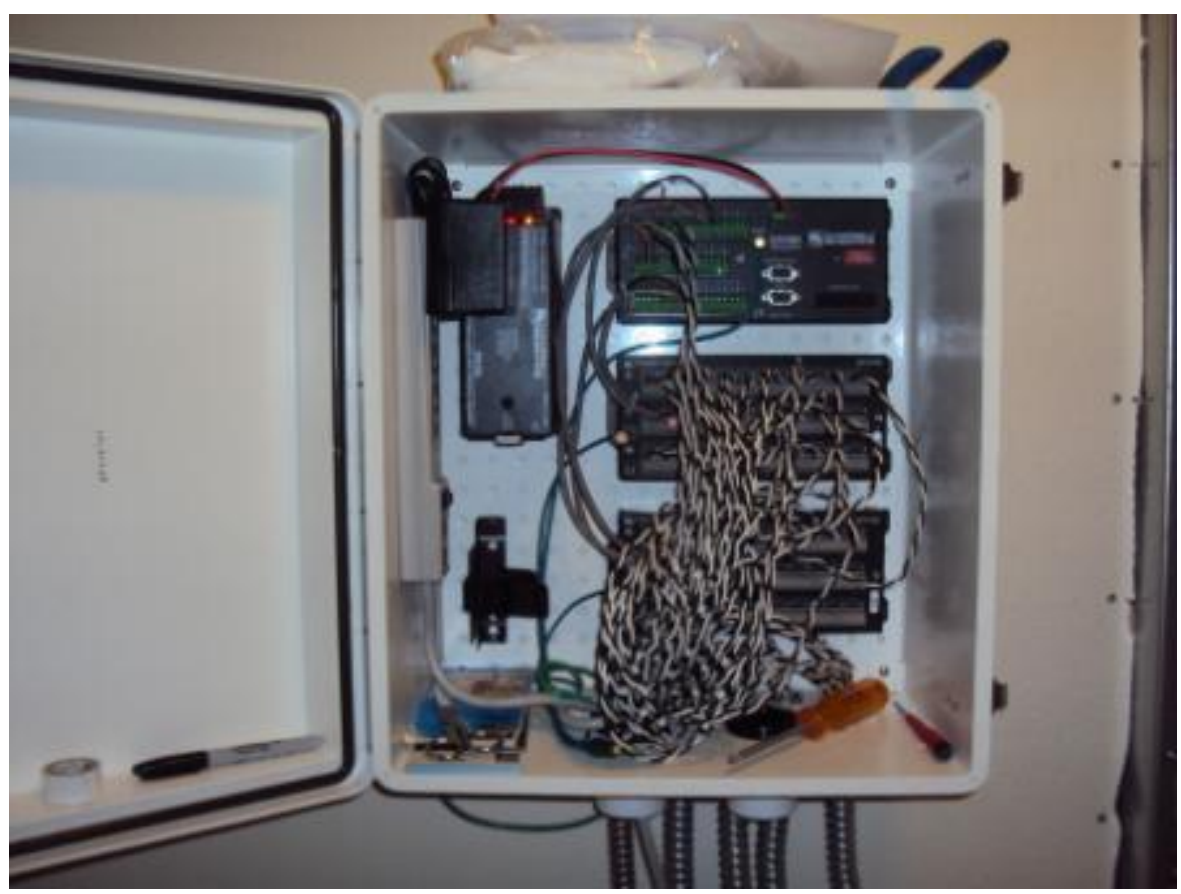

Figure B.14. Close-Up of Campbell Data Logger and CT Terminations

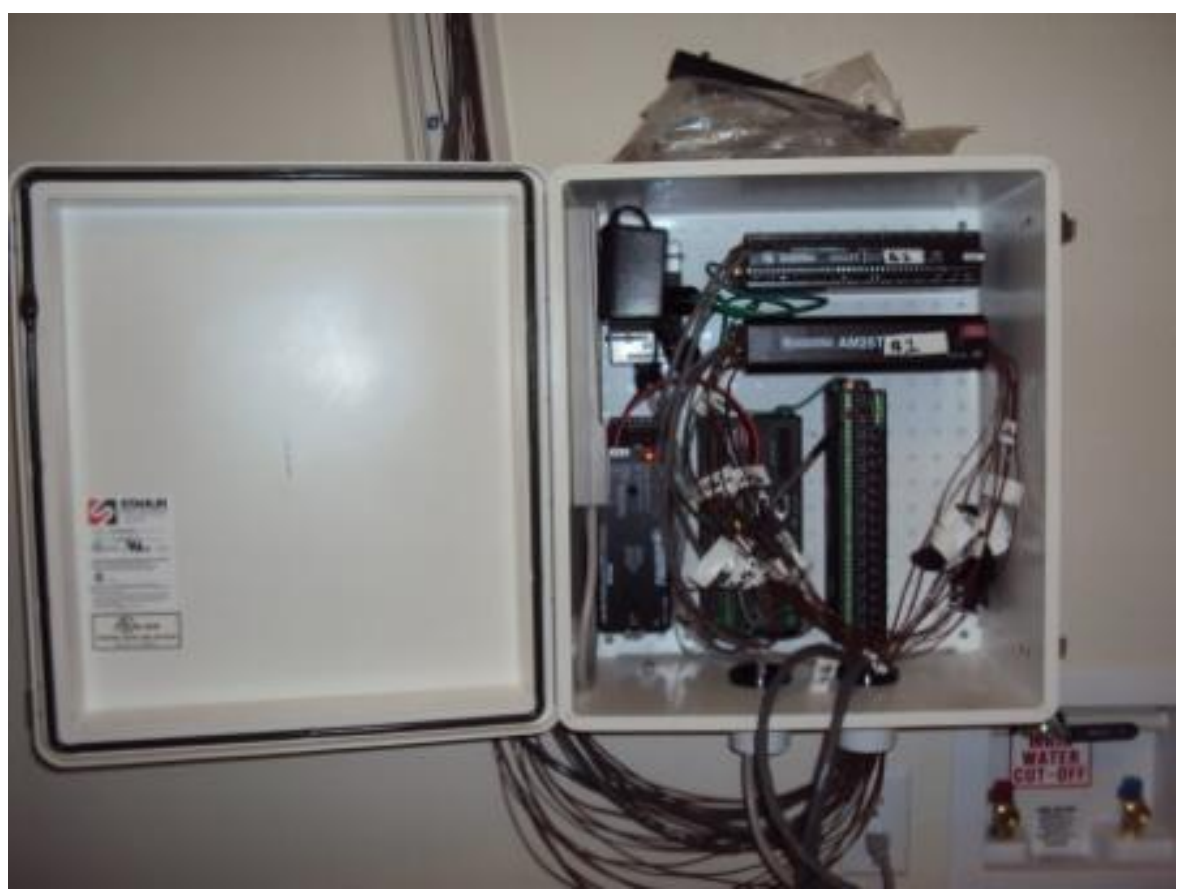

Figure B.15. Campbell Scientific Data Logger Use for Temperature and Humidity Measurements, and for Control Functions 


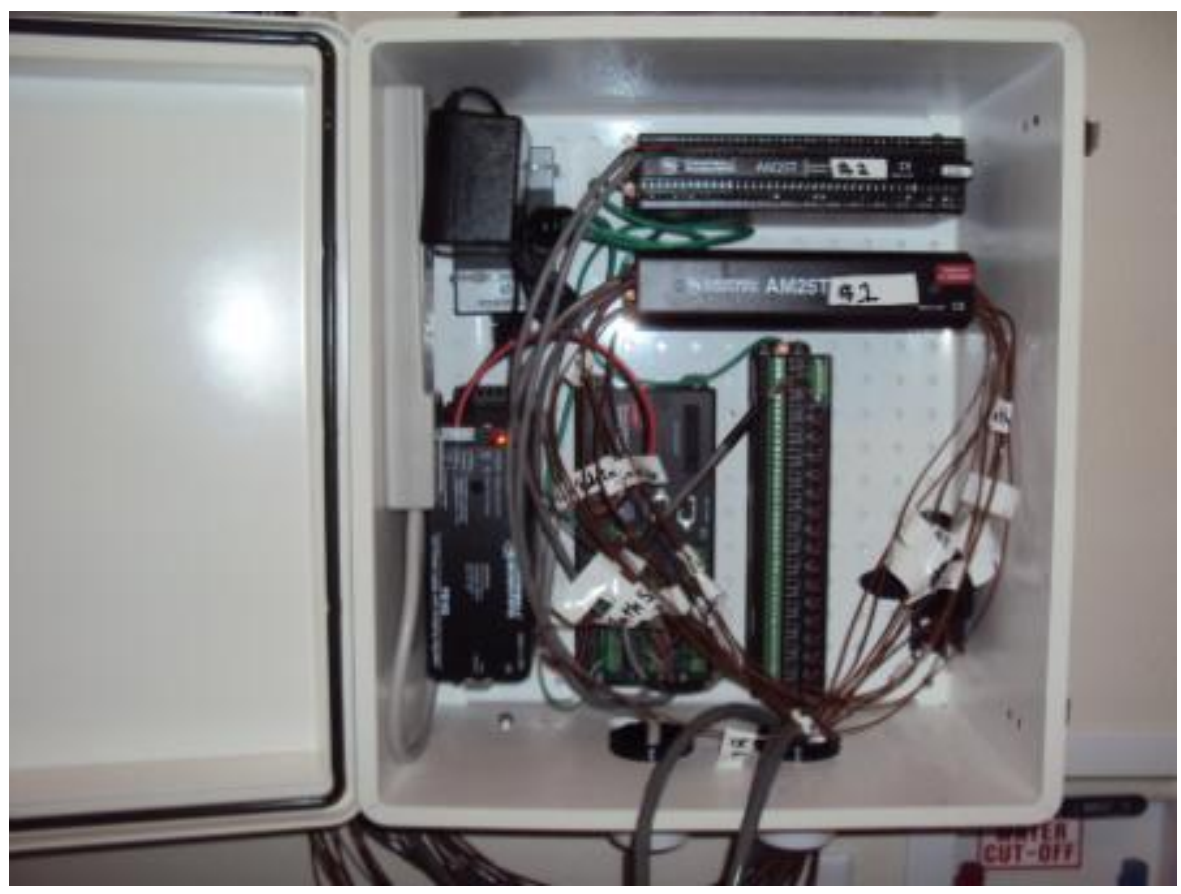

Figure B.16. Close-Up of Campbell Data Logger and Thermocouple and Control Wire Terminations 



\section{Appendix C}

\section{Occupancy Simulation Schedule}





\section{Appendix C}

\section{Occupancy Simulation Schedule}

Table 9.1 and Table 9.2 present the load simulation and occupancy schedules for the Lab Homes highly insulating windows demonstration. The bases for occupancy simulation were data and analysis developed in previous residential simulation activities (NREL 2010, ORNL 2010). The occupancy simulations and schedules developed here were derived specific to the home style, square footage, and an assumed occupancy of three adults. The per-person sensible heat generation and occupancy profiles were mapped from previous studies to be applicable to this demonstration.

Occupancy and connected-lighting heat generation were simulated by activating portable and fixed lighting fixtures throughout the home. Each bedroom was equipped with a table lamp to simulate human occupancy; occupancy and lighting loads in other areas of the home were simulated via fixed lighting. In both cases (portable and fixed lighting), schedules were programmed into the electrical panel for run times commensurate with identified use profiles. The profiles enabled sought to match daily total occupancy characteristics with less emphasis on defined hourly simulation.

This set of experiments focused on sensible loads only; latent loads and their generation will be simulated in the next set of experiments detailing the cooling season implications of the high-performance windows.

Table 9.1. Daily Occupancy Schedules and Simulated Load

\begin{tabular}{cccl}
\hline Hours of Day & Simulation Strategy & Simulated Watts & \multicolumn{1}{c}{ Load Locations } \\
\hline 1 a.m. -7 a.m. & 3 60-Watt table lamps & 180 & Lamps in master and each bedroom \\
7 a.m. -8 a.m. & 3 60-Watt table lamps & 180 & Lamps in master and each bedroom \\
8 a.m. -9 a.m. & 160 -Watt table lamp & 60 & Lamp in master \\
9 a.m. -4 p.m. & 160 -Watt table lamp & 60 & Lamp in master \\
4 p.m. -5 p.m. & 160 -Watt table lamp & 60 & Lamp in master \\
5 p.m. - 6 p.m. & 2 60-Watt table lamps & 120 & Lamps in master and East bedroom \\
6 p.m. - 9 p.m. & 360 -Watt table lamps & 180 & Lamps in master and each bedroom \\
9 p.m. -12 p.m. & 360 -Watt table lamps & 180 & Lamps in master and each bedroom \\
Wattage Totals & & 3,180 & \\
\hline
\end{tabular}


Table 9.2. Daily Lighting Schedules and Simulated Load

\begin{tabular}{|c|c|c|c|}
\hline Hours of Day & Simulation Strategy & $\begin{array}{l}\text { Simulated } \\
\text { Watts }\end{array}$ & Load Locations \\
\hline 1 a.m. -4 a.m. & Ceiling fixture, 1 60-Watt lamp & 60 & Hall fixture \\
\hline 4 a.m. -5 a.m. & Ceiling fixture, 2 60-Watt lamps & 120 & Entry and living room fixtures \\
\hline 5 a.m. -6 a.m. & 2 ceiling fixtures, 260 -Watt lamps each & 240 & Kitchen fixtures \\
\hline 6 a.m. -7 a.m. & 2 ceiling fixtures, 2 60-Watt lamps each & 240 & Kitchen fixtures \\
\hline 7 a.m. -8 a.m. & 2 ceiling fixtures, 2 60-Watt lamps each & 240 & Kitchen fixtures \\
\hline 8 a.m. -9 a.m. & Ceiling fixture, 260 -Watt lamps & 120 & Kitchen fixtures \\
\hline 9 a.m. -3 p.m. & Ceiling fixture, 1 60-Watt lamp & 60 & Hall fixture \\
\hline 3 p.m. -4 p.m. & Ceiling fixture, 260 -Watt lamps & 120 & Entry and living room fixtures \\
\hline 4 p.m. -5 p.m. & 2 ceiling fixtures, 260 -Watt lamps each & 240 & Kitchen fixtures \\
\hline 5 p.m. -6 p.m. & 3 ceiling fixtures, 2 60-Watt lamps each & 360 & Kitchen and entry fixtures \\
\hline 6 p.m. -7 p.m. & 5 ceiling fixtures, 260 -Watt lamps each & 600 & $\begin{array}{l}\text { Master, kitchen, and } 2 \text { bedroom } \\
\text { fixtures }\end{array}$ \\
\hline 7 p.m. -8 p.m. & 5 ceiling fixtures, 260 -Watt lamps each & 600 & $\begin{array}{l}\text { Master, kitchen, and } 2 \text { bedroom } \\
\text { fixtures }\end{array}$ \\
\hline 8 p.m. -9 p.m. & 5 ceiling fixtures, 2 60-Watt lamps each & 600 & $\begin{array}{l}\text { Master, kitchen, and } 2 \text { bedroom } \\
\text { fixtures }\end{array}$ \\
\hline 9 p.m. -10 p.m. & $\begin{array}{l}4 \text { ceiling fixtures, } 1 \text { and } 260 \text {-Watt lamps } \\
\text { each }\end{array}$ & 420 & Master, kitchen and hall fixtures \\
\hline 10 p.m. -11 p.m. & 2 ceiling fixtures, 2 60-Watt lamps each & 240 & Kitchen fixtures \\
\hline 11 p.m. -12 p.m. & Ceiling fixture, 1 60-Watt lamp & 60 & Hall fixture \\
\hline Wattage Totals & & 4,800 & \\
\hline
\end{tabular}

\section{C.1 References}

NREL 2010. Building America House Simulation Protocols. National Renewable Energy Laboratory, Golden, Colorado 2010. TP-550-49426

ORNL 2010. Tennessee Valley Authority's Campbell Creek Energy Efficiency Homes Project: 2010 First Year Performance Report July 1, 2009 - August 31, 2010. Oak Ridge National Laboratory, Oak Ridge, Tennessee, 2010. ORNL/TM-2010/206 


\section{Appendix D}

\section{Electrical Metering Equipment and Sensors}





\section{Appendix D}

\section{Electrical Metering Equipment and Sensors}

\section{D.1 Controllable Electrical Panel}

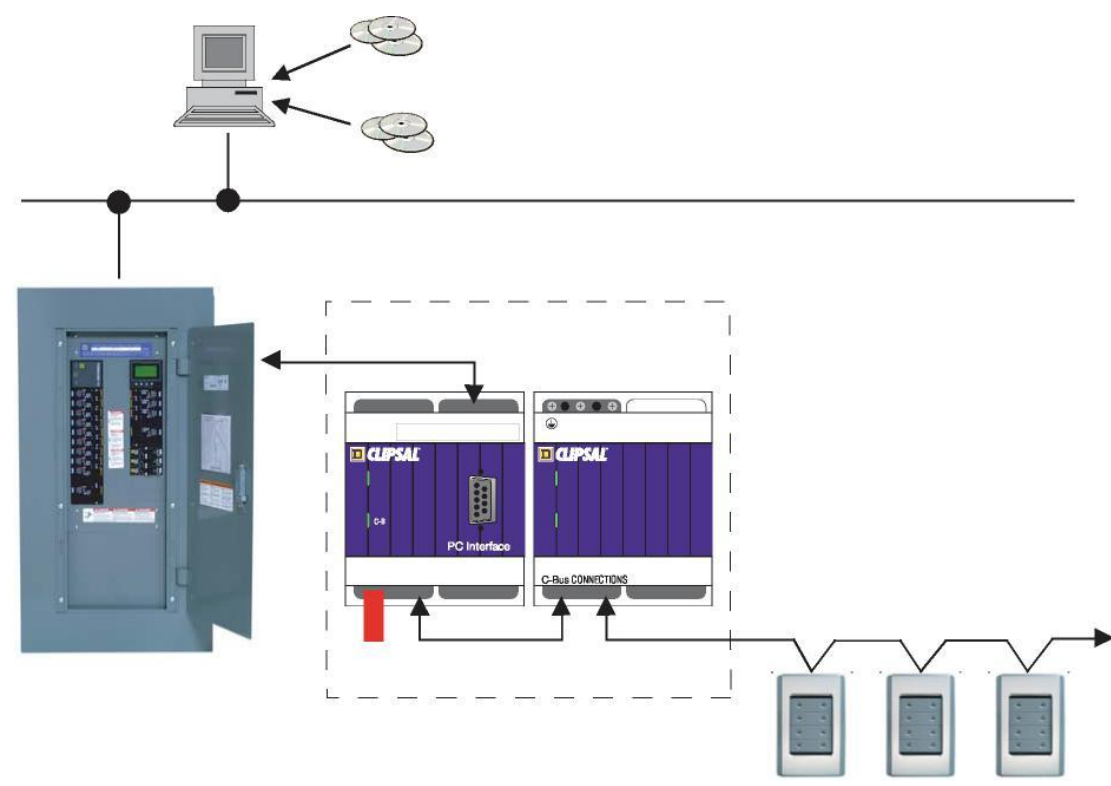

Figure D.1. Square D Power Link Electrical Panel

\section{D.1.1 Schneider Electric/Square D Power Link G3 Control System}

The Square D Powerlink G3 offers programmable and controllable breakers affording the ability to schedule on/off events at 1 minute resolution intervals.

\section{D.1.1.1 Specifications}

Square D Powerlink G3 Controllers accept commands from both dry-contact inputs and serial communications. Typical control devices include low-voltage pushbutton wall switches, occupancy sensors, photo sensors, card access, and building automation systems.

Terminals on the controller allow connection to external control devices. The 500-level controllers can accept up to eight separate control inputs, while the 1000-, 2000-, and 3000-level controllers can accommodate either eight 3-wire or sixteen 2-wire inputs. All controllers provide $24 \mathrm{Vdc}$ control power [National Electric Code (NEC) Class 2] for sensing input contact status. Input types include:

- maintained NO (normally open with or without blink)

- maintained NC (normally closed with or without blink)

- momentary toggle/maintained toggle

- momentary on/momentary OFF

- dual momentary 
Other features and specifications include:

Controller inputs can be configured for status feedback to operate pilot lights or actuate other control equipment. A total maximum current of $60 \mathrm{~mA}$ at $24 \mathrm{Vdc}$ is available to eight status outputs.

Input timers, with settings from 1 second to 18 hours, can also be incorporated into the input configuration to provide timed override control

Combines the control, input, and scheduling features of the other systems with the added benefit of embedded Ethernet connectivity.

Provides control capabilities and communication with a true peer-to-peer (P2P) control network to allow different controllers to share input signals, schedules, and lighting zone states.

Ethernet connectivity reduces network installation costs and enhances reliability by eliminating the need for a dedicated lighting control network.

Ethernet infrastructure can also be more cost effective: it uses commonly available off-the-shelf components rather than manufacturer-specific proprietary components.

Enhanced system reliability: local IT staff can quickly diagnose and resolve most problems associated with the network infrastructure.

Web-enabled benefits include: ability to override zones, change schedules, and view system status from the convenience of a standard web-browser.

\section{D.2 Metering Data Logger}

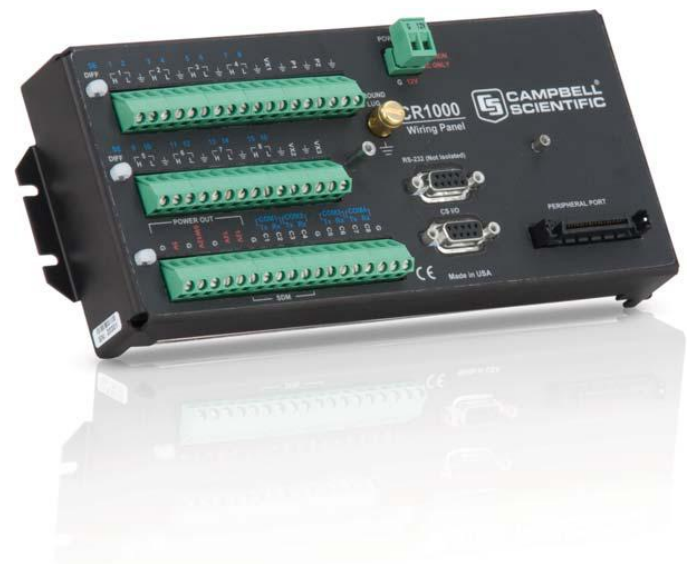

Figure D.2. Campbell CR 1000

\section{D.2.1 Campbell CR 1000 Specifications and Features}

- 4 Mbyte memory

- Program execution rate of up to $100 \mathrm{~Hz}$ 
- CS input/output (I/O) and RS-232 serial ports

- 13-bit analog-to-digital conversions

- 16-bit H8S Renesas Microcontroller with 32-bit internal central processing unit (CPU) architecture

- Temperature-compensated real-time clock

- Background system calibration for accurate measurements over time and temperature changes

- Single DAC used for excitation and measurements to give ratio for metric measurements

- Gas discharge tube protected inputs

- Data values stored in tables with a time stamp and record number

- Battery-backed static random access memory (SRAM) and clock ensuring data, programs, and accurate time are maintained while the CR1000 is disconnected from its main power source

- Serial communications with serial sensors and devices supported via I/O port pairs

- PakBus®, Modbus, Distributed Network Protocol 3 (DNP3), Transmission Control Protocol/Internet Protocol (TCP/IP), FTP, and Simple Mail Transfer Protocol (SMTP) protocols supported

\section{D.2.1.1 Communications Protocols}

The CR1000 supports the PakBus, Modbus, DNP3, TCP/IP, FTP, and SMTP communication protocols. With the PakBus protocol, networks have the distributed routing intelligence to continually evaluate links. Continually evaluating links optimizes delivery times and, in the case of delivery failure, allows automatic switch over to a configured backup route.

The Modbus remote terminal unit (RTU) protocol supports both floating point and long formats. The data logger can act as a slave and/or master.

The DNP3 protocol supports only long data formats. The data loggers are level 2 slave compliant, with some of the operations found in a level 3 implementation.

The TCP/IP, FTP, and SMTP protocols provide TCP/IP functionality when the CR1000 is used in conjunction with an NL115, NL120, or third party serial internet protocol (IP) device.

\section{D.3 Temperature Multiplexer}

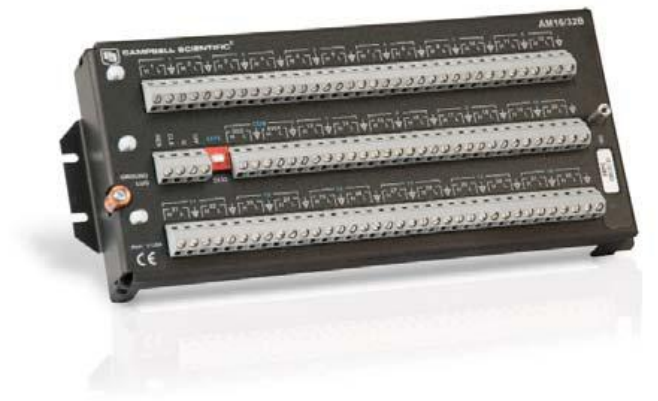

Figure D.3. Campbell AM25T/1632B Multiplexer 
Multiplexers increase the number of sensors that can be measured by a CR1000 by sequentially connecting each sensor to the data logger. Several multiplexers can be controlled by a single CR1000.

Depending on sensor type, the AM16/32B can multiplex 16, 32, or 48 sensors. Up to six AM16/32Bs may be connected to the same datalogger, depending on the number of control ports and analog inputs available.

The AM16/32B either multiplexes 16 groups of four lines (a total of 64 lines) through four common (COM) terminals, or multiplexes 32 groups of two lines (also a total of 64 lines) through two COM terminals. A cable connects the common terminals to datalogger analog inputs, excitation channels, or ground as required by the sensor. The datalogger controls the multiplexer using two control ports or one control port and one excitation channel.

\section{D.3.1 AM16/32B Specifications}

- Power: 9.6 to $16 \mathrm{Vdc}$ (under load)

- Scan Advance: Occurs on the leading edge of the clock pulse transition (from below $1.5 \mathrm{~V}$ to above $3.3 \mathrm{~V}$ )

- Minimum Clock Pulse Width: 1 ms

- Maximum Actuation Time for Relay: $20 \mathrm{~ms}$

- Relay Operation: break before make

- Initial Relay Resistance, Closed: 0.1 Ohm

- Maximum Switching Voltage: $50 \mathrm{Vdc}$. A voltage divider such as the VDIV10:1 may be needed between the AM16/32B and the datalogger to stay within the input limits of the datalogger channel.

- Maximum Switching Current: $500 \mathrm{~mA}$. Switching currents greater than $30 \mathrm{~mA}$ (occasional $50 \mathrm{~mA}$ acceptable) degrade the suitability of that channel for switching low-voltage signals.

- Minimum Contact Life: $10^{7}$ closures

- CE Compliance: EN 61326: 1998 EN 55022: 1998 Class B

- Surge: Complies with IEC 61000-4-5, test level 3 ( \pm 2 kV, 2 ohms coupling impedance)

- CE Compliant

- Weight: $680 \mathrm{~g}(1.5 \mathrm{lb})$ 


\section{D.4 Weather Station}

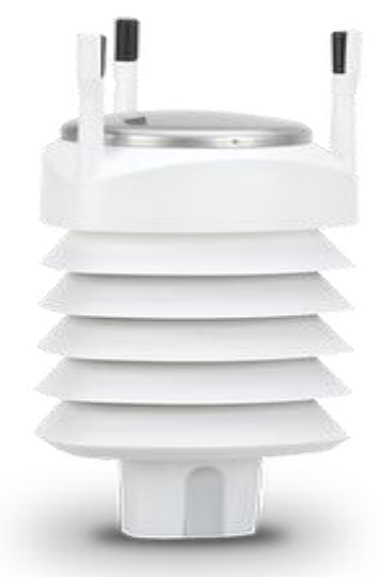

Figure D.4. Campbell WXT520 Weather Station

The WXT520 is a solid-state, all-in-one weather instrument that measures wind speed and direction, precipitation, barometric pressure, temperature, and relative humidity. Its small size makes it ideal for quick, short-term deployments. However, the WXT520 is not intended for weather stations that require research-grade performance.

\section{D.4.1 Specifications}

- Electromagnetic Compatibility (EMC): Complies with EMC standard EN61326-1

- International Electrotechnical Commission (IEC) Standards: IEC 60945/61000-4-4, IEC $60945 / 61000-4-2$

- Input Voltage: 5 to $30 \mathrm{Vdc}$ (below $5.3 \mathrm{~V}$ the measurement performance for high wind speeds may be degraded)

- Typical Current Drain @ 12 Vdc: 0.1 mA [Serial Data Interface at 1200 Baud (SDI-12) standby]; $3 \mathrm{~mA}$ (Default Measuring Intervals)

- Output: SDI-12

- Operating Temperature: $-52^{\circ}$ to $+60^{\circ} \mathrm{C}$

- Storage Temperature: $-60^{\circ}$ to $+70^{\circ} \mathrm{C}$

- Operating Relative Humidity: 0 to $100 \%$ RH

- Height: $23.8 \mathrm{~cm}$ (9.38 in)

- Diameter: $11.5 \mathrm{~cm}$ (4.52 in)

- Weight: $650 \mathrm{~g}(1.43 \mathrm{lb})$

\section{D.4.2 Air Temperature}

- Measurement Range: $-52^{\circ}$ to $+60^{\circ} \mathrm{C}$ 
- Accuracy: $\pm 0.3^{\circ} \mathrm{C} @+20^{\circ} \mathrm{C}$

- Output Resolution: $0.1^{\circ} \mathrm{C}$

\section{D.4.3 Barometric Pressure}

- Measurement Range: 600 to $1100 \mathrm{hPa}$

- Accuracy: $\pm 0.5 \mathrm{hPa} @ 0^{\circ}$ to $30^{\circ} \mathrm{C}$;

$\pm 1 \mathrm{hPa} @-52^{\circ}$ to $+60^{\circ} \mathrm{C}$

- Output Resolution: $0.1 \mathrm{hPa}$

\section{D.4.4 Relative Humidity}

- Measurement Range: 0 to $100 \%$ RH

- Accuracy: $\pm 3 \%$ RH @ 0 to 90\% RH; $\pm 5 \% \mathrm{RH} @ 90$ to $100 \% \mathrm{RH}$

- Output Resolution: 0.1\% RH

\section{D.4.5 Wind Speed}

- Measurement Range:

0 to $60 \mathrm{~m} \mathrm{~s}^{-1}$

- Response Time: $0.25 \mathrm{~s}$

- Accuracy: $\pm 0.3 \mathrm{~m} \mathrm{~s}^{-1}$ or $\pm 3 \%$, whichever is greater $\left(0\right.$ to $\left.35 \mathrm{~m} \mathrm{~s}^{-1}\right)$; $\pm 5 \%\left(36\right.$ to $\left.60 \mathrm{~m} \mathrm{~s}^{-1}\right)$

\section{D.4.6 Wind Direction}

- Measurement Range: $0^{\circ}$ to $360^{\circ}$

- Response Time: $0.25 \mathrm{~s}$

- Accuracy: $\pm 3^{\circ}$

- Output Resolution: $1^{\circ}$

\section{D.4.7 Precipitation}

- Rainfall Measurement: cumulative accumulation after latest automatic or manual reset

- Collecting Area: $60 \mathrm{~cm}^{2}$

- Output Resolution: $0.01 \mathrm{~mm}(0.001 \mathrm{in})$

- Field Accuracy for Daily Accumulation: better than 5\% (weather dependent; does not include possible wind induced error) 
- Rain Duration: Counting each 10-s increment whenever droplet detected

- Rain Intensity: 1-min. running average in 10-s steps

- Rain Intensity Range: 0 to $200 \mathrm{~mm} \mathrm{hr}^{-1}$ (broader range possible with reduced accuracy)

\section{D.5 Pyranometer}

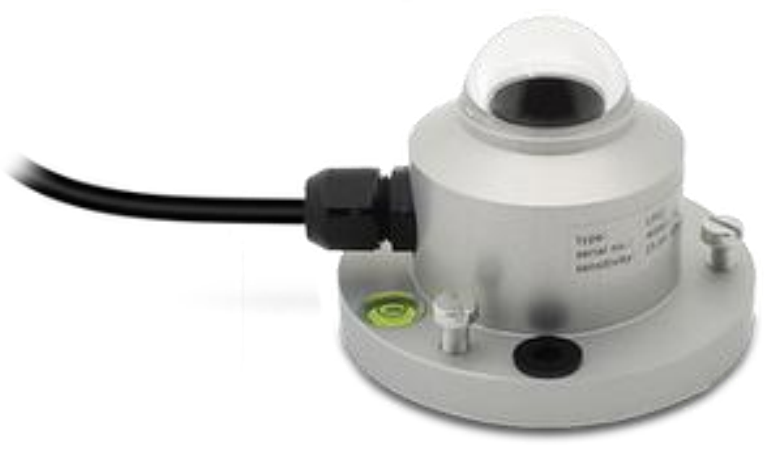

Figure D.5. Campbell Scientific LP02 Blackened Thermopile Pyranometer

\section{D.5.1 Technical Description}

The LP02 measures solar radiation with a high-quality blackened thermopile protected by a dome. The blackened thermopile provides a flat spectral response for the full solar spectrum range, which enables the LP02 to be used under plant canopies or lamps, when the sky is cloudy, and for reflected radiation measurements.

The LP02 includes a bubble level, three adjusting screws, and a cable gland. The bubble level and adjusting screws allow the sensor to be leveled without using a leveling base. The gland facilitates cable replacement.

The LP02 produces a millivolt signal that is measured directly by a Campbell Scientific datalogger.

Two LP02 pyranometers can be mounted back-to-back to make a low-cost albedometer; contact Campbell Scientific for more information.

\section{D.5.2 LP02-L Specifications}

- Light Spectrum Waveband: 305 to $2800 \mathrm{~nm}$

- Maximum Irradiance: $2000 \mathrm{~W} / \mathrm{m}^{2}$

- Sensitivity: $15 \mu \mathrm{V} / \mathrm{W} / \mathrm{m}^{2}$

- Operating Temperature: $-40^{\circ}$ to $+80^{\circ} \mathrm{C}$

- Temperature Dependence: $<0.15 \% /{ }^{\circ} \mathrm{C}$

- International Standards Organization (ISO) Classification: Second Class

- Width: $7.8 \mathrm{~cm}$ (3.1 in.) 
- Height: $5.9 \mathrm{~cm}(2.3$ in.)

- Dome Diameter: $3.0 \mathrm{~cm}$ (1.2 in.)

- Weight with $15 \mathrm{ft}$ cable: $363 \mathrm{~g}$ (0.8 lb)

\section{D.6 Mean Radiant Temperature (Black Globe) Sensor}

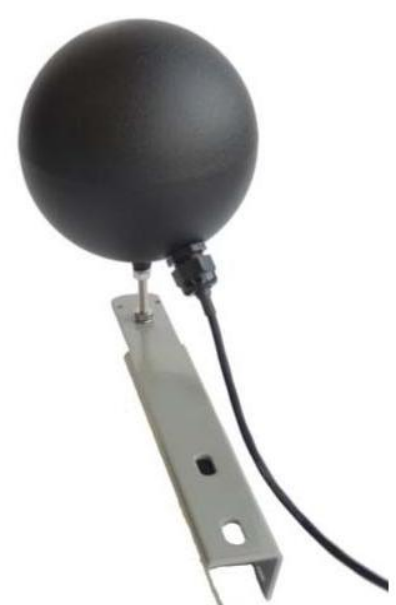

Figure D.6. Campbell Scientific Black Globe Temperature Sensor

The Black Globe temperature sensor uses a thermistor inside a 6" hollow black copper sphere to measure radiant temperature.

\section{D.6.1 Specifications:}

- Temperature measurement range: $\quad-5^{\circ}$ to $+95^{\circ} \mathrm{C}$

- Temperature Survival Range: $\quad-50^{\circ}$ to $+100^{\circ} \mathrm{C}$

- Thermistor Interchangeability Error: Typically $< \pm 0.2^{\circ} \mathrm{C}$ over $0^{\circ} \mathrm{C}$ to $70^{\circ} \mathrm{C}$ and $\pm 0.3 @ 95^{\circ} \mathrm{C}$

- Polynomial Linearization Error: $\quad \pm 0.5^{\circ} \mathrm{C}$ over $-7^{\circ} \mathrm{C}$ to $+90^{\circ} \mathrm{C}$ 


\section{D.7 Thermocouples}

D.7.1 Space Temperature: Omega TMQSS-062U-2 Copper-Constantan (Type T) Thermocouple

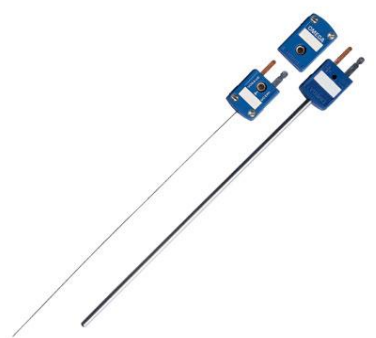

Figure D.7. Space Temperature: Omega TMQSS-062U-2 Copper-Constantan (Type T) Thermocouple

\section{D.7.1.1 Specifications:}

- Maximum temperature range:

- Thermocouple Grade

○ $\quad-328$ to $662^{\circ} \mathrm{F}$

○ $\quad-200$ to $350^{\circ} \mathrm{C}$

- Extension Grade

○ $\quad-76$ to $212^{\circ} \mathrm{F}$

- -60 to $100^{\circ} \mathrm{C}$

- Limits of error

○ Standard: $1.0^{\circ} \mathrm{C}$ or $0.75 \%$ above $0^{\circ} \mathrm{C}, 1.0^{\circ} \mathrm{C}$ or $1.5 \%$ Below $0^{\circ} \mathrm{C}$

- Special: $0.5^{\circ} \mathrm{C}$ or $0.4 \%$

\section{D.7.2 Surface Temperature: Omega S2C-T-120 Copper-Constantan (Type T) Thermocouple}

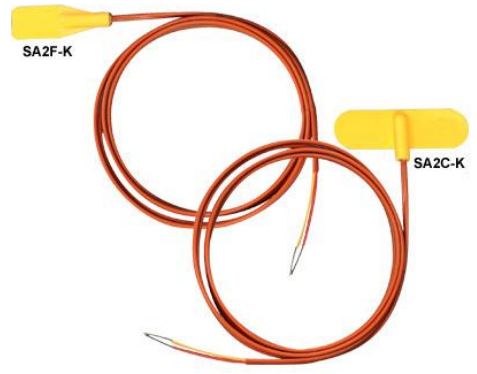

Figure D.8. Surface Temperature: Omega S2C-T-120 Copper-Constantan (Type T) Thermocouple 


\section{D.7.2.1 Specifications:}

- Ultra-Slim Silicone Rubber for Maximum Flexibility

- Self-Adhesive Foil Backing for Faster Response Time

- Two Styles Available for Flat or Curved Surfaces

- Resistant to a Variety of Chemicals and Oils

- Temperature Range: -50 to $200^{\circ} \mathrm{C}\left(-58\right.$ to $\left.392^{\circ} \mathrm{F}\right)$

- Available in J, K, T and E-Color Coded for Instant Thermocouple Recognition

- 24 American wire gauge (AWG) Stranded Thermocouple-Grade Lead Wire

- Limits of error

- Standard: $1.0^{\circ} \mathrm{C}$ or $0.75 \%$ above $0^{\circ} \mathrm{C} 1.0^{\circ} \mathrm{C}$ or $1.5 \%$ Below $0^{\circ} \mathrm{C}$

- Special: $0.5^{\circ} \mathrm{C}$ or $0.4 \%$

\section{D.8 Relative Humidity Sensors}

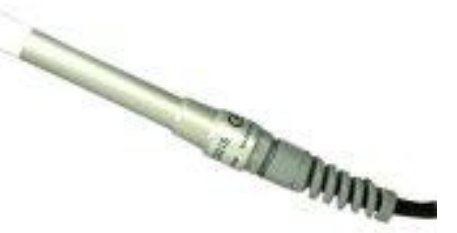

Figure D.9. Campbell Scientific Relative Humidity Sensor

\section{D.8.1 Specifications:}

Campbell Scientific Europe's CS215 temp \& RH sensor uses a Swiss manufactured digital humidity and temperature element which provides excellent measurement accuracy and reliability.

- Relative Humidity

- Measurement Range: 0 to $100 \%$ RH $\left(-20^{\circ}\right.$ to $\left.+60^{\circ} \mathrm{C}\right)$

- Accuracy (at $\left.25^{\circ} \mathrm{C}\right): \pm 2 \%$ (10-90\% range), $\pm 4 \%$ (0-100\% range)

- Temperature

- Measurement Range: $-40 \mathrm{C}^{\circ}$ to $+70^{\circ} \mathrm{C}$

- Accuracy: $\pm 0.4^{\circ} \mathrm{C}\left(+5^{\circ}\right.$ to $\left.+40^{\circ} \mathrm{C}\right), \pm 0.9^{\circ} \mathrm{C}\left(-40^{\circ} \mathrm{C}\right.$ to $\left.+70^{\circ} \mathrm{C}\right)$

- General

- Weight: $150 \mathrm{~g} \mathrm{(w/3} \mathrm{m} \mathrm{cable);} 5.3 \mathrm{oz}$ (w/10 ft cable)

- Diameter: $1.2 \mathrm{~cm}\left(0.5^{\prime \prime}\right)$ at sensor tip, $1.8 \mathrm{~cm}(0.7 ")$ at cable end 
Appendix E

Windows Retrofit Description and Photos 



\section{Appendix E}

\section{Windows Retrofit Description and Photos}

Prior to beginning heating season experiments, the factory installed windows were retrofit with highly insulating windows in the experimental home and double-pane clear windows typical of existing homes in the region in the baseline home. In addition to characterizing the energy use and thermal comfort impacts of the improved window performance, this research also documented the impact of proper installation practices.

The baseline windows were installed by local trades with no special instruction. For this installation, the existing factory windows were removed and silicone caulk was applied on the outside of the rough opening. The retrofit baseline windows were installed by squaring the window in the opening, screwing the window in place, and foaming/caulking the interior seam as necessary. This installation was meant to typify normal construction practices.

The experimental windows were installed in accordance with manufacturer's instructions and with the assistance of Jeld-Wen field installers. In the experimental window installation, the existing windows were removed and a butyl adhesive was sprayed on the bottom sill of the rough opening to prepare the surface for the moisture barrier material. Figure E.1 shows a picture of the butyl adhesive used in this installation.

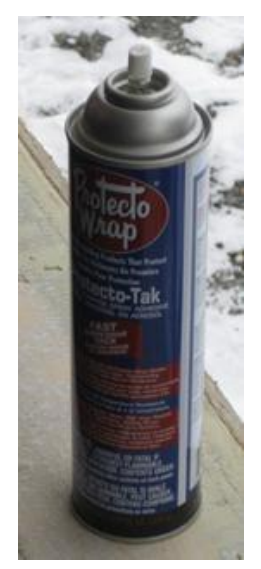

Figure E.1. Butyl Adhesive Spray and Prepared Rough Opening in Experimental Home

On the butyl adhesive, a felt and foam peel-and-stick membrane was applied which covered the lip of the rough opening (to sit under the window) and wrapped around to the front of the house on the siding. A foam strip on top of the felt should line up with the inside seam of the window. The foam acts as a moisture barrier, preventing water from entering the home under the window, while the felt wicks any water out of the sill and to the exterior drainage plane. The felt would have been installed on house wrap, but the Lab Homes do not have house wrap installed so it was installed directly on the siding. Figure E.2 shows installation of the peel-and-stick felt membrane.

The felt membrane was installed with a heat gun and roller to provide a water-tight seal to the drainage plane, as depicted in Figure E.3. 


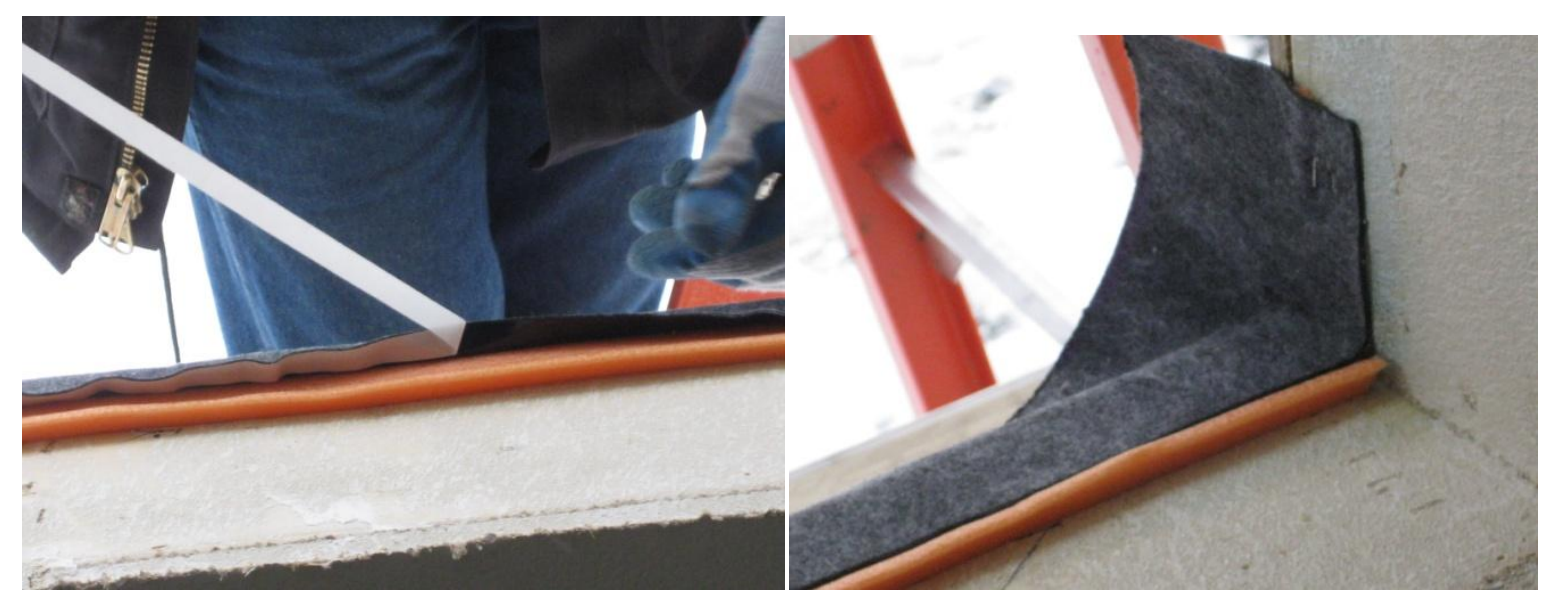

Figure E.2. Felt and Foam Peel-and-Stick Membrane Applied to Experimental Home Rough Opening Sill Plate to Manage Water Intrusion

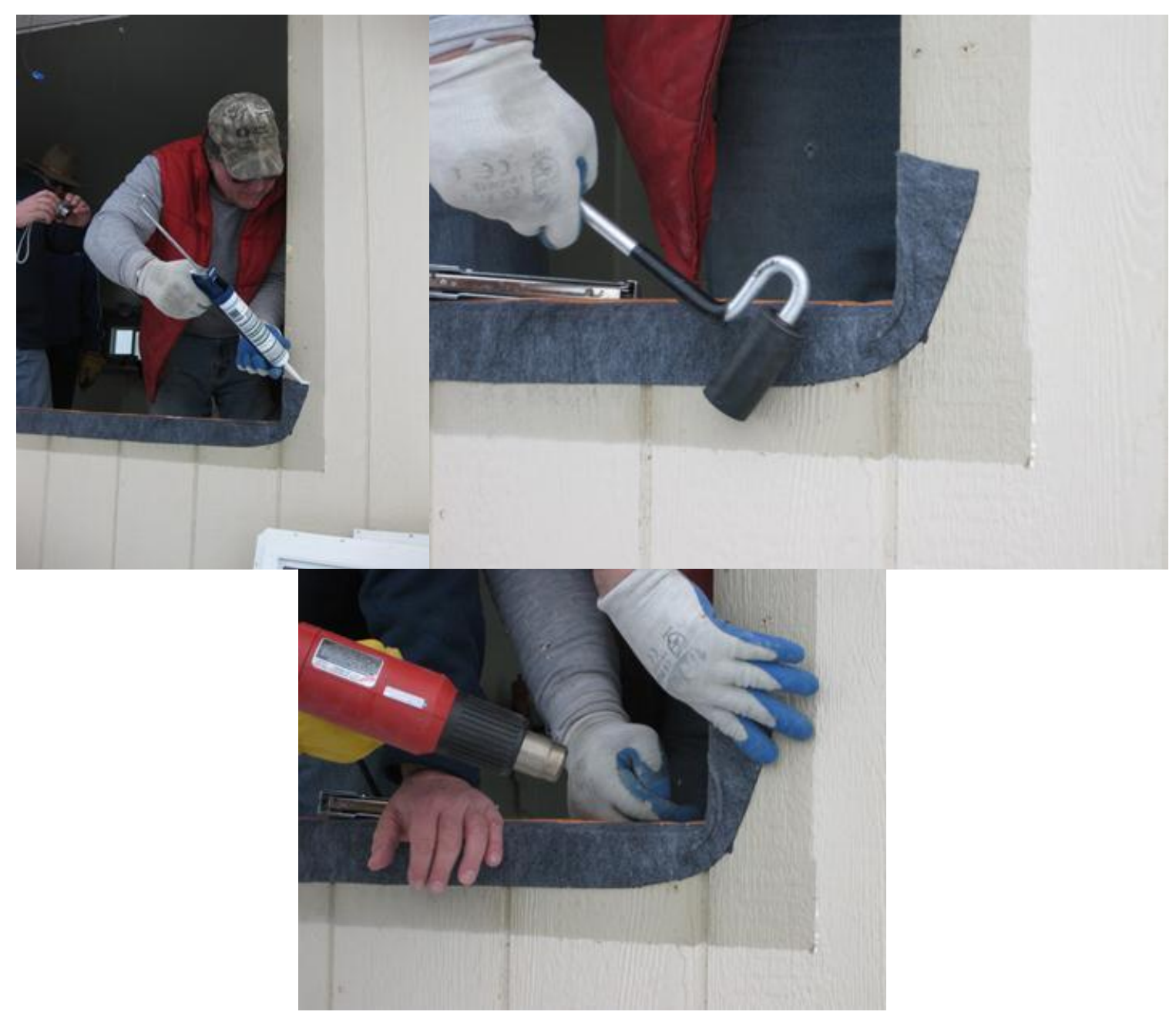

Figure E.3. Installation of Sill Plate Moisture Barrier 
The sill plate moisture barrier was caulked at the seams to ensure a water-tight installation.

On the two patio doors, a graded sill pan was used.

New windows were installed in the prepared rough opening. Windows were squared, shimmed when necessary, and screwed to the exterior.

Limited caulk, spray foam, and cylindrical foam rod was used to seal window in place.

Reinstalled strip on inside and outside.

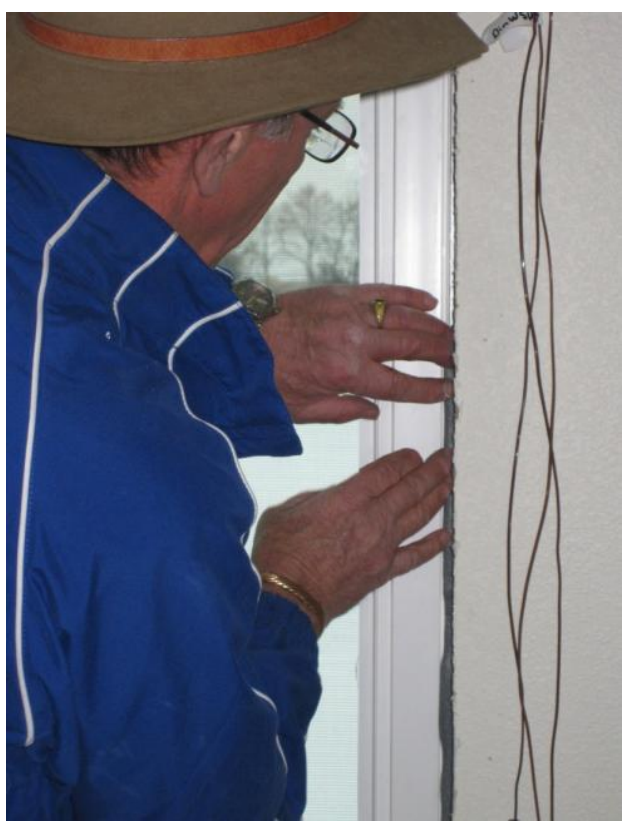

Figure E.4. Peel-and-Stick Membrane Applied with Heat Gun, Roller, and Caulker at Seams for Air-Tight Installation

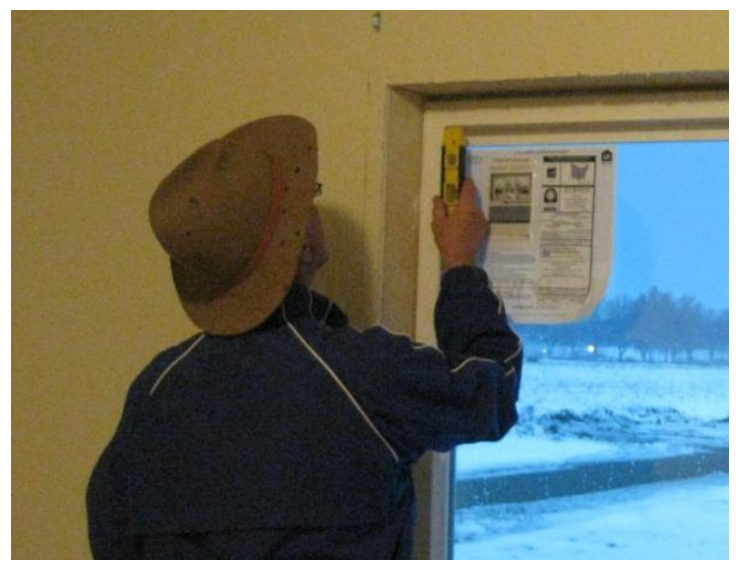

Figure E.5. Installation of Foam Rod (left) to Seal Window and Squaring of Window in Opening (right) 



\section{Appendix F}

\section{Interior Light Level Measurements}





\section{Appendix F}

\section{Interior Light Level Measurements}

\section{F.1 Introduction}

The use of windows with lower visible transmittance $(\mathrm{VT})^{1}$ glazing has the capability of reducing unwanted solar infiltration that is associated with added interior heat and glare. As a general rule, the better the window is as an insulator, the lower the VT. However, the lower VT glazing will also reduce the availability of sunlight that may be used for interior tasks such as reading. A potential concern is that a lower VT glazing may increase electric lighting use to compensate for lost daylighting. Also, a lower VT may give the appearance to the naked eye of a 'darker' view outside compared to a glazing with a higher VT. The darker view may also be of concern to a homeowner.

For these reasons, an experiment was conducted to measure the VT of the Lab Homes in identical selected locations in the homes. Measurements were taken at the Lab Homes with the windows shown in Table F.1.

Table F.1. VT Specifications of the Windows Lab Home A and Lab Home B

\begin{tabular}{lccc}
\hline \multicolumn{1}{c}{ Window Type } & $\begin{array}{c}\text { National Fenestration } \\
\text { Rating Council VT Rating }\end{array}$ & $\begin{array}{c}\text { Lab Home A } \\
\text { (Baseline) }\end{array}$ & $\begin{array}{c}\text { Lab Home B } \\
\text { (Experimental) }\end{array}$ \\
\hline Vinyl Double-Pane Low-E (Kinro) & 0.59 & $\mathrm{X}$ & $\mathrm{X}$ \\
Vinyl Triple-Pane Low-E (Jeld-Wen) & 0.36 & $\mathrm{X}$ & $\mathrm{X}$ \\
Aluminum Double-Pane Clear & 0.71 & $\mathrm{X}$ & \\
\hline
\end{tabular}

\section{F.2 VT Measurement Evaluation Options}

To realistically qualify and quantify a representative loss of daylighting, and therefore electric lighting use to compensate, would require a year-long study to capture the variability of all the involved factors including:

- sun angle (varies throughout the year)

- cloud cover (varies over seasons, days, and hours)

- interior space use by occupants (a typical pattern would need to be determined)

Sensitivity of occupants to light levels (the human eye is quite adaptable) and thus a typical threshold when electrical lighting was manually operated would need to be established. However, given that the

\footnotetext{
${ }^{1}$ The visible transmittance (VT) is an optical property that indicates the amount of visible light transmitted. The National Fenestration Rating Council (www.nfrc.org) VT rating is a whole window rating and includes the impact of the frame, which does not transmit any visible light. While VT theoretically varies between 0 and 1 , most values among double- and triple-pane glazing windows are between 0.30 and 0.70 . The higher the VT, the more light is transmitted. A high VT is desirable to maximize daylight.
} 
Lab Homes are not occupied and there were insufficient time and resources to undertake such a study, this approach was considered too involved to address the issue at hand.

Another option would be extensive modeling of the lighting conditions in the homes covering changing conditions over a year. From this modeling, representative light levels at specific locations verified with spot measurements could be developed. Again, given insufficient time and resources, this level of effort was not considered appropriate for the issue.

A third more reasonable level of effort option involves a simple comparison of glazing transmittance characteristics as they relate to possible "reading" conditions in representative spaces in the homes. This would involve a few sets of representative measurements aimed at understanding the magnitude of the effect on "reading" capability with the three window types. While this approach would not capture all conditions for a complete calendar year, it may be sufficient to allay any major concerns about VT and/or help identify and needed further analysis.

\section{F.3 Measurement Method}

A representative set of tests were carried out in the two homes using a calibrated Konica Minolta T-10 illuminance meter with detachable head and cable (see below) to capture basic characteristics of lighting with the factory and two retrofit window products in the homes.

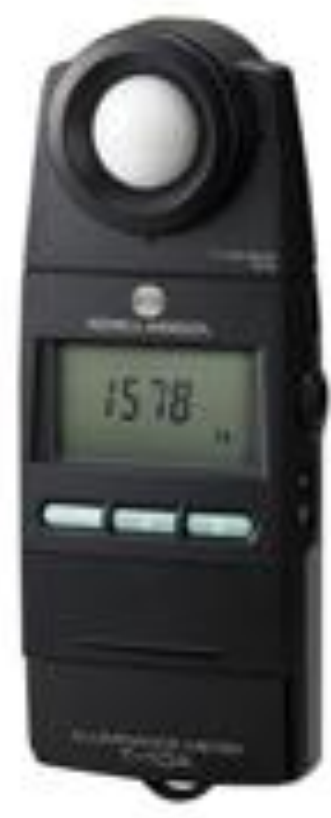

Figure F.1. Konica Minolta T-10 Illuminance Meter

For each window condition, the measurements were taken in Lab Home A and Lab Home B on a single day within a $1 \frac{1}{2}$ hour time period in order to take measurements during nearly identical weather conditions (daylight/sky conditions).

Measurements were first taken in both homes with the identical factory-installed vinyl-fame doublepane low-e windows in each home. Measurements were then taken after the homes were retrofitted: Lab 
Home A with aluminum-frame double-pane clear windows and Lab Home B with vinyl-frame triple-pane low-e windows. For all measurements, there were no screens on the exterior of the windows and no window coverings.

The measurements taken are as follows:

- location: one bedroom each on the north and south sides of each home. These are considered the most likely to have lowest light levels (one window only).

- illuminance measurements \#1: 3 feet and 6 feet from the center of the window on floor surface in each bedroom

- illuminance measurements \#2: at a representative location near the window surface just inside and just outside each window to capture relative solar transmittance of the glazing product.

Figure F.2 shows the measurement layout for the illuminance measurements at the floor level and Figure F. 3 shows the measurements being taken. Figure F.4 shows the interior vertical measurement taken at a representative location near the window surface and the vertical transmittance measurement taken inside. Figure F.5 shows the vertical transmittance measurement taken outside. See Attachment 1 for the measurement procedure for test method details.

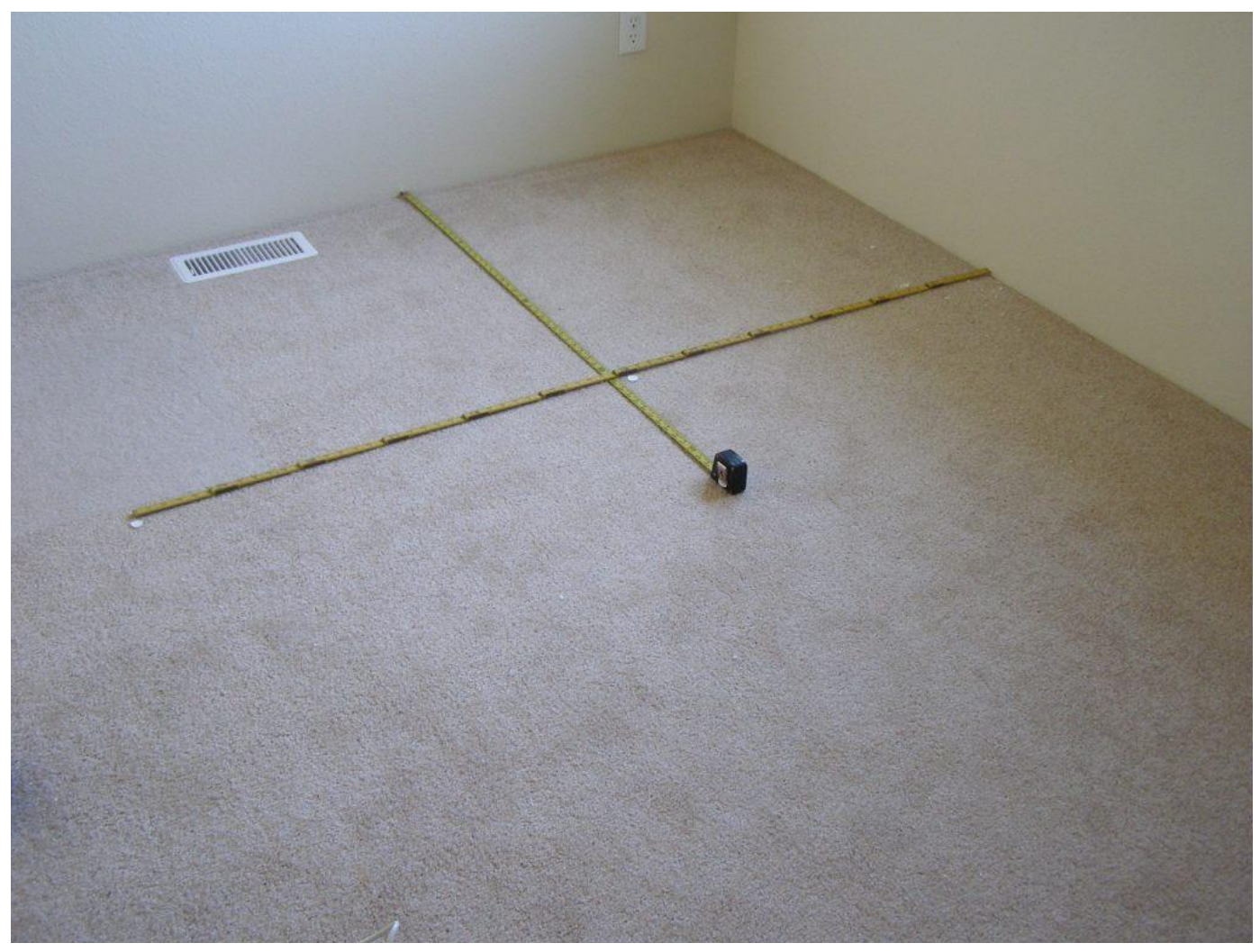

Figure F.2. Layout of Horizontal Floor-Level Light Level Measurements 


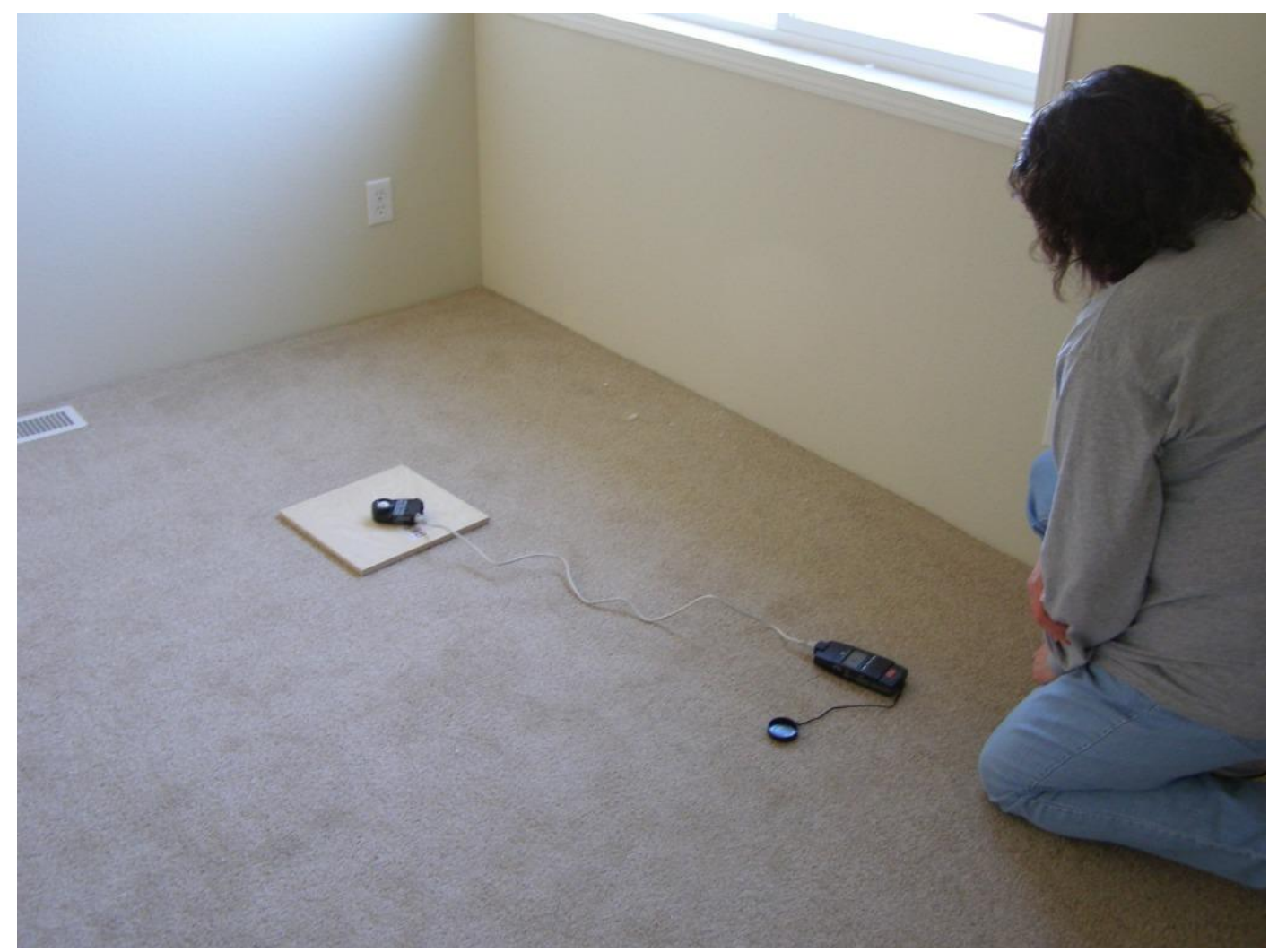

Figure F.3. Recording Horizontal Floor-Level Light Level Measurements

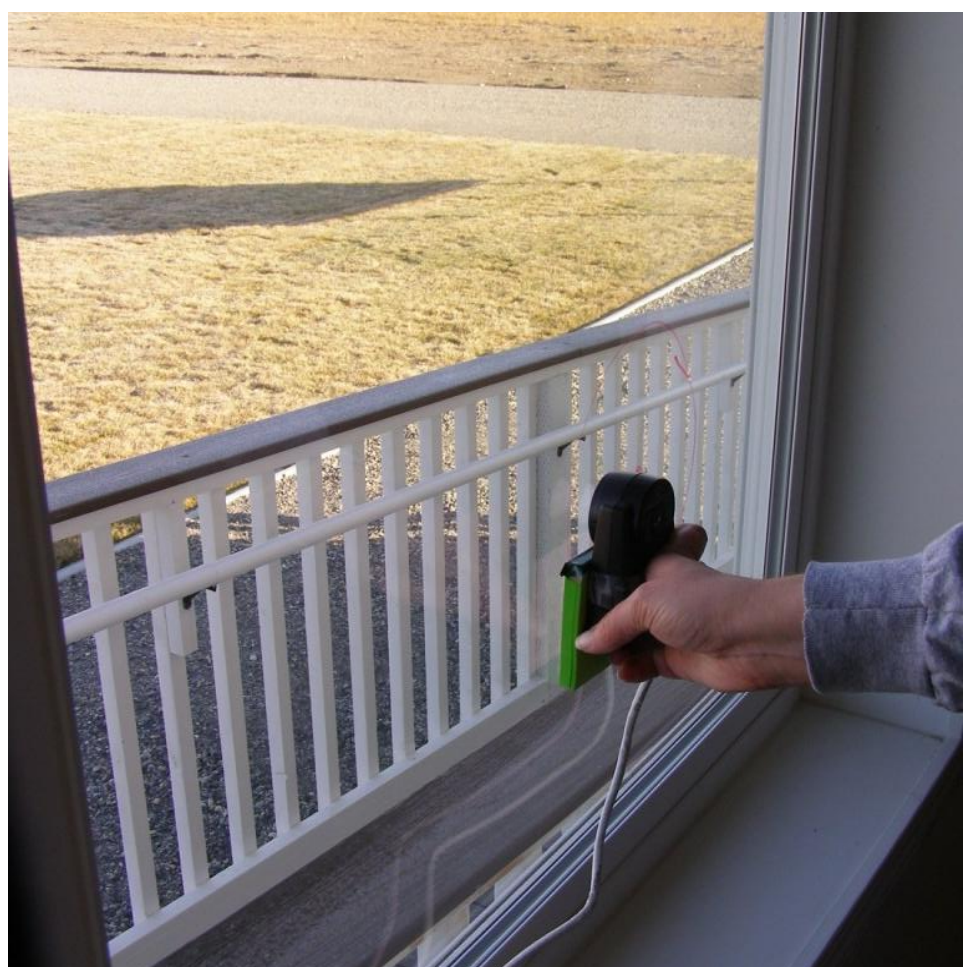

Figure F.4. Recording Vertical Light Level Transmittance Measurements Inside 


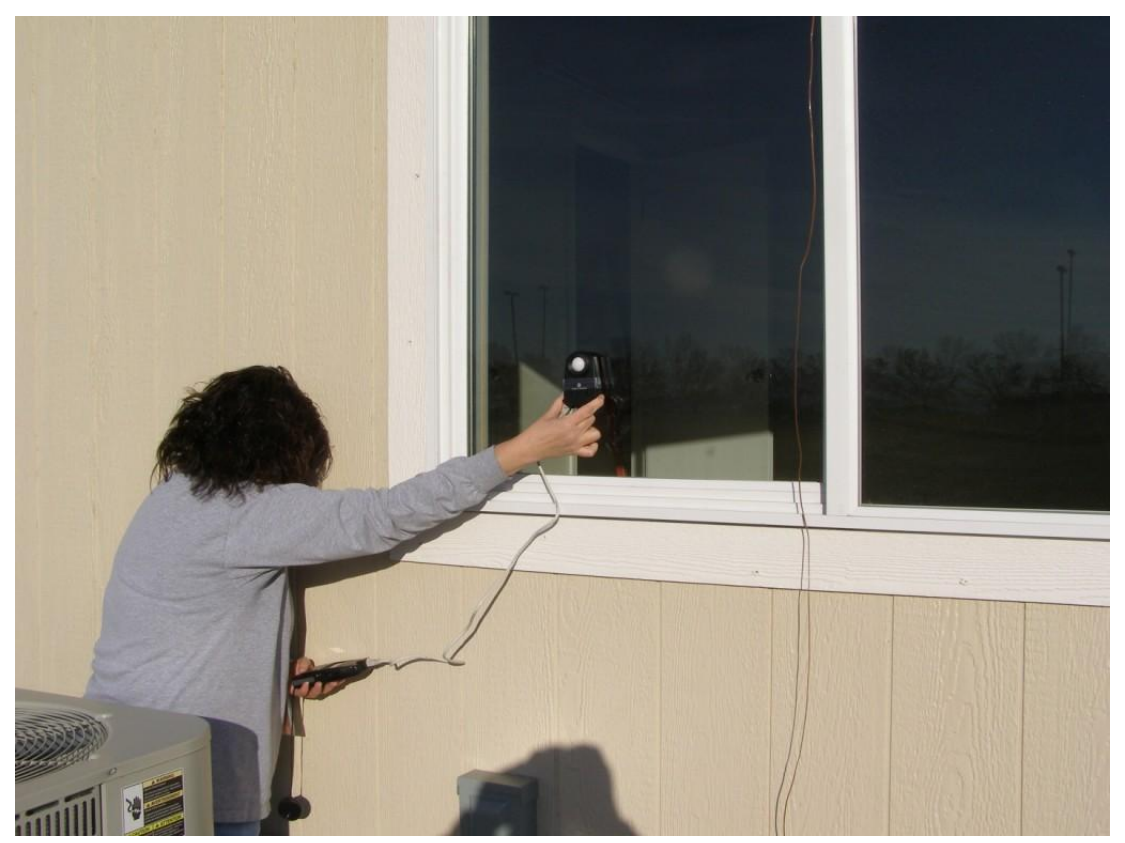

Figure F.5. Recording Vertical Light Level Transmittance Measurements Outside

\section{F.4 Results}

Table F.2 summarizes the average values found in footcandles (fc) for the floor measurements at 3 feet and 6 feet from the windows and in percent $(\%)$ for the transmittance of the glazing.

Table F.2. Measured Illuminance and Light Transmittance for Lab Home Windows

\begin{tabular}{|c|c|c|c|c|c|c|c|}
\hline $\begin{array}{l}\text { Lab } \\
\text { Home }\end{array}$ & Window Type & Location & Date/Time & $\begin{array}{c}\text { Sky } \\
\text { Conditions }\end{array}$ & $\begin{array}{l}3^{\prime} \text { From } \\
\text { Window } \\
\text { (fc) }\end{array}$ & $\begin{array}{l}6^{\prime} \text { From } \\
\text { Window } \\
\text { (fc) }\end{array}$ & $\begin{array}{c}\text { Transmittance } \\
\text { Average Both } \\
\text { Rooms }(\%)\end{array}$ \\
\hline $\mathrm{A} \& \mathrm{~B}$ & $\begin{array}{l}\text { Vinyl Double- } \\
\text { Pane Low-E }\end{array}$ & $\mathrm{NE}^{(\mathrm{a})}$ Bedroom & Jan. $12,0930-1000$ & Clear & 30 & 32 & 66.1 \\
\hline$A \& B$ & $\begin{array}{l}\text { Vinyl Double- } \\
\text { Pane Low-E }\end{array}$ & $\mathrm{SE}^{(\mathrm{b})}$ Bedroom & Jan. $12,0930-1000$ & Clear & 175 & 182 & 66.1 \\
\hline A & $\begin{array}{l}\text { Aluminum } \\
\text { Double-Pane } \\
\text { Clear }\end{array}$ & NE Bedroom & Jan. $30,1330-1400$ & Cloudy & 66 & 47 & 77.0 \\
\hline A & $\begin{array}{l}\text { Aluminum } \\
\text { Double-Pane } \\
\text { Clear }\end{array}$ & SE Bedroom & Jan. $30,1330-1400$ & Cloudy & 135 & 79 & 77.0 \\
\hline B & $\begin{array}{l}\text { Vinyl Triple- } \\
\text { Pane Low-E }\end{array}$ & NE Bedroom & Jan. $30,1330-1400$ & Cloudy & 29 & 22 & 37.3 \\
\hline B & $\begin{array}{l}\text { Vinyl Triple- } \\
\text { Pane Low-E }\end{array}$ & SE Bedroom & Jan. $30,1330-1400$ & Cloudy & 71 & 50 & 37.3 \\
\hline
\end{tabular}

(a) northeast

(b) southeast 
Note that for most measurements the light level is at or above $30 \mathrm{fc}$, which according to the Illuminating Engineering Society $10^{\text {th }}$ edition handbook (2011) is considered an appropriate typical light level for casual reading (for desk area reading the value is $40 \mathrm{fc}$ ). Figure F.6 shows the sky conditions for the January 12 measurement and Figure F.7 shows the sky conditions for the January 30 measurements.

In Lab Home B with the vinyl triple-pane low-e windows, at 6 feet away from the window in the NE bedroom with no direct sun, the value drops to $22 \mathrm{fc}$. However, it is also understood by the lighting industry, that an approximate $15 \mathrm{fc}$ reduction is the threshold where the typical human is able to discern a difference in light levels and therefore it is unlikely that $22 \mathrm{fc}$ would necessitate use of artificial lighting.

It should be noted that the measurements taken after installation of the retrofit of the vinyl double-pane low-e windows in both homes were taken on a day (January 30) in the afternoon under cloudy conditions compared to the measurements prior to retrofit that were taken in on a day (January 12) in the morning with clear sky (sunny) conditions. However, the difference in diffuse daylight availability between the sunny and cloudy conditions (as measured outside the north windows) is less than $10 \%$. Therefore, even under morning cloudy conditions, the interior light availability is not significantly affected.

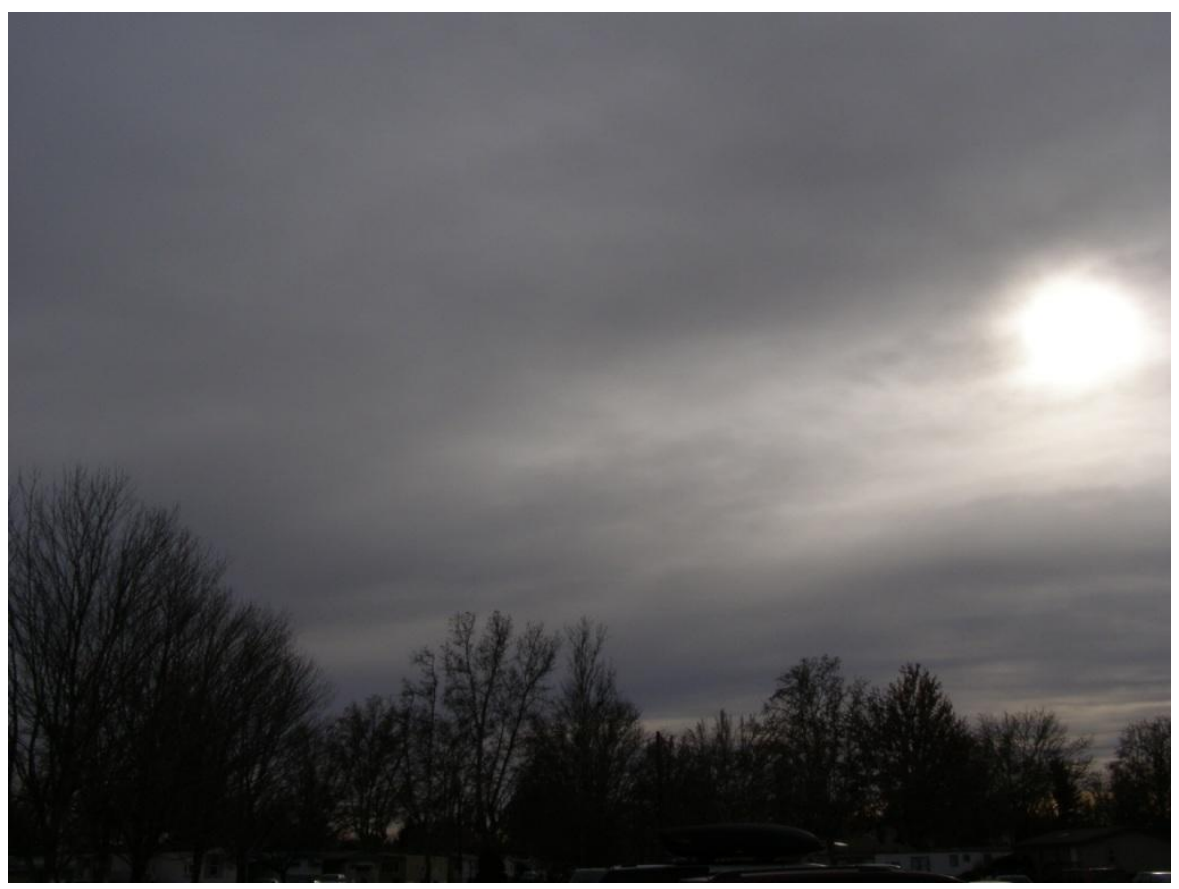

Figure F.6. Sky Conditions during the January 12, 2012 Light Level Measurements 


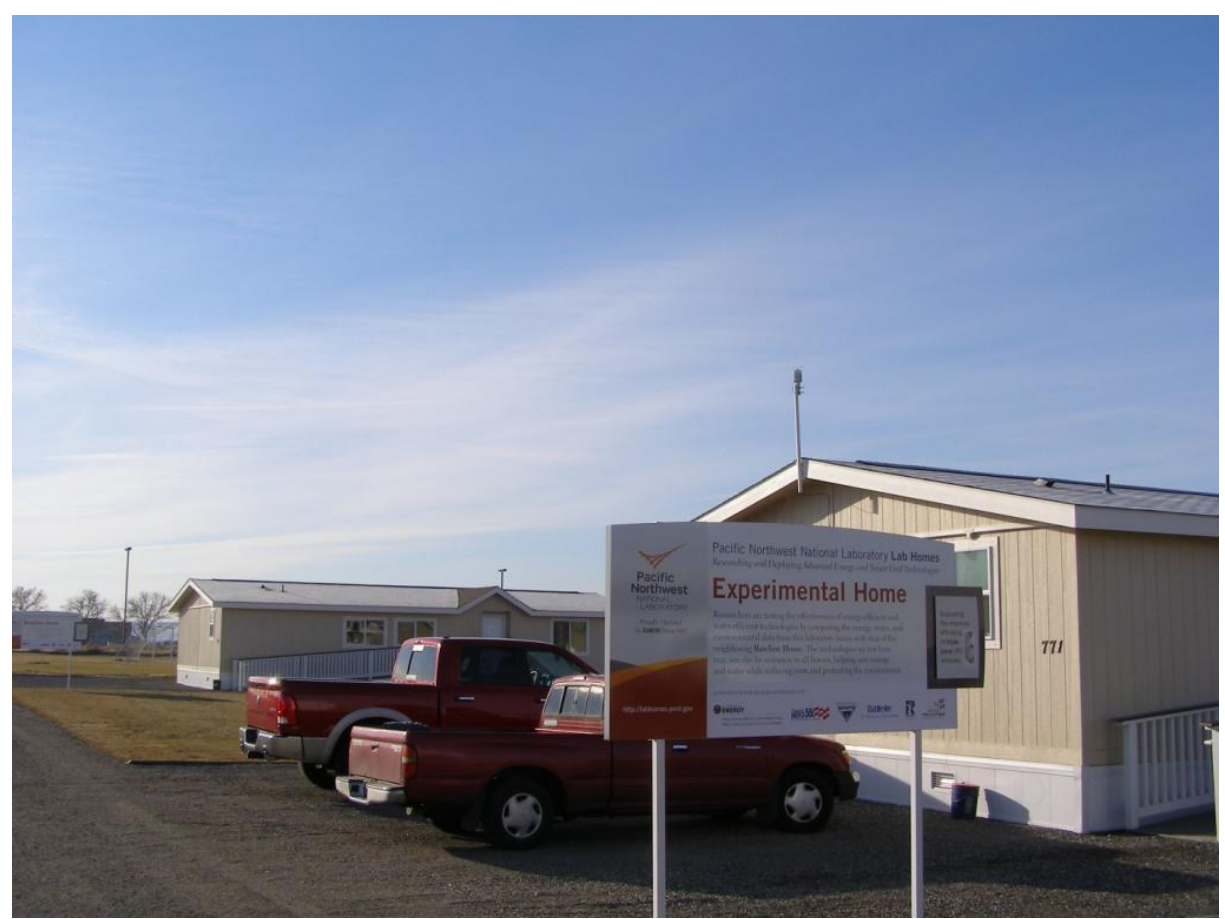

Figure F.7. Sky Conditions during the January 30, 2012 Light Level Measurements

It is known and shown with these measurements that lower VT glazing will reduce sunlight levels transmitted into a room. However, the direct measurements of interior light levels before and after retrofit of windows (Table F.2) show that for reasonable typical daytime conditions the interior lighting levels in the experimental home are not reduced sufficiently with the installation of the triple-pane low-e windows to cause any significant issues with typical residential reading conditions using natural light.

For short periods of time at early morning or evening times when the sun is just rising or setting, the available light for reading will be reduced with lower VT glazing, but occupant use of lighting at those specific times is not a known quantity and therefore cannot be equated to any measurable change in electric lighting use. These results indicate that the use of lower VT (0.36) glazing should not cause the use of significant additional artificial lighting.

\section{Attachment 1: Measurement Procedure}

\section{Measurement procedure}

- Complete the "setup" steps for both homes prior to taking measurements, to reduce time between measurements in Lab Homes A and B.

- Use a calibrated or new instrument - T-10 Minolta illuminance meter with detachable head, cable, and connector.

- Take measurements in Lab Home A (baseline home) and Lab Home B (experimental home) with the factory windows in both homes. Take these sets of measurements as close to the same day and time as possible as described in the rest of this procedure.

- Take measurements with retrofit windows in Lab Home A and Lab Home B. Take these sets of measurements as close to the same day and time as possible as described in the rest of this procedure. 
- Measurements with the existing windows need to take place before January 23 as these windows will be retrofitted the week of January 23.

- Measurements of the retrofitted windows should take place before January 30 as the homes will be 'sealed' the week of January 30 for the start of the first experiment.

\section{Setup}

1. For each set of measurements, choose measurement day and time at which there is minimal:
a. low-angle sun (avoid late afternoons or early mornings)
b. cloud cover
c. fog
d. blowing dust, leaves, etc.
e. frost on ground

2. Ensure there is no blockage at any windows (i.e. vehicles, equipment, persons, foliage) or objects that are nearby that could reflect sunlight into windows.

3. Clean inside and outside of all windows in the room where measurements will be taken within a few days prior to the measurements.

4. Open all blinds (if existing) on all windows in the room.

5. Turn off all electric lights in the room.

6. The room should be free of obstructions (furniture, etc.).

7. Have ready a large stiff flat panel to use as a floor platform for horizontal measurements. The panel should be:
a. at least 1 foot square
b. neutral to dark flat color; can be black but should not be white or very shiny
c. any material but must be reasonably stiff
d. placed centered over each measurement point with measurement point indicated on the platform

8. Identify a spot on the window that will be consistently lighted by the sun during the entire set of measurements with either full unshaded sun or fully shaded sun (i.e. from roof overhang) and is not obstructed by any objects.

a. Draw an approximate 6 inch circle on this window spot (inside) with a thin marker that can be cleaned off later.

b. Record the location of the center of this circle:

i. Identify window.

ii. Record dimensions of center of circle from identifiable edges (i.e., $\mathrm{X}$ inches from bottom, $\mathrm{Y}$ inches from left side - measured on the inside).

c. Have ready a small shim block (approximately 2" by 2") that is $3 / 8$ inch thick (to offset the meter sensor when taking vertical measurements - needed for the T-10 meter and probably others) 
9. Take photographs of each test setup and room configuration.

\section{Horizontal Measurements}

1. Start with Lab Home A (baseline home—-south home).

2. Ensure all setup steps are completed.

3. Shut all doors to room.

4. Place light meter measurement head flat on the platform centered over the measurement point. Make sure it lies flat with no tilt. Use double-sided tape if it will not stay flat.

5. Move out of the way of the sensor head so that you are:
a. not in the way of any sunlight
b. not in a position where any significant sunlight can reflect off of you and onto the sensor.

6. Record:
a. date
b. time
c. location
d. $\operatorname{lux}$
e. exterior and interior room conditions if other than described in this procedure
f. window type
g. meter model and serial numbers.

7. Complete the same measurement in two rooms on opposite sides of the lab home (see measurement location list).

8. Move directly to Lab Home B (experimental home-north home) and repeat and record the same measurements.

9. Move back to Lab Home A and repeat and record the same measurements for reference purposes. (Note: this provides the data to determine whether sun movement changes have affected the initial Lab Home A readings).

\section{Vertical Measurements}

1. Start with Lab Home A or B (If two measurement teams/persons and two similar meters are available, the horizontal and vertical measurements can be taken simultaneously but this is not required).

2. Ensure all setup steps are completed.

3. Using the meter with the head in detached and connected configuration, tape the 2" by 2 " shim onto the face of the connector adapter (just below the sensor). This is critical to keep the white sensor dome from contacting the window glass.

4. From the inside, place the light meter measurement head (with shim) flat against the window within the marked circle (ensure no tilt) with the white sensor dome facing outside.

5. Record: 

a. date
b. time
c. location (location of circle should have been measured and recorded at setup)
d. $\operatorname{lux}$
e. meter model and serial numbers.

6. On the outside of the same window, place the light meter measurement head flat against the window within the marked circle (ensure no tilt) with the white sensor dome again facing outside. Ensure that you and other objects are against the wall and out of the path of any sunlight.

7. Move directly to the second lab home and repeat and record the same measurements

8. Move back to the initial lab home and repeat and record the same measurements for reference purposes. (Note: this provides the data to determine whether sun movement changes have affected the initial home A or B readings).

\section{Measurement location list: Same for each lab home}

Horizontal on floor using platform panel:

1. Master bedroom (SE corner)
a. 3 feet back from window directly on centerline of window (suggest measuring from east wall to center of window as the other measurement)
b. 6 feet back from window directly on centerline of window

2. Bedroom \#2 (farthest east bedroom on north side)
a. 3 feet back from window directly on centerline of window
b. 6 feet back from window directly on centerline of window

Vertical:

Within 6" circle on window in each room as described in procedure 
PNNL-21524

\section{Distribution}

No. of

Copies

2 Kacie Bedney

Bonneville Power Administration

KLJD-1

P.O. Box 3621

Portland, OR 97208-3621

2 Marc LaFrance

U.S. DOE

1000 Independence Ave. SW

Washington DC 20585

3 David Lee, Eric Werling, and Sam Rashkin

U.S. DOE

1000 Independence Ave. SW

Washington DC 20585

1 Dan Ton

U.S. Department of Energy

1000 Independence Avenue, SW

Washington, DC 20585

2 Ken Eklund

WSU Extension Energy Program

905 Plum Street SE

Olympia, WA 98504-3165

2 Brady Peeks

NEW, Inc.

1815 NW Juniper Place

Corvallis, OR 97330

1 Bob Hammond

City of Richland

840 Northgate Drive

Richland, WA 99352

1 Diahann Howard

Tri Cities Research District

3100 George Washington Way

Richland, WA 99352

1 Greg Sullivan

Efficiency Solutions, LLC

1857 Kingston Road

Richland, WA 99354-4940
No. of

Copies

\section{\# Local Distribution}

Pacific Northwest National Laboratory

Sarah Widder

K6-05

Nathan Bauman

K5-16

Mark Morgan

K1-85

Todd Samuel

K6-05

Sriram Somasundaram 
PNNL-21524

No. of

No. of

Copies

Copies

1 Ray Garries

JELD-WEN, inc

P.O. Box 1329

Klamath Falls, OR 97601 



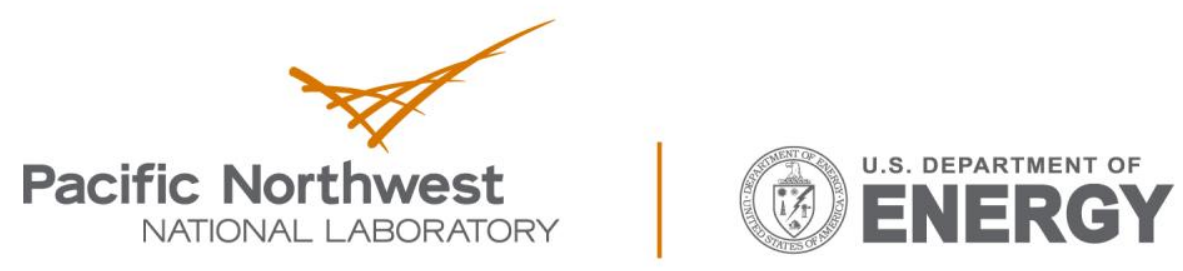

Proudly Operated by Battelle Since 1965

902 Battelle Boulevard

P.O. Box 999

Richland, WA 99352

1-888-375-PNNL (7665)

www.pnnl.gov 